Np and Pu Sorption to Manganese Oxide Minerals

P. Zhao, M. R. Johnson, S. K. Roberts, M. Zavarin

September 2, 2005 
This document was prepared as an account of work sponsored by an agency of the United States Government. Neither the United States Government nor the University of California nor any of their employees, makes any warranty, express or implied, or assumes any legal liability or responsibility for the accuracy, completeness, or usefulness of any information, apparatus, product, or process disclosed, or represents that its use would not infringe privately owned rights. Reference herein to any specific commercial product, process, or service by trade name, trademark, manufacturer, or otherwise, does not necessarily constitute or imply its endorsement, recommendation, or favoring by the United States Government or the University of California. The views and opinions of authors expressed herein do not necessarily state or reflect those of the United States Government or the University of California, and shall not be used for advertising or product endorsement purposes.

This work was performed under the auspices of the U.S. Department of Energy by University of California, Lawrence Livermore National Laboratory under Contract W-7405-Eng-48. 


\title{
Np And Pu Sorption to Manganese Oxide Minerals
}

\author{
Pihong Zhao ${ }^{1}$, Mackenzie R. Johnson ${ }^{2}$, Sarah K. Roberts ${ }^{2}$, \\ and Mavrik Zavarin ${ }^{2}$ \\ ${ }^{1}$ Chemical Biology and Nuclear Sciences Division \\ Chemistry and Materials Sciences Directorate \\ ${ }^{2}$ Environmental Science Division \\ Energy and Environment Directorate \\ Lawrence Livermore National Laboratory \\ Livermore, California
}

Prepared for the Underground Test Area Project

U. S. Department of Energy

National Nuclear Security Administration

Nevada Site Office

Final Report

August 30, 2005 


\section{TABLE OF CONTENTS}

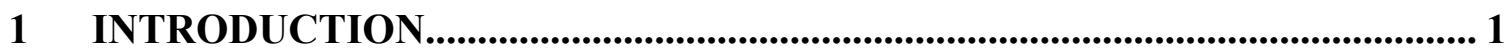

2 SORPTION DATA AVAILABLE IN THE LITERATURE ................................ 3

3 SORPTION EXPERIMENT METHODS .............................................................. 5

3.1 Manganese Oxide Preparation ....................................................................... 5

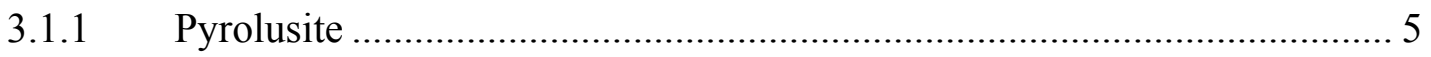

3.1.2 Birnessite and Cryptomelane .............................................................. 6

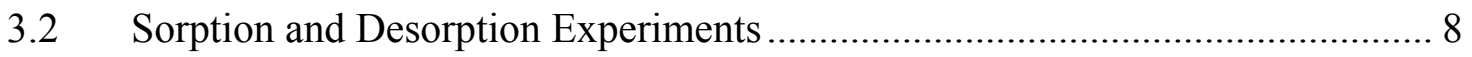

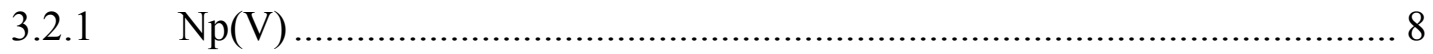

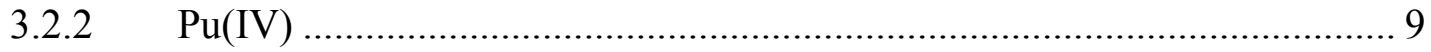

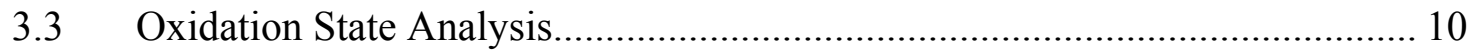

$3.4 \quad$ Modeling Approach ............................................................................. 10

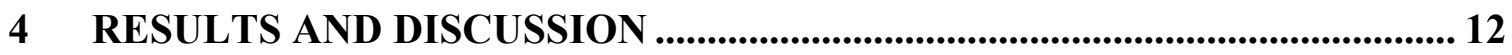

4.1 Aqueous Speciation of $\mathrm{Pu}$ and $\mathrm{Np}(\mathrm{V})$ and Surface Speciation of Birnessite ... 12

4.2 Mn Oxide Mineral Characteristics ........................................................... 14

$4.3 \mathrm{~Np}(\mathrm{~V})$ Sorption and Desorption Experiments.............................................. 21

4.3.1 Np Sorption Data …………………………................................... 21

4.3.2 Np Desorption Data ........................................................................ 24

4.3.3 Np Oxidation State Characterization ..................................................... 24

4.3.4 Np Data Modeling.......................................................................... 25

4.4 Pu Sorption and Desorption Experiments ........................................................ 30

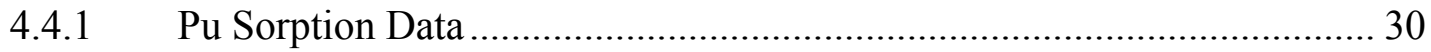

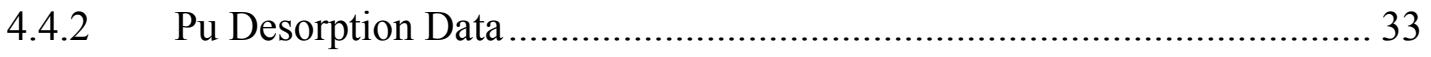

4.4.3 Pu Oxidation State Characterization........................................................ 36

5 CONCLUSIONS AND RECOMMENDATIONS.................................................. 39

6 ACKNOWLEDGEMENTS .................................................................................... 40

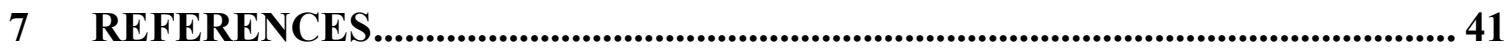

8 APPENDIX. BATCH SORPTION RAW DATA................................................ 46 


\section{LIST OF FIGURES}

Figure 1. $\mathrm{Np}(\mathrm{V})$ sorption to various minerals at $\mathrm{pH} 8$ and in $\mathrm{J}-13$ surrogate waters (a) and $\mathrm{Pu}(\mathrm{V})$ sorption to various minerals at $\mathrm{pH} 8$ and in $\mathrm{J}-13$ surrogate waters (b). Note that $\mathrm{Pu}(\mathrm{V})$ is reduced to $\mathrm{Pu}(\mathrm{IV})$ on the mineral surfaces. Data from Kersting and

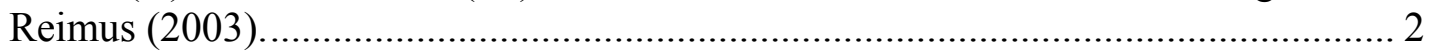

Figure 2. XRD pattern of purchased pyrolusite......................................................... 5

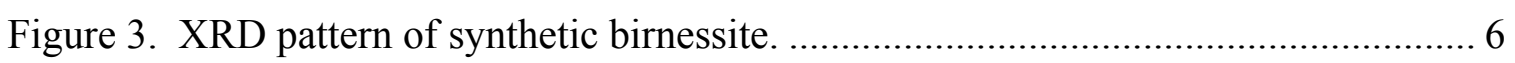

Figure 4. XRD pattern of synthetic cryptomelane.................................................... 7

Figure 5. Aqueous speciation of (a) $\mathrm{Np}(\mathrm{V})$ and (b) $\mathrm{Pu}(\mathrm{IV})$ as a function of $\mathrm{pH}$ given the

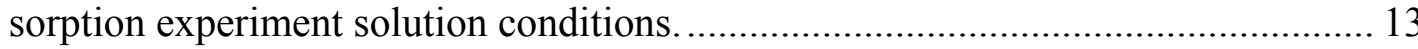

Figure 6. Surface speciation of birnessite based on the model of Tonkin et al. (2004) and water chemistry from the Np-birnessite sorption experiment. Species concentration (left axis) and surface charge (right axis).

Figure 7. Surface speciation of birnessite (dominant species only) based on the model of Appelo and Postma (1999) and water chemistry from the Np-birnessite sorption experiment. Species concentrations (left axis) and surface charge (right axis)....... 16

Figure 8. SEM images of the three manganese oxide minerals. Images on the left are magnified by $1500 \mathrm{x}$; images on the right are magnified by $20,000 \mathrm{x}$.

Figure 9. $\mathrm{Mn}^{2+}$ concentrations in $\mathrm{Np}(\quad)$ and $\mathrm{Pu}(\quad)$ sorption experiments with (a) pyrolusite, (b) birnessite, and (c) cryptomelane, predicted $\mathrm{Mn}^{2+}$ concentrations at $\log \left(\mathrm{O}_{2}(\mathrm{~g})\right)=-0.7(\quad)$ and $\log \left(\mathrm{O}_{2}(\mathrm{~g})\right)=-10(\quad)$, and $\mathrm{O}_{2}(\mathrm{~g})$ fugacity consistent with measured $\mathrm{Mn}^{2+}$ concentrations at pH $3(\mathrm{~Np}(\quad)$ and $\mathrm{Pu}(\quad))$..................... 19

Figure 10. Predicted aqueous, total, and sorbed $\mathrm{Mn}^{2+}$ as a result of surface complexation using the Tonkin diffuse double layer model (Tonkin et al., 2004).

Figure 11. Np sorption to (a) birnessite, (b) cryptomelane, and (c) pyrolusite as functions of $\mathrm{pH}$ and time. 22

Figure 12. Comparison of $\mathrm{Np}$ sorption to three manganese oxides.............................. 23

Figure 13. $\mathrm{Np} \mathrm{K}_{\mathrm{d}}$ versus $\mathrm{pH}$ at the end of the 30 day sorption experiment. .................... 23

Figure 14. Comparison of Np sorption (cryptomelane, solid line) and desorption (birnessite $(\bigcirc)$, cryptomelane $(\triangle)$, and pyrolusite $(\square)$ ) data.

Figure 15. Model fits to Np sorption data based on the diffuse double layer model of Tonkin et al. (2004). (a) single surface species, (b) two surface species. Data and model fits reported as mol L ${ }^{-1}$ sorbed. Model names are explained in Table 5...... 28

Figure 16. Model fits to Np sorption data based on the diffuse double layer model of Appelo and Postma (1999) using single surface species (green, red, blue) and two surface species (black). 
Figure 17. Pu sorption to (a) birnessite, (b) cryptomelane, and (c) pyrolusite as functions

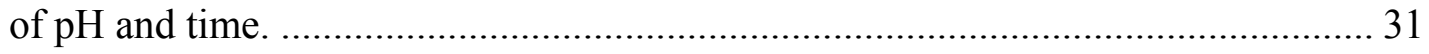

Figure 18. Bicarbonate concentrations as a function of $\mathrm{pH}$ for $\mathrm{Pu}$ sorption solutions. .... 32

Figure 19. Comparison of $\mathrm{Pu}$ sorption to three manganese oxides at 34 days................ 32

Figure 20. Pu sorption to (a) birnessite, (b) cryptomelane, and (c) pyrolusite as functions of solution $\mathrm{pH}$ and time in desorption experiments.............................................. 34

Figure $21 . \mathrm{K}_{\mathrm{d}}$ versus $\mathrm{pH}$ in 30 day Pu sorption (a) and 30 day Pu desorption (b)

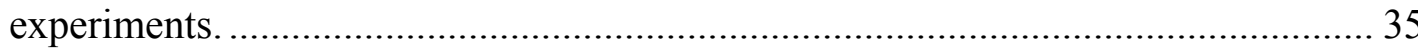




\section{LIST OF TABLES}

Table 1. Manganese oxide sorption data available in the literature............................... 4

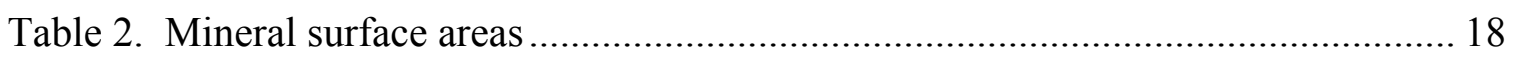

Table 3. Np oxidation state in supernatant measured by solvent extraction.................... 25

Table 4. Reaction constants used in FITEQL surface complexation model................... 26

Table 5. Np surface complexation reaction constants. ................................................ 30

Table 6. Pu oxidation states in supernatant at the end of desorption experiments. .......... 36

Table 7. Oxidation state characterization of sorbed $\mathrm{Pu}$ (after $1 \mathrm{~N} \mathrm{HCl}$ acidification)....... 37

Table 8. Oxidation state characterization of sorbed $\mathrm{Pu}$ ( $\mathrm{Pu}$-manganese oxide wet pastes).

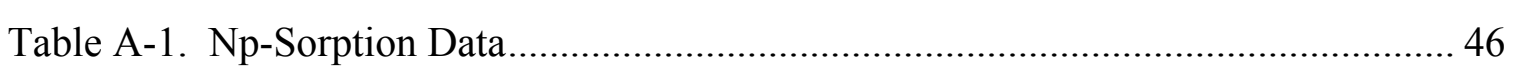

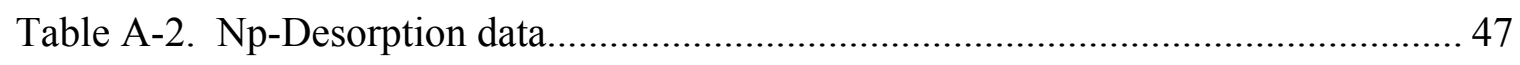

Table A-3. Np batch-sorption major cation analyses (mol/ L) ................................... 48

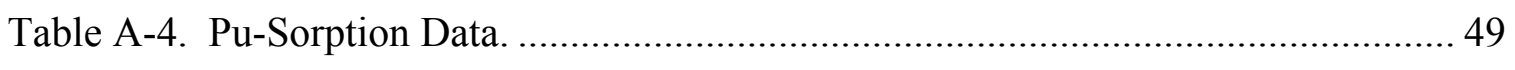

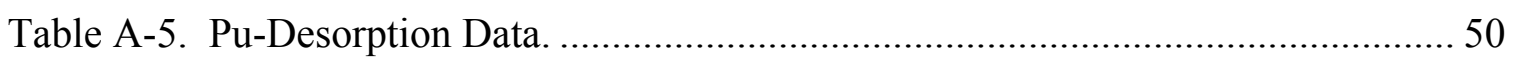

Table A-6. Pu batch-sorption major cation analyses (mol/ L) ...................................... 51 


\section{INTRODUCTION}

Manganese oxide minerals are a significant component of the fracture lining mineralogy at Yucca Mountain (Carlos et al., 1993) and within the tuff-confining unit at Yucca Flat (Prothro, 1998), Pahute Mesa (Drellack et al., 1997), and other locations at the Nevada Test Site (NTS). Radionuclide sorption to manganese oxide minerals was not included in recent Lawrence Livermore National Laboratory (LLNL) hydrologic source term (HST) models which attempt to predict the migration behavior of radionuclides away from underground nuclear tests. However, experiments performed for the Yucca Mountain Program suggest that these minerals may control much of the retardation of certain radionuclides, particularly $\mathrm{Np}$ and $\mathrm{Pu}$ (Triay et al., 1991; Duff et al., 1999). As a result, recent HST model results may significantly overpredict radionuclide transport away from underground nuclear tests.

The sorption model used in HST calculations performed at LLNL includes sorption to iron oxide, calcite, zeolite, smectite, and mica minerals (Zavarin and Bruton 2004a; $2004 b)$. For the majority of radiologic source term (RST) radionuclides, we believe that this accounts for the dominant sorption processes controlling transport. However, for the case of $\mathrm{Np}$, sorption is rather weak to all but the iron and manganese oxides (Figure 1). Thus, we can expect to significantly reduce predicted $\mathrm{Np}$ transport by accounting for $\mathrm{Np}$ sorption to manganese oxides. Similarly, Pu has been shown to be predominantly associated with manganese oxides in Yucca Mountain fractured tuffs (Duff et al., 1999). Recent results on colloid-facilitated Pu transport (Kersting and Reimus, 2003) also suggest that manganese oxide coatings on fracture surfaces may compete with colloids for $\mathrm{Pu}$, thus reducing the effects of colloid-facilitated $\mathrm{Pu}$ transport (Figure $1 \mathrm{~b}$ ). The available data suggest that it is important to incorporate $\mathrm{Np}$ and $\mathrm{Pu}$ sorption to manganese oxides in reactive transport models. However, few data are available for inclusion in our model. A survey of published data found only single-point (Triay et al., 1991; Kersting and Reimus, 2003; Keeney-Kennicutt and Morse, 1984; 1985) and qualitative (Duff et al., 1999; Dyer et al., 2000a; 2000b) Np and Pu sorption information.

This report describes recent experiments that quantified the sorption and desorption of $\mathrm{Np}(\mathrm{V})$ and $\mathrm{Pu}(\mathrm{IV})$ onto three manganese oxide minerals as a function of $\mathrm{pH}$ and time. The three manganese oxides (pyrolusite, birnessite, and hollandite ${ }^{1}$ ) have all been observed on fracture surfaces at Yucca Mountain and are likely to predominate at the NTS. Pyrolusite, birnessite, and hollandite comprise both a range of manganese oxide structure (framework, layered, and tunnel, respectively) and composition and a range of observed manganese oxide mineralogies. The $\mathrm{pH}$ range of 3-10 used in these experiments covers the range of $\mathrm{pH}$ observed in NTS groundwater (Rose et al., 1997). ${ }^{2}$

\footnotetext{
${ }^{1}$ Cryptomelane, the $\mathrm{K}^{+}$endmember of the hollandite group was used in our experiments.

${ }^{2}$ Of the $107 \mathrm{pH}$ values reported by Rose et al. for southern Nevada groundwater (Table 2 in Rose et al., 1997), only one value was outside the experimental range: the water tested from one well in Area 12 of the NTS measured 10.5. Otherwise, the values listed all fell within $\mathrm{pH}$ 6.4-9.6.
} 
Upon completion of sorption and desorption experiments, the sorption data were modeled based on surface complexation theory. The resulting reaction constants can be appended to the databases of Zavarin and Bruton (2004a; 2004b) for use in future HST modeling at the NTS. The sorption data are relevant to larger scale NTS radionuclide transport models as well.
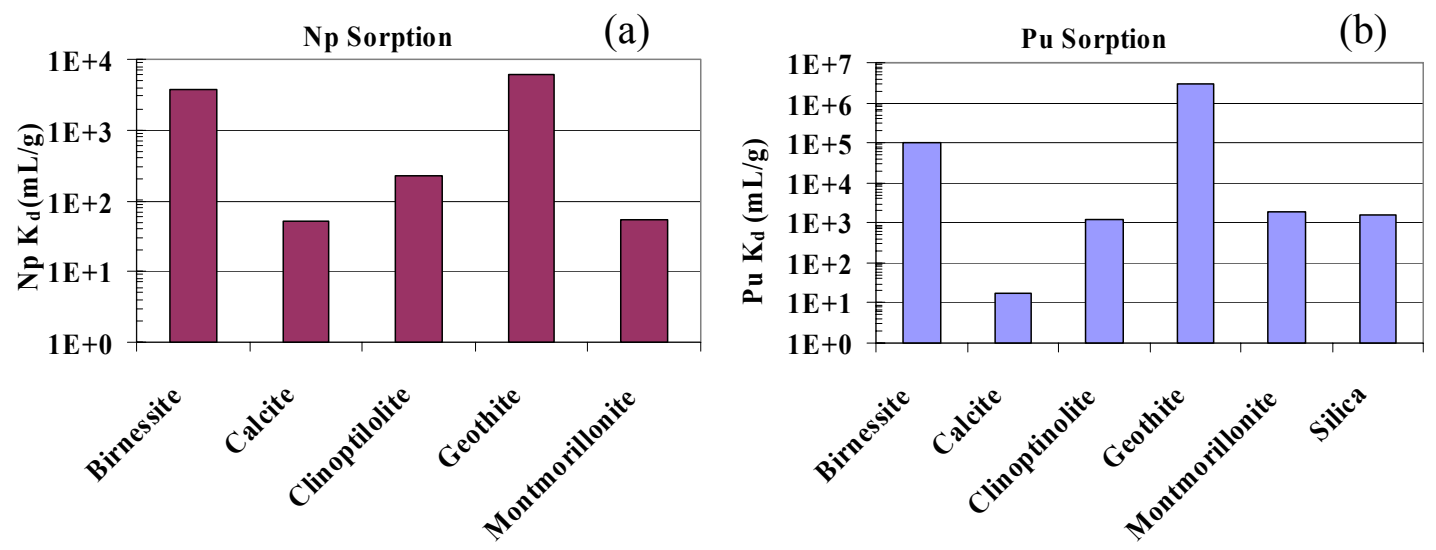

Figure 1. $\mathrm{Np}(\mathrm{V})$ sorption to various minerals at $\mathrm{pH} 8$ and in $\mathrm{J}-13$ surrogate waters (a) and $\mathrm{Pu}(\mathrm{V})$ sorption to various minerals at $\mathrm{pH} 8$ and in $\mathrm{J}-13$ surrogate waters (b). Note that $\mathrm{Pu}(\mathrm{V})$ is reduced to $\mathrm{Pu}(\mathrm{IV})$ on the mineral surfaces. Data from Kersting and Reimus (2003). 


\section{SORPTION DATA AVAILABLE IN THE LITERATURE}

Manganese oxides (Mn oxides) form a large class of minerals often noted for their wide range of crystal structure, including minerals with tunnel and layer structures. General and detailed overviews of the various Mn oxide mineral compositions, structures, and occurrences can be found in Post (1999) and Waychunas (1991). X-ray absorption spectroscopy has further elucidated the crystal structure of several Mn oxides, and has been instrumental in advancing our understanding of the molecular interactions that occur during sorption (for instance: (Manceau et al., 1992; Axe et al., 2000; Trivedi et al., 2001; Foster et al., 2003; Shaughnessy et al., 2003). Laboratory investigations of manganese oxide surface chemistry (Murray, 1974, 1975; Mckenzie, 1979; Balistrieri and Murray, 1982) have shown that they have a large surface area relative to other minerals and they have a high cation sorption capacity over a wide $\mathrm{pH}$ range (Tonkin et al., 2004). In the case of birnessite, the manganese oxide surface is negatively charged above $\mathrm{pH} \sim 2$ which provides a strong negatively charged surface to which most positively charged cations readily sorb.

This class of minerals has been studied as a potential contaminant sorber for several decades, in part due to its ubiquitous presence in clays, soils and sediments (Tonkin et al., 2004). Most of the previous studies focused on the uptake of stable aqueous species by manganese oxides (Table 1). These studies can provide useful analog data for a number of radionuclides not examined in this report. While most of these radionuclides are not examined in this report, they comprise a significant fraction of the RST at the NTS. For instance, Al-Attar and Dyer (2002) investigated uranium sorption onto several ionexchanged birnessites as a function of $\mathrm{pH}$. They calculated different distribution coefficients for the different types of exchanged birnessites; maximum distribution coefficients $\left(\mathrm{K}_{\mathrm{d}}\right)$ were measured at $\mathrm{pH} 6\left(5.7 \times 10^{4} \mathrm{~mL} / \mathrm{g}\right.$ for $\mathrm{U}$ sorption to Cs-exchanged birnessite $)$ or at $\mathrm{pH} 4\left(5.6 \times 10^{4} \mathrm{~mL} / \mathrm{g}\right.$ for $\mathrm{U}$ sorption to Co-exchanged birnessite). Misaelides et al. (2002) observed considerable sorption of Th, $U$ and ${ }^{233} \mathrm{~Pa}$ onto natural todorokite, a tunnel-structure manganese oxide, with maximum $\mathrm{K}_{\mathrm{d}}$ values of 697,94 , and $6.3 \times 10^{4} \mathrm{~mL} / \mathrm{g}$, respectively.

With respect to $\mathrm{Np}$ and $\mathrm{Pu}$, a number of published data are pertinent to the present study. Keeney-Kennicutt and Morse (Keeney-Kennicutt and Morse, 1984) found that $\mathrm{Np}(\mathrm{V}) \mathrm{O}_{2}{ }^{+}$ sorption to a synthetic $\mathrm{MnO}_{2}$ and natural $\mathrm{Mn}$ nodule increased with decreasing ionic strength (most likely resulting from reduced competition between cations for surface sites). Compared to the Mn oxides, however, Np sorbed more strongly to iron oxide. Turin et al. (2002) observed a stronger correlation between $\mathrm{Np}$ sorption and iron oxide content than $\mathrm{Np}$ sorption and $\mathrm{Mn}$ oxide content. Interestingly, plutonium appears to exhibit the opposite behavior. Means et al. (1978) studied ${ }^{244} \mathrm{Cm},{ }^{241} \mathrm{Am}$, and ${ }^{238} \mathrm{Pu}$ sorption onto soils near the Oak Ridge National Laboratory radioactive waste burial site. Duff et al. (1999), examined Pu(VI) sorption onto a natural zeolitic tuff. In both cases, researchers observed that $\mathrm{Pu}$ sorbed more strongly to Mn oxides than Fe oxides when both minerals were present. 
Dyer et al. (2000a) reported that uptake of ${ }^{236} \mathrm{Pu}$ and other radionuclides by a synthetic birnessite was $\mathrm{pH}$ dependent. The $\mathrm{Pu} \mathrm{K} \mathrm{d}_{\mathrm{d}}$ at $\mathrm{pH} 9.1$ was $39700 \mathrm{~mL} / \mathrm{g}$ while at $\mathrm{pH} 1.2$ and 13 it was 49 and $1620 \mathrm{~mL} / \mathrm{g}$, respectively. We would expect $\mathrm{Np}$ to exhibit $\mathrm{pH}$ dependent behavior as well.

Several researchers have attempted to model cation sorption to manganese oxides using a surface complexation approach. Catts and Langmuir (Catts and Langmuir, 1986) used a seven-variable model with monodentate complexation reactions to investigate uptake of several heavy metals onto $\delta \mathrm{MnO}_{2}$. Smith and Jenne (Smith and Jenne, 1991) used those results in conjunction with the results from Balistrieri and Murray (1982) to constrain surface complexation constants in their triple layer model of metal adsorption onto iron and manganese oxides. Questioning the applicability of monodentate complexation reactions, Appelo and Postma (1999) formulated a new model to account for cation uptake by birnessite that incorporated diprotic sorption sites in a diffuse double layer model. More recently, Tonkin et al. (Tonkin et al., 2004) developed a two-site diffuse double layer model using the data from seven earlier studies to develop a consistent set of surface acidity and divalent cation complexation constants. Nevertheless, just as there is a limited amount of experimental data available for radionuclide sorption onto $\mathrm{Mn}$ oxides, there are few publications that describe attempts to model the processes responsible for sorption.

Table 1. Manganese oxide sorption data available in the literature.

\begin{tabular}{ll|ll}
\hline Element & Reference & Element & Reference \\
\hline $\mathrm{Ca}$ & $3,11,12,19,22,27$ & $\mathrm{Na}$ & $3,11,18,26$ \\
$\mathrm{Ni}$ & $6,9,19,20,27,31$ & $\mathrm{Mg}$ & $3,19,22,27$ \\
$\mathrm{Co}$ & $6,11,12,16,19,25,33$ & $\mathrm{~K}$ & $3,18,26$ \\
$\mathrm{Sr}$ & $2,6,19,22,29,30$ & $\mathrm{Cr}$ & 13 \\
$\mathrm{Nb}$ & 28 & $\mathrm{Mn}$ & $6,15,19,22$ \\
$\mathrm{Cs}$ & 6,26 & $\mathrm{Cu}$ & $4,15,27$ \\
$\mathrm{Ce}$ & 10 & $\mathrm{Zn}$ & $4,6,11,12,15,19,27,30,31$ \\
$\mathrm{Sm}$ & 10,28 & $\mathrm{As}$ & 7 \\
$\mathrm{Eu}$ & 10 & $\mathrm{Se}$ & $7,13,28$ \\
$\mathrm{U}$ & $1,13,17,28$ & $\mathrm{Ag}$ & 22 \\
$\mathrm{~Np}$ & $8,28,32$ & $\mathrm{Ba}$ & 22 \\
$\mathrm{Pu}$ & $5,6,16,23,28,32$ & $\mathrm{~Pb}$ & $4,13,14,15,21,27$ \\
$\mathrm{Am}$ & $16,28,32$ & $\mathrm{Th}$ & 17,28 \\
$\mathrm{Cm}$ & 16 & & \\
\hline
\end{tabular}

Key to references: 1) (Al-Attar and Dyer, 2002); 2) Axe et al., 2000; 3) Balistrieri and Murray, 1982; 4) Catts and Langmuir, 1986; 5) Duff et al., 1999; 6) Dyer et al., 2000a; 7) Foster et al., 2003; 8) Keeney-Kennicutt and Morse, 1984; 9) Kennedy et al., 2004; 10) Koeppenkastrop and Carlo, 1992; 11) Loganathan and Burau, 1973; 12) Loganathan et al., 1977; 13) Manceau et al., 1992; 14) Matocha et al., 2001;15) Mckenzie, 1979; 16) Means et al., 1978; 17) Misaelides et al., 2002; 18 and 19) Murray, 1974, 1975; 20) Olin and Lehikoinen, 1997; 21) O'Reilly and Hochella, 2003; 22) Posselt et al., 1968; 23) Shaughnessy et al., 2003; 24) Stahl and James, 1991; 25) Tamura et al., 1997; 26) Tanaka and Tsuji, 1997; 27) Tessier et al., 1996; 28) Triay et al., 1997; 29 and 30) Trivedi and Axe, 1999, 2001;31) Trivedi et al., 2001;32) (Turin et al., 2002); and 33) Zachara et al., 1995. 


\section{SORPTION EXPERIMENT METHODS}

\subsection{Manganese Oxide Preparation}

Pyrolusite, birnessite, and cryptomelane were chosen for sorption-desorption experiments based on their common occurrence at Yucca Mountain (Carlos et al., 1993). Mineralogic analysis of Mn-oxides at the NTS has not been performed, though the presence of Mnoxides is well known. It is expected that the Mn-oxide mineralogy at NTS will be similar to that observed at Yucca Mountain. Natural samples of these Mn oxide minerals rarely occur in pure form and could not be purchased. As a result, synthetic minerals were used. While synthetic pyrolusite could be purchased, birnessite and cryptomelane were synthesized using recipes from the literature.

\subsubsection{Pyrolusite}

Reagent grade $\mathrm{MnO}_{2}$ was purchased from Mallinckrodt Baker, Inc. chemical supplies. XRD analysis confirmed that this black powder was crystalline, chemically pure pyrolusite (Figure 2). Powder X-ray diffraction (XRD) patterns of each mineral were collected on a Scintag Pad V diffractometer with $\mathrm{Cu}-\mathrm{K}_{\alpha}$ radiation.

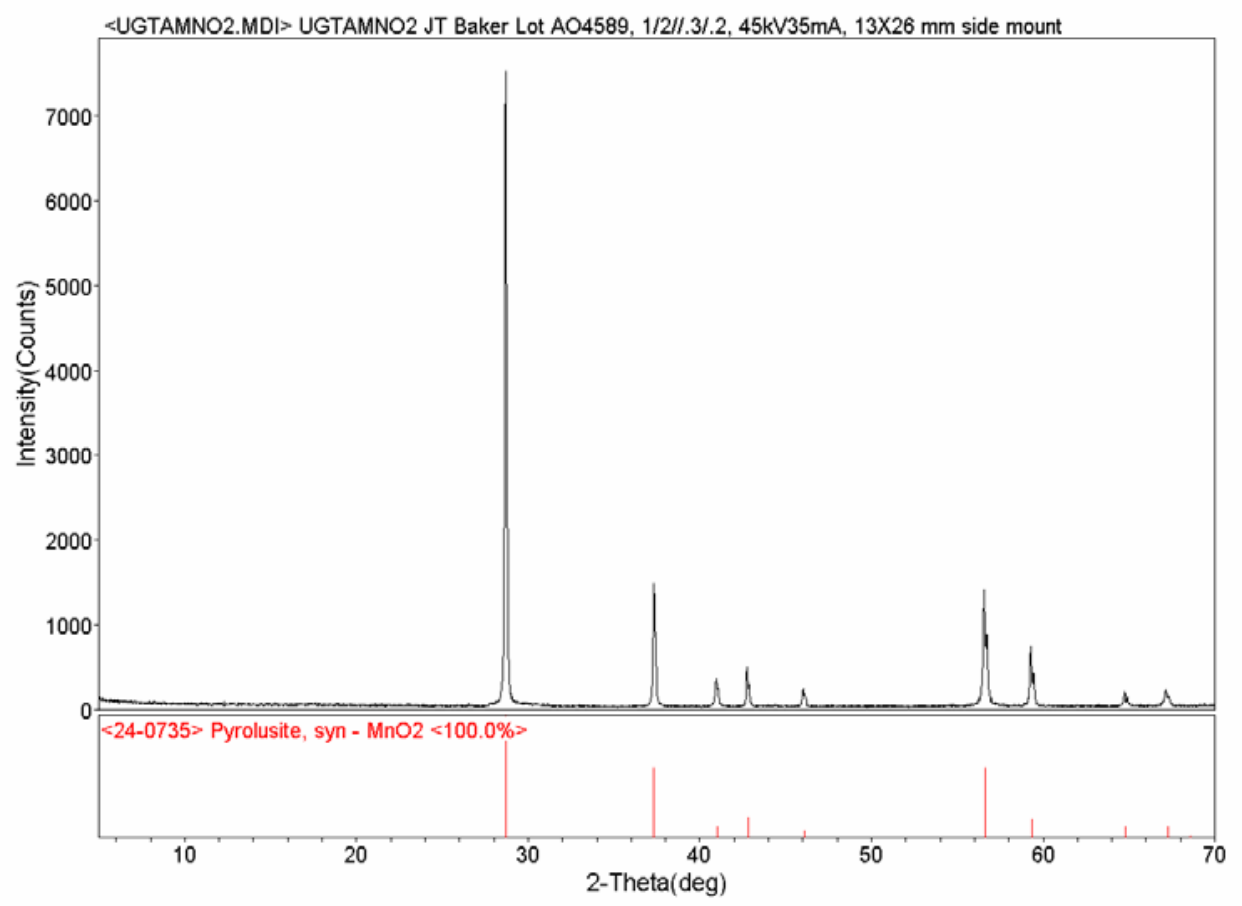

Figure 2. XRD pattern of purchased pyrolusite. 


\subsubsection{Birnessite and Cryptomelane}

Birnessite was synthesized according to the methods outlined by (Golden et al., 1986). After adding $250 \mathrm{~mL}$ of $5.5 \mathrm{M} \mathrm{NaOH}$ to $200 \mathrm{~mL}$ of $0.5 \mathrm{M} \mathrm{MnCl}_{2}$, oxygen was bubbled into the resulting $\mathrm{Mn}(\mathrm{OH})_{2}$ suspension, usually through a glass frit, at a minimum rate $^{3}$ of $3.6 \mathrm{ft}^{3} \mathrm{hr}^{-1}\left(1.7 \mathrm{~L} \mathrm{~min}^{-1}\right)$ for 5 hours. When the recipe was doubled or quadrupled, the oxygen was introduced into the suspension for 6 or 8 hours, respectively.

After oxygenation, the suspension was divided into $250 \mathrm{~mL}$ HDPE bottles and $50 \mathrm{~mL}$ polycarbonate centrifuge tubes and the precipitates were separated from the solution using an International Equipment Company Centra-8 centrifuge (5 minutes at 2200 RPM). The supernatant was discarded and the precipitates were rinsed 8-10 times with Milli-Q purified water and then freeze dried for at least 24 hours with a LABCORP Freeze Dryer 4.5 lyophilizer. The resultant black powder was examined using XRD analysis and the identified peaks (Figure 3 ) confirmed the presence of crystalline birnessite $\left(\mathrm{Na}_{0.55} \mathrm{Mn}_{2} \mathrm{O}_{4} \cdot 1.5 \mathrm{H}_{2} \mathrm{O}\right)$. A single run yielded approximately $8-9 \mathrm{~g}$ of product.

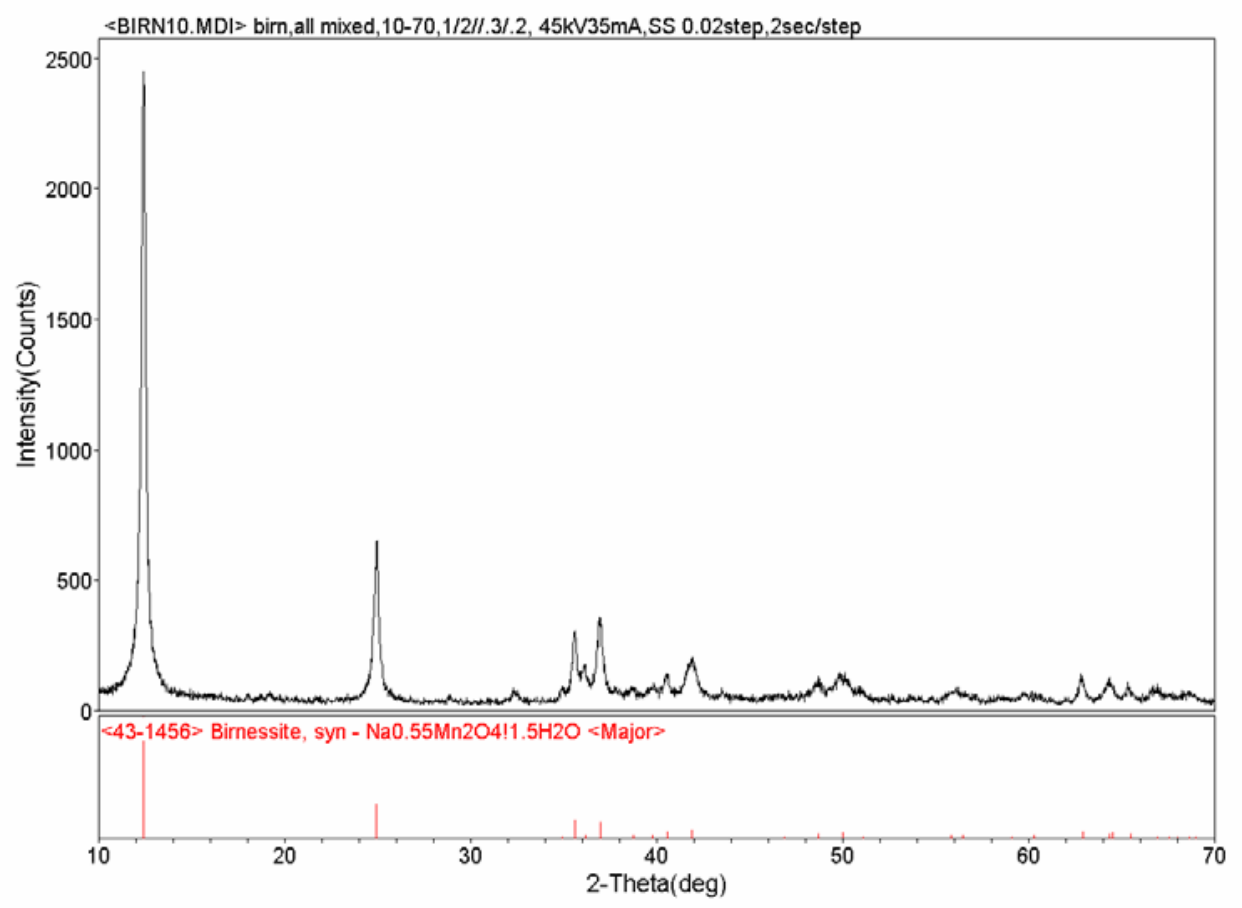

Figure 3. XRD pattern of synthetic birnessite.

To synthesize cryptomelane, the recipe of Chen et al. (Chen et al., 1986) was used. Portions of synthetic birnessite were washed and centrifuged 8 times with $1 \mathrm{M} \mathrm{KCl}$ to initiate ion exchange between the $\mathrm{Na}$ in the birnessite and the $\mathrm{K}$ in solution. The

\footnotetext{
${ }^{3}$ During one synthesis, the oxygen regulator was incorrectly adjusted such that the flow was much lower than the $3.6 \mathrm{ft}^{3} \mathrm{hr}^{-1}$ minimum that the meter displayed. It became obvious after this run that the minimum flow rate is crucial because the resultant mineral was hausmannite $\left(\mathrm{Mn}_{3} \mathrm{O}_{4}\right)$.
} 
precipitates were then rinsed 5 times with Milli-Q water to remove any excess $\mathrm{KCl}$. Five rinses resulted in supernatant conductivity values of 75 to $130 \mu \mathrm{S}$. The rinsed precipitates were then placed in an oven at $200^{\circ} \mathrm{C}$. The temperature was raised by $200^{\circ} \mathrm{C}$ every two hours until a final temperature of $800^{\circ} \mathrm{C}$ was achieved. After the minerals had been at $800^{\circ} \mathrm{C}$ for 2 hours they were placed in a $25^{\circ} \mathrm{C}$ oven to cool overnight before being examined by XRD. The XRD pattern (Figure 4 ) indicated that the resultant black powder was a mixture of vernadite $\left(\mathrm{Mn}(\mathrm{OH})_{4}\right)$ and cryptomelane $\left(\mathrm{K}_{2} \mathrm{Mn}_{8} \mathrm{O}_{16}\right)$ with some sodium impurities resulting from incomplete $\mathrm{Na}-\mathrm{K}$ exchange between the birnessite and the $\mathrm{KCl}$ solution.

During $\mathrm{Pu}(\mathrm{IV})$ sorption experiments using these two minerals, it was observed that the solution $\mathrm{pH}$ increased dramatically. It suggested that excess hydroxide remained in the dried solids. As a result, prior to starting $\mathrm{Np}(\mathrm{V})$ sorption experiments, the birnessite and cryptomelane were rinsed several times in weak $\mathrm{NaNO}_{3}$ and $\mathrm{KNO}_{3}$ solutions, respectively. The rinses affected the measured surface area of the birnessite, but did not significantly alter the surface area of the cryptomelane (see Section 4.2).

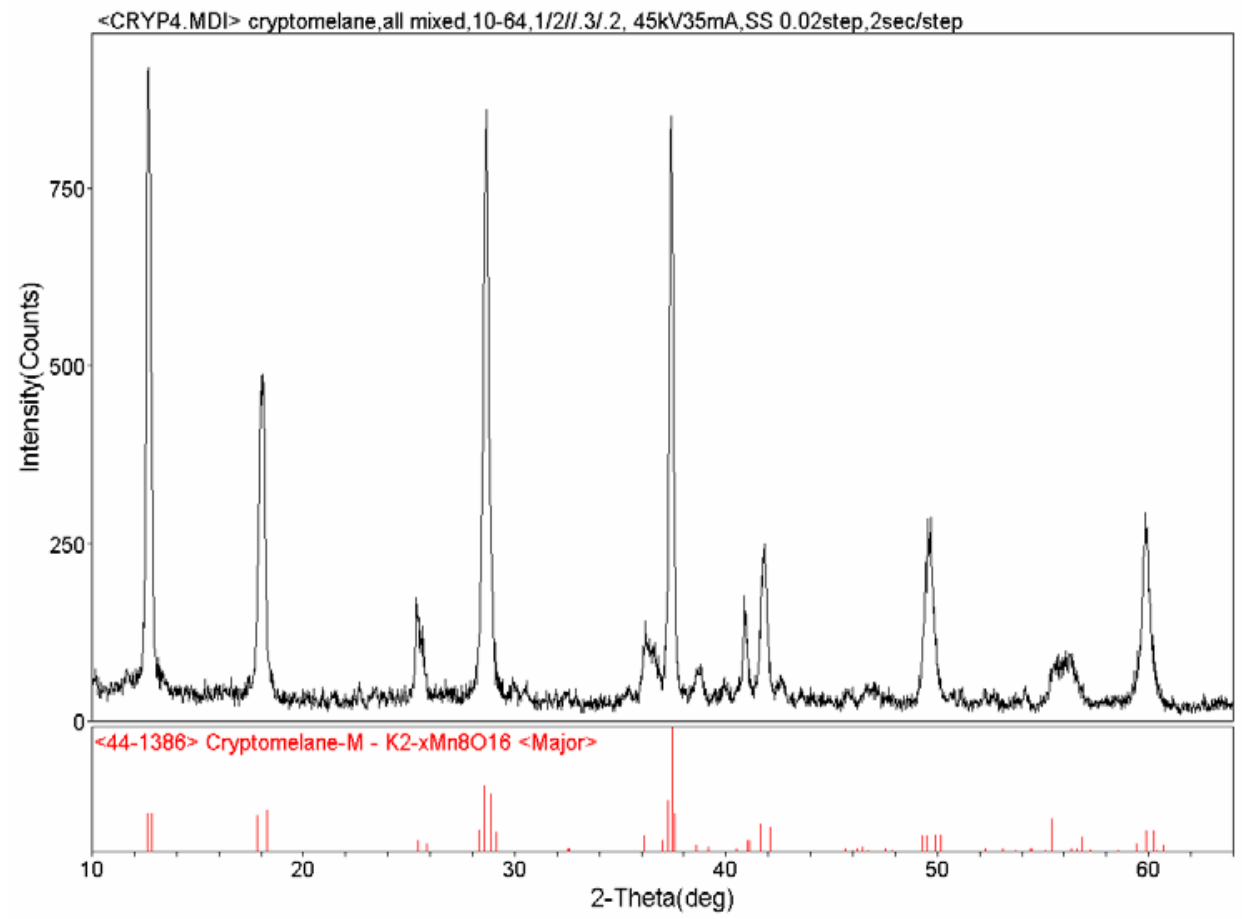

Figure 4. XRD pattern of synthetic cryptomelane. 


\subsection{Sorption and Desorption Experiments}

\subsection{1 $\mathrm{Np}(\mathrm{V})$}

A stock solution of $\mathrm{Np}(\mathrm{V})\left(8.10 \times 10^{-4} \mathrm{~mol} \mathrm{~L}^{-1}\right)$ in $1 \mathrm{M} \mathrm{HNO}_{3}$ was used as the spike solution in the sorption experiments. The oxidation state of $\mathrm{Np}(\mathrm{V})$ was confirmed using a Guided Wave Model 260 Fiber Optic spectrophotometer. A Tri-Carb 2500 Liquid Scintillation analyzer from Packard Instrument Company was used for liquid scintillation counting (LSC) of the $\alpha$-emitter ${ }^{237} \mathrm{~Np}$. An $\alpha, \beta$ discrimination mode was used in LSC for ${ }^{237} \mathrm{~Np}$ to reduce the counting interference from $\beta$-emitter ${ }^{234} \mathrm{~Pa}$, a daughter of ${ }^{237} \mathrm{~Np}$. Gamma spectrometry with a high purity germanium detector was used for accurate nuclear counting at $29.4 \mathrm{keV}$ to determine the concentrations of ${ }^{237} \mathrm{~Np}$ in the stock and reference solutions.

A small spike $(\leq 20 \mu \mathrm{L})$ of the $\mathrm{Np}(\mathrm{V})$ stock was added to each of 8 reaction tubes filled with $50 \mathrm{mg}$ of each manganese oxide mineral and $35 \mathrm{~mL}$ of a synthetic groundwater ranging in $\mathrm{pH}$ from 3 to 10 . The synthetic groundwater solutions were based on a $4.5 \mathrm{x}$ $10^{-3}$ mol L-1 $\mathrm{NaHCO}_{3}$ solution with $\mathrm{pH}$ adjusted using $\mathrm{HNO}_{3}$ or $\mathrm{NaOH}$. The synthetic groundwater had been allowed to pre-equilibrate at room temperature $\left(23 \pm 2^{\circ} \mathrm{C}\right)$ for up to a week with the $50 \mathrm{mg}$ of manganese oxide mineral prior to starting the sorption experiment. The $\mathrm{pH}$ of each reaction tube was re-adjusted using $\mathrm{NaOH}$ and/ or $\mathrm{HNO}_{3}$ if a large deviation from initial $\mathrm{pH}$ was observed during the pre-equilibration period. A $\mathrm{Np}(\mathrm{V})$ spike was added only after the $\mathrm{pH}$ in the reaction tubes stabilized. $\mathrm{Np}(\mathrm{V})$ was added to achieve an initial concentrations of $3.4 \times 10^{-6} \mathrm{~mol} \mathrm{~L}^{-1} \mathrm{~Np}(\mathrm{~V})$. All the reaction tubes were continuously rotated end-over-end to ensure thorough mixing during the experiment. At the prescribed sampling intervals, solutions were centrifuged for 5-10 minutes@5000 RPM prior to sampling the supernatant. A negligible volume of supernatant was sampled at 1 day, 15 days and $\sim 30$ days and analyzed for ${ }^{237} \mathrm{~Np}$ using LSC. The $\mathrm{pH}$ of each sorption solution was not adjusted, only monitored during each sampling. After the 30 day sampling, the remaining supernatant was sampled and analyzed for carbonate alkalinity, cation, and anion concentrations.

The partition coefficient $\left(\mathrm{K}_{\mathrm{d}}, \mathrm{mL} / \mathrm{g}\right)$ obtained from sorption and desorption experiments was calculated using equations (1) and (2), respectively.

$$
\begin{aligned}
\mathrm{K}_{\mathrm{d}} & =\frac{\left(A_{i}-A\right)}{A} \times \frac{V}{m} \\
\mathrm{~K}_{\mathrm{d}} & =\frac{\% \text { Sorption }}{100-\% \text { Sorption }} \times \frac{V}{m}
\end{aligned}
$$

where $A_{i}$ and $A$ are the activity (cpm mL ${ }^{-1}$ ) of $\mathrm{Np}$ or $\mathrm{Pu}$ in the supernatant before and after it contacted the manganese oxides, respectively; $m$ is the mass $(\mathrm{g})$ of the minerals used; and $V$ is the volume $\left(\mathrm{mL}^{3}\right)$ of solution. The \%Sorption was calculated in desorption 
experiments from the total activity of $\mathrm{Np}$ or $\mathrm{Pu}$ in each sample and the activity in the aqueous phase.

At the end of the 30 day sorption experiment, the solids containing sorbed Np were mixed with $35 \mathrm{~mL}$ radionuclide-free solution to start the desorption experiments ( $\mathrm{pHs}$ were kept the same). All the reaction tubes were continuously rotated during the desorption experiment ( $\sim 33$ days). The supernatants were sampled at 1 day, 15 days and $\sim 30$ days. At the end of the 30 day desorption experiment, the oxidation state of Np was characterized using solvent extraction.

\subsection{2 $\mathrm{Pu}(\mathrm{IV})$}

The Pu(IV) stock solution $\left(2.96 \times 10^{-7} \mathrm{~mol} \mathrm{~L}^{-1}\right)$ used in the sorption experiments was purified from ${ }^{241} \mathrm{Am}$, the $\beta$-decay daughter of ${ }^{241} \mathrm{Pu}$, using a TEVA resin (Eichrom Technologies, Inc.) column, then the final effluent was diluted into $1 \mathrm{M} \mathrm{HNO}_{3}$. The total $\mathrm{Pu}$ contained in the stock solution was comprised of $7.03 \%{ }^{238} \mathrm{Pu}, 87.2 \%{ }^{239} \mathrm{Pu}, 5.57 \%$

${ }^{240} \mathrm{Pu}, 0.153 \%{ }^{241} \mathrm{Pu}$ and $0.051 \%{ }^{242} \mathrm{Pu}$ by mass, as determined by $\alpha$-spectrometry. Due to the low $\mathrm{Pu}$ concentration of the Pu stock solution, the Pu oxidation state could not be confirmed using the standard UV/VIS spectrometric technique; instead we used a solvent extraction method with 4-Benzoyl-3-methyl-1-phenyl-2-pyrozolln-5-one (PMBP) ${ }^{4}$. The extraction results showed that $>90 \pm 5 \%$ of Pu was Pu(IV). A Tri-Carb 2500 Liquid Scintillation analyzer from Packard Instrument Company was used for $\mathrm{Pu} \alpha$-LSC.

A spike $(\leq 20 \mu \mathrm{L})$ of the $\mathrm{Pu}(\mathrm{IV})$ stock was added to each of 8 reaction tubes filled with 35 $\mathrm{mL}$ of $\mathrm{pH} 3$ to 10 sodium bicarbonate solutions. The background solutions had been allowed to pre-equilibrate for up to 3 days at room temperature $\left(23 \pm 2^{\circ} \mathrm{C}\right)$ with $10 \mathrm{mg}$ of each manganese oxide mineral. The $\mathrm{pH}$ of each solution was re-adjusted using $\mathrm{NaOH}$ and/ or $\mathrm{HNO}_{3}$ if a large deviation from initial $\mathrm{pH}$ was observed during the preequilibration period. After the $\mathrm{pH}$ in the reaction tubes stabilized, the tubes were spiked with $\mathrm{Pu}(\mathrm{IV})$ to achieve an initial $\mathrm{Pu}(\mathrm{IV})$ concentration of $5 \times 10^{-9} \mathrm{~mol} \mathrm{~L}^{-1}$. All the reaction tubes were continuously rotated to ensure thorough mixing during the reaction time ( 34 days). The supernatant, separated from the Pu-sorbed minerals by centrifugation for 5-10 minutes at 5000 RPM, was sampled after 1 day, 15 days and 34 days, and analyzed for $\mathrm{Pu}$ using $\alpha$-LSC. The $\mathrm{pH}$ of each sorption solution was not adjusted, only monitored during each sampling. At the end of the sorption experiment, the supernatant was analyzed for carbonate alkalinity, cation, and anion concentrations.

For the desorption experiment, the solid phases, containing sorbed $\mathrm{Pu}$, were mixed with $35 \mathrm{~mL}$ of $\mathrm{pH}$-adjusted radionuclide-free solution. All the reaction tubes were constantly rotated during the reaction time ( $\sim 23$ days). The supernatants were sampled after 1 day, 15 days and 23 days. At the end of desorption experiments, the oxidation state of $\mathrm{Pu}$ in the supernatant and on the minerals was characterized using solvent extraction.

\footnotetext{
${ }^{4}$ See Section 4.4 .3 on page 36.
} 


\subsection{Oxidation State Analysis}

Organic chemical reagents 4-benzoyl-3-methyl-1-phenyl-2-pyrozolln-5-one (PMBP) and bis(2-ethylhexyl) hydrogen phosphate (D2EHPA) contain functional groups that can chelate the +4 and $+4 /+6 \mathrm{~Np}$ (or Pu) oxidation states, respectively. In our experiments, these two chemical reagents, dissolved in xylene, were used to extract $\mathrm{Np}$ and $\mathrm{Pu}$ species into the organic phase from a $1 \mathrm{~N} \mathrm{HCl}$ solution and quantify the fractions of +4 and +6 oxidation states. Sodium dichromate quantitatively oxidizes +3 to +4 and +5 to +6 species in $1 \mathrm{~N} \mathrm{HCl}$. When combined with PMBP and D2EHPA extractions, we can quantify the fraction of $+3,+4,+5$, and $+6 \mathrm{~Np}$ (or $\mathrm{Pu}$ ) oxidation states in solution. We used the combination of dichromate oxidation and organic extraction to determine the percentage of each $\mathrm{Np}$ and $\mathrm{Pu}$ oxidation state in desorption solutions and on the mineral surfaces.

The procedure for determining oxidation state was as follows:

Mix 0.8-4 mL of Pu/Np containing aqueous solution with $0.2-1 \mathrm{~mL} 5 \mathrm{~N} \mathrm{HCl}$ and $0.5-1$ $\mathrm{mL} \mathrm{PMBP/xylene} \mathrm{or} \mathrm{D2EHPA/xylene} \mathrm{solvent} \mathrm{in} \mathrm{a} \mathrm{centrifuge} \mathrm{tube;} \mathrm{shake} \mathrm{the} \mathrm{tube}$ vigorously for $>5$ minutes on a Vortex shaker/mixer. Finally, centrifuge the tube for 1 minute at $>3000$ RPM to separate the aqueous and organic phases. The aqueous phase is extracted twice by each organic chelating reagent, and a sample of 0.4 to $1 \mathrm{~mL}$ from each phase is taken for $\alpha$-LSC. The PMBP extraction yields +4 species. The D2EHPA extraction yield +4 and +6 species.

Next, $0.8-4 \mathrm{~mL}$ of $\mathrm{Pu} / \mathrm{Np}$ containing aqueous solution is reacted with $0.2-1 \mathrm{~mL}$ of a 0.02 mol L ${ }^{-1} \mathrm{Na}_{2} \mathrm{Cr}_{2} \mathrm{O}_{7}$ solution. This reaction oxidizes all +3 species to +4 and all +5 species to +6 . The oxidized solution is then extracted with either PMBP or D2EHPA as described above. The PMBP extraction yields +3 and +4 species. The D2EHPA extraction yields $+4,+5$, and +6 species. The results from all four extractions are used to calculate the fractions of $+3,+4,+5$, and +6 species.

\subsection{Modeling Approach}

The modeling approach was based on a mechanistic description of the aqueous speciation and surface complexation of radionuclides. We refer the reader to recent summary documents that describe the surface complexation modeling approach and relevant aqueous speciation constants (Zavarin and Bruton 2004a; 2004b). In those documents, the authors describe a database of non-electrostatic surface complexation and ion exchange reactions that model the sorption of several radionuclides (including $\mathrm{Np}$ and $\mathrm{Pu}$ ) to iron oxide, calcite, and aluminosilicate minerals. The results described in this report provide the needed information to expand our modeling approach and include additional sorption reaction relevant to accurately predict radionuclide sorption at the NTS: surface complexation to manganese oxide minerals.

Aqueous speciation and surface complexation modeling was accomplished using the Geochemist's Workbench (Bethke, 2002) or the FITEQL program (Herbelin and Westall, 
1999). A surface complexation model for birnessite was developed by Tonkin et al. (2004) and is used as the foundation for our modeling of $\mathrm{Np}(\mathrm{V})$ sorption data. Some modeling using the earlier model of Appelo and Postma (1999) is also discussed. Models of cation sorption to cryptomelane and pyrolusite have not been reported in the literature. As a result, no attempt was made to model sorption to those minerals. However, we discuss the relationship between the birnessite, cryptomelane, and pyrolusite data; in general, we found that the behavior of all three minerals is similar. Pu sorption data were not modeled because it was found that the Pu oxidation state changed during the experiments; furthermore, oxidation state changes appeared to be $\mathrm{pH}$ dependent. Due to this complex behavior, Pu sorption modeling was not attempted. 


\section{RESULTS AND DISCUSSION}

\subsection{Aqueous Speciation of $\mathrm{Pu}$ and $\mathrm{Np}(\mathrm{V})$ and Surface Speciation of Birnessite}

The redox chemistry of $\mathrm{Np}$ is simple relative to $\mathrm{Pu}$. In NTS-type, low ionic strength sodium bicarbonate groundwaters, $\mathrm{Np}$ predominantly occurs in the +5 oxidation state as the $\mathrm{NpO}_{2}{ }^{+}$ion (Keeney-Kennicutt and Morse, 1984) and forms carbonate or hydroxide species depending on the $\mathrm{pH}$ and carbonate alkalinity of the solution. While changes in the redox state of $\mathrm{Np}(\mathrm{V})$ were not expected, the $\mathrm{Np}$ oxidation state was examined at the end of desorption experiments (see Section 4.3.3).

Unlike Np, Pu can exist in several oxidation states under ambient groundwater conditions. While it has been shown that $\mathrm{Pu}(\mathrm{IV})$ added to a solution will eventually oxidize such that the dominant aqueous species becomes $\mathrm{Pu}(\mathrm{V}), \mathrm{Pu}$ can occur simultaneously in the $+3,+4,+5$, and +6 oxidation states (Duff et al., 1999). Each valence state exhibits different solubility and mobility behavior (Duff et al., 1999), but the more-oxidized forms are typically more soluble (Shaughnessy et al., 2003). Several researchers have noted a change in the oxidation state of $\mathrm{Pu}$ following mineral contact. In some cases $\mathrm{Pu}(\mathrm{VI})$ was reported to reduce to $\mathrm{Pu}(\mathrm{IV})$ following contact with $\delta \mathrm{MnO}_{2}$ (Shaughnessy et al., 2003), while others have reported the disproportionation of $\mathrm{Pu}(\mathrm{V})$ to $\mathrm{Pu}(\mathrm{VI})$ and $\mathrm{Pu}(\mathrm{IV})$ (Keeney-Kennicutt and Morse, 1985). The results of Shaughnessy et al. (2003) were based on EXAFS analysis of solid samples, which is a less-invasive technique than the solvent extraction method used by Keeney-Kennicutt and Morse (1985). However, both techniques may contribute to redox changes. Redox changes due to x-ray beam damage has been observed in some EXAFS studies (e.g. Zavarin, 1999). The solvent extraction process may also be problematic for evaluating the oxidation state of sorbed Pu since the samples need to be pre-treated, typically with acid, to desorb the $\mathrm{Pu}$ prior to solvent extraction. Thus, the results of our solvent extractions should be interpreted with caution. The Pu oxidation state in our sorption experiments is discussed in Section 4.4.3.

Based on the solution composition of our sorption experiments, carbonate complexes of $\mathrm{Pu}(\mathrm{IV})$ and $\mathrm{Np}(\mathrm{V})$ are expected to dominate at high $\mathrm{pH}$ (Figure 5). At the low $\mathrm{pH}$, the two radionuclides are dominated by oxide and hydroxide species. From $\mathrm{pH} 3$ to 7 , $\mathrm{NpO}_{2}{ }^{+}$is the dominant $\mathrm{Np}(\mathrm{V})$ species while $\mathrm{Pu}(\mathrm{IV})$ forms a series of hydroxide species in this same $\mathrm{pH}$ range. 


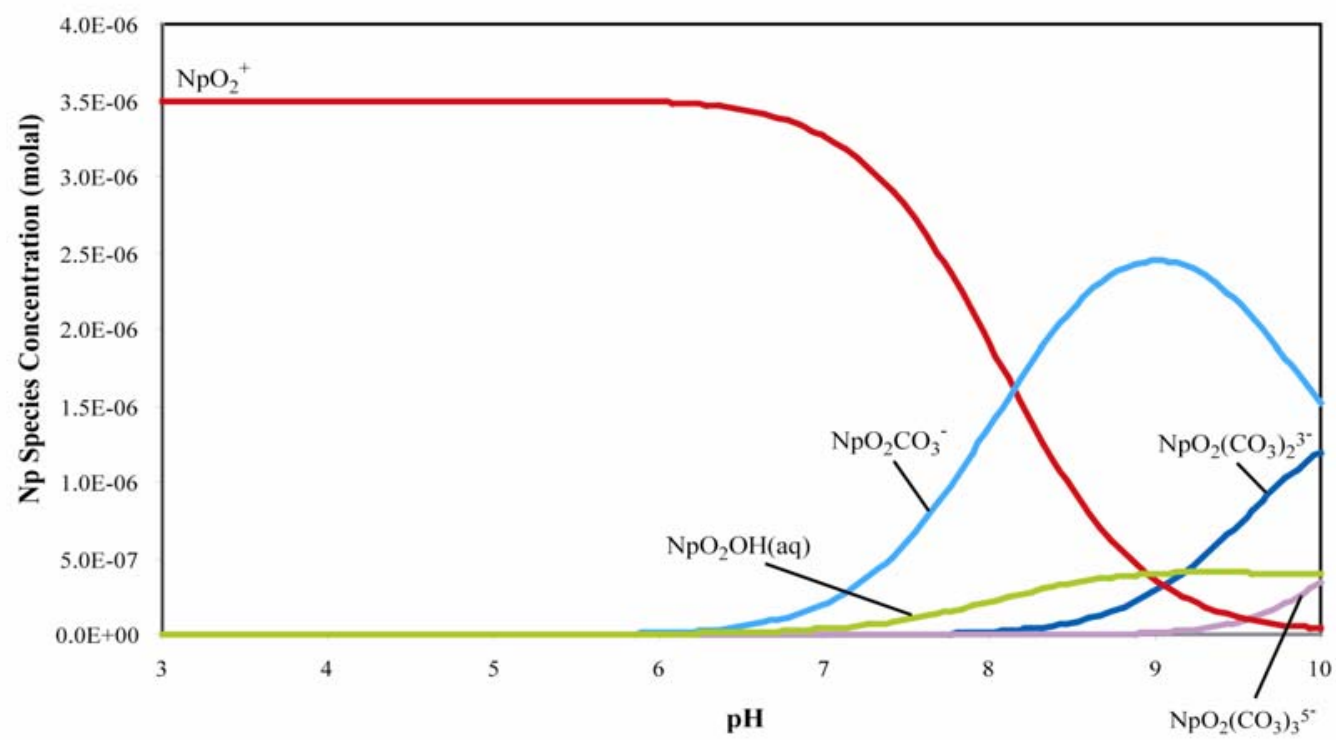

(a)

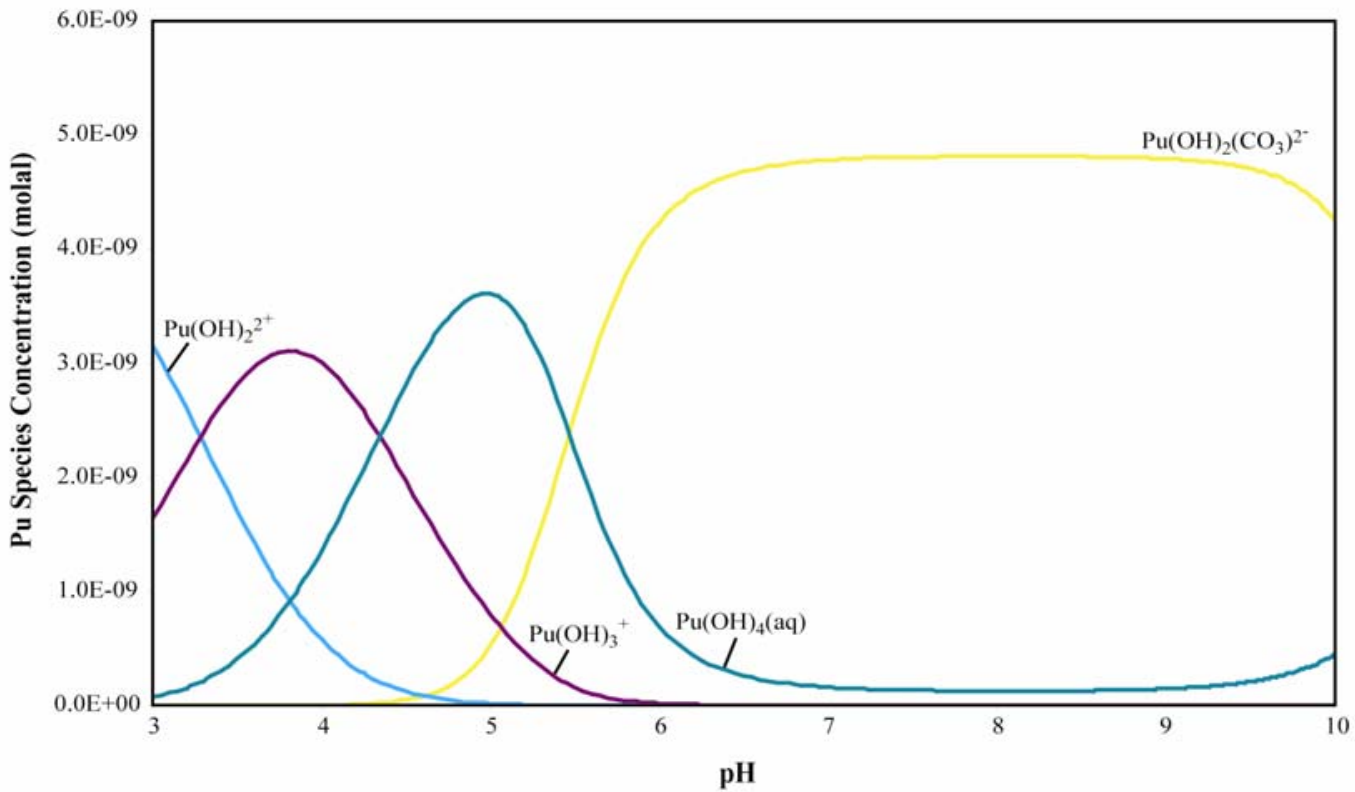

(b)

Figure 5. Aqueous speciation of (a) $\mathrm{Np}(\mathrm{V})$ and (b) $\mathrm{Pu}(\mathrm{IV})$ as a function of $\mathrm{pH}$ given the sorption experiment solution conditions. 
In addition to aqueous speciation, the Mn oxide surface will undergo changes in surface speciation. Figure 6 shows the predicted surface speciation of birnessite based on the diffuse double layer model reaction constants of Tonkin et al. (2004) and the aqueous solution composition in the $\mathrm{Np}(\mathrm{V})$-birnessite sorption experiment (details regarding this

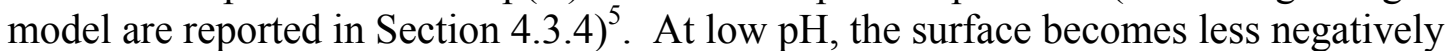
charged. However, the charge on the birnessite surface remains negative over the entire $\mathrm{pH}$ range examined in our experiments. Above $\mathrm{pH} \sim 7$, sorbed $\mathrm{Mn}$ (II) nearly saturates one of the two surface site types (the $>\mathrm{XOH}$ site) on the birnessite surface. The total percentage of available surface sites occupied by the background cations increases linearly from only $1.65 \%$ at the lowest $\mathrm{pH}$ to $61.4 \%$ at the highest $\mathrm{pH}$. Interestingly, the modeled divalent cations only sorb to the $>\mathrm{XOH}$ site type.

The model of Appelo and Postma (1999) predicts similar, but not identical, surface speciation (Figure 7). As in the previous model, $\mathrm{Mn}^{2+}$ is the dominant sorber. However, unlike the Tonkin et al. (2004) model, $\mathrm{Na}^{+}$outcompetes $\mathrm{Ca}^{2+}$ and $\mathrm{Mg}^{2+}$ for surface sites at low $\mathrm{pH}$. Since the Tonkin model only addresses the sorption of divalent cations, predicted $\mathrm{Na}^{+}$sorption cannot be compared. Interestingly, due to the strong sorption of $\mathrm{Mn}^{2+}$ at low $\mathrm{pH}$, the surface is predicted to be positively charged below $\mathrm{pH} 6$.

Differences between the two models illustrate how model predictions are dependent on our description of the Mn oxide surface, the associated surface complexation model, and the data used to calibrate the model. Because the Tonkin model focused on the sorption of divalent cations while the Appelo and Postma model accounted for both divalent and monovalent cations, we would expect some significant differences in our modeling results. Nevertheless, both models predict that sorbed $\mathrm{Mn}^{2+}$ will dominate the birnessite surface.

\subsection{Mn Oxide Mineral Characteristics}

In addition to the XRD analysis used to identify the crystallographic phase of each manganese oxide (see Section 3.1), images of the mineral surfaces were made using Scanning Electron Microscopy (SEM), and surface areas were measured on a Micromeritics Gemini II 2370 surface area analyzer using multipoint Brunauer-EmmettTeller (BET)- $\mathrm{N}_{2}$ adsorption.

According to the SEM images (Figures $8 \mathrm{a}$ and $8 \mathrm{~b}$ ), the framework mineral pyrolusite exhibits a bimodal size distribution with smaller fragments ranging from $0.1-0.5 \mu \mathrm{m}$ and larger fragments ranging from 1-5 $\mu \mathrm{m}$. Birnessite (Figures 8c and 8d), a layered mineral, primarily occurs as 5-20 $\mu \mathrm{m}$ aggregates of .5-2 $\mu \mathrm{m}$ bladed-to-platy crystals, although there is some finer grained material present. SEM images of cryptomelane (Figures 8e and $8 \mathrm{f}$ ), indicate that this tunnel-structure mineral formed as $0.1-0.5 \mu \mathrm{m}$ needles or plates that cluster into 1-10 $\mu \mathrm{m}$ aggregates.

\footnotetext{
${ }^{5}$ In this report, we describe surface complexation only on the birnessite surface. Surface complexation models for the cryptomelane and pyrolusite surfaces were not available in the literature at the time this report was prepared.
} 

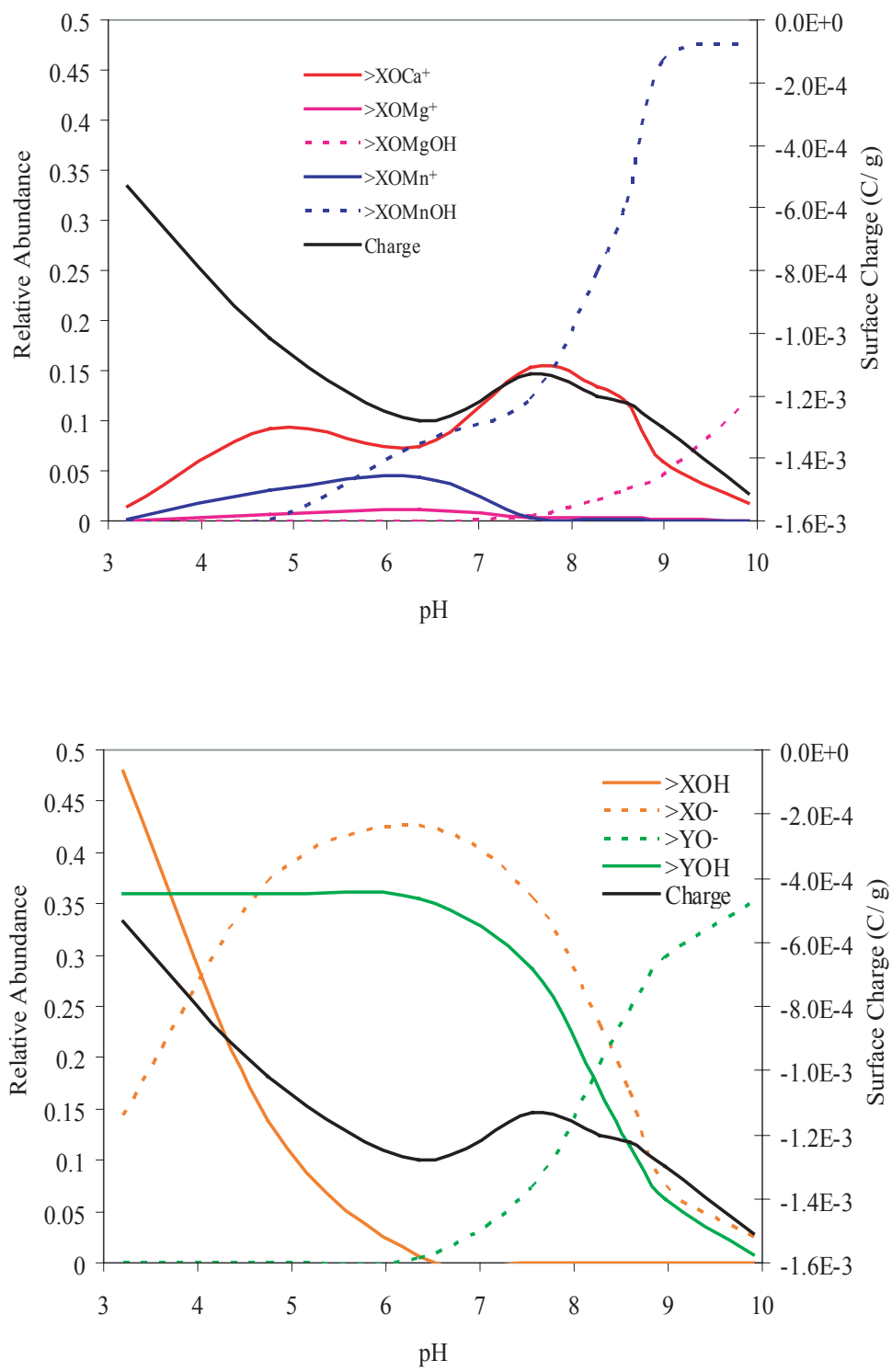

Figure 6. Surface speciation of birnessite based on the model of Tonkin et al. (2004) and water chemistry from the Np-birnessite sorption experiment. Species concentration (left axis) and surface charge (right axis). 

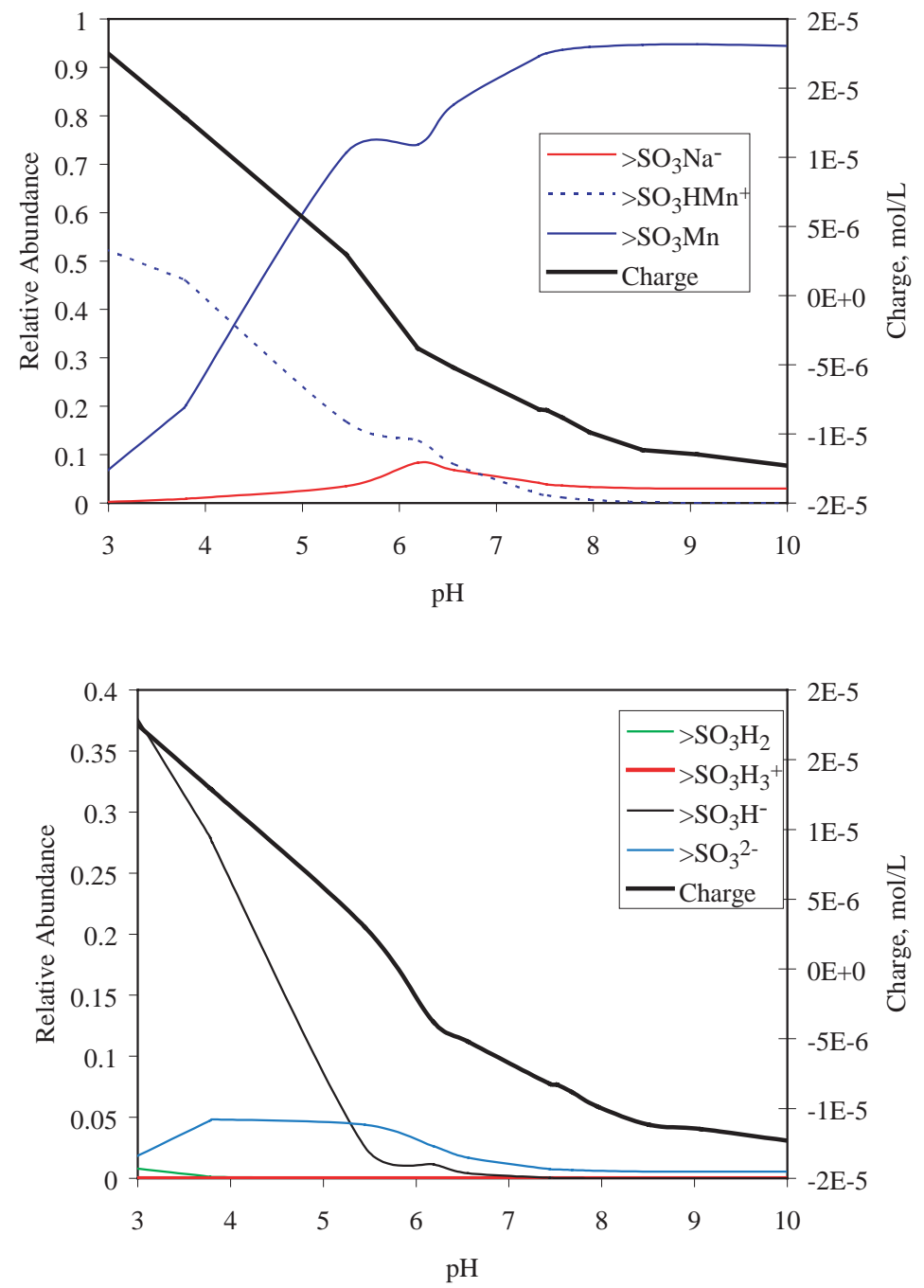

Figure 7. Surface speciation of birnessite (dominant species only) based on the model of Appelo and Postma (1999) and water chemistry from the Np-birnessite sorption experiment. Species concentrations (left axis) and surface charge (right axis). 


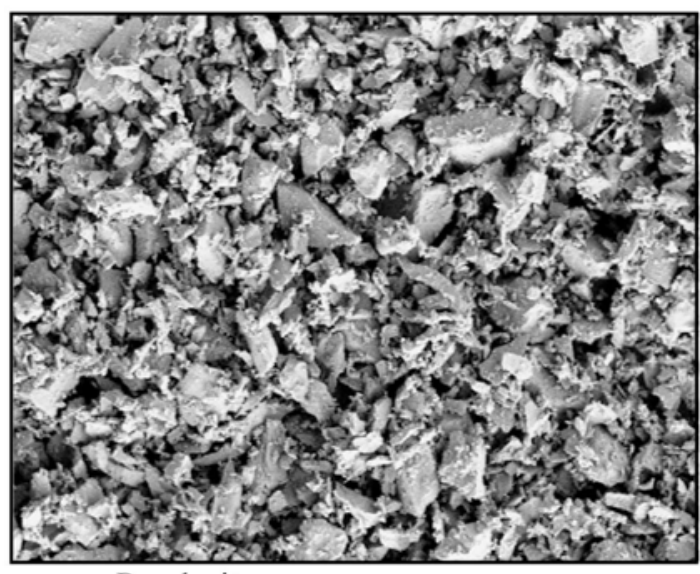

a) Pyrolusite $3.0 \mathrm{kV}, 1.5 \mathrm{~K} \times \quad 20$ microns

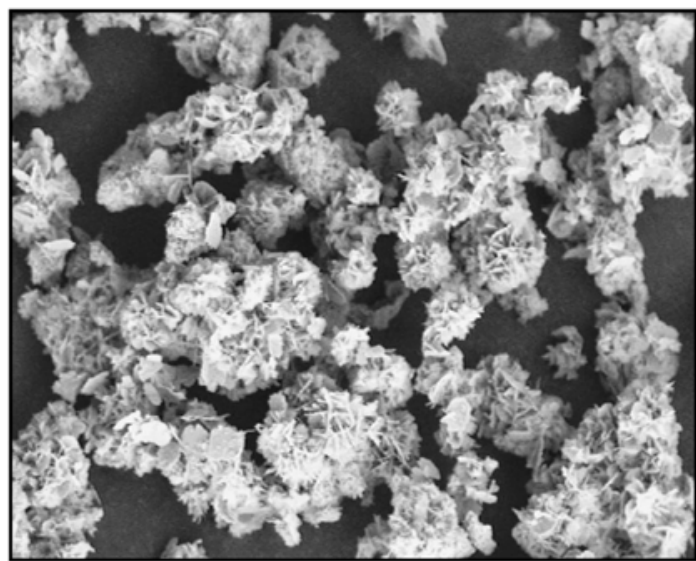

c)
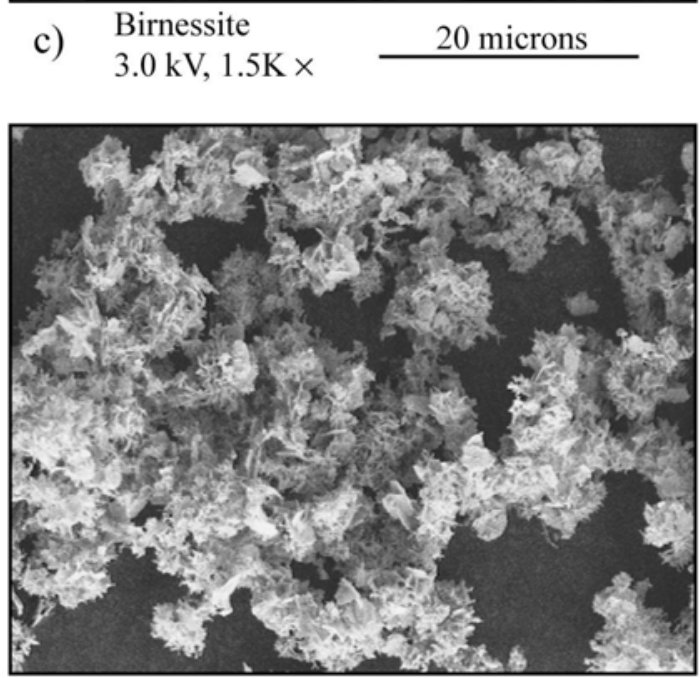

e) Cryptomelane

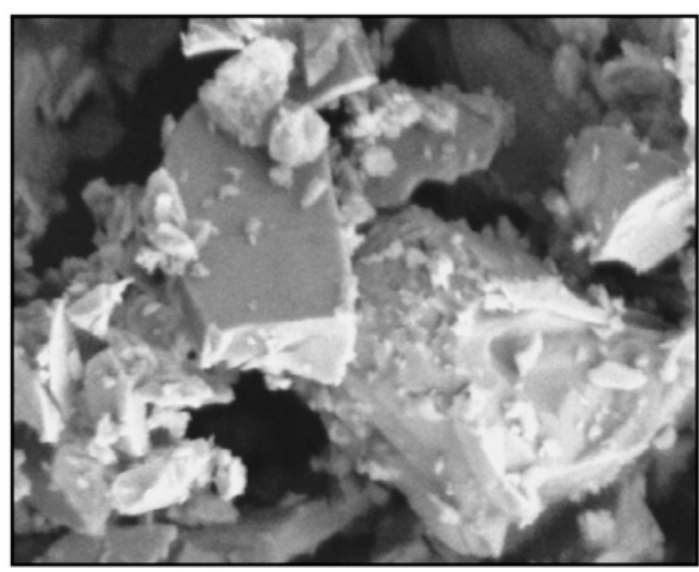

b) Pyrolusite $3.0 \mathrm{kV}, 20 \mathrm{~K} \times \quad 1.5$ microns

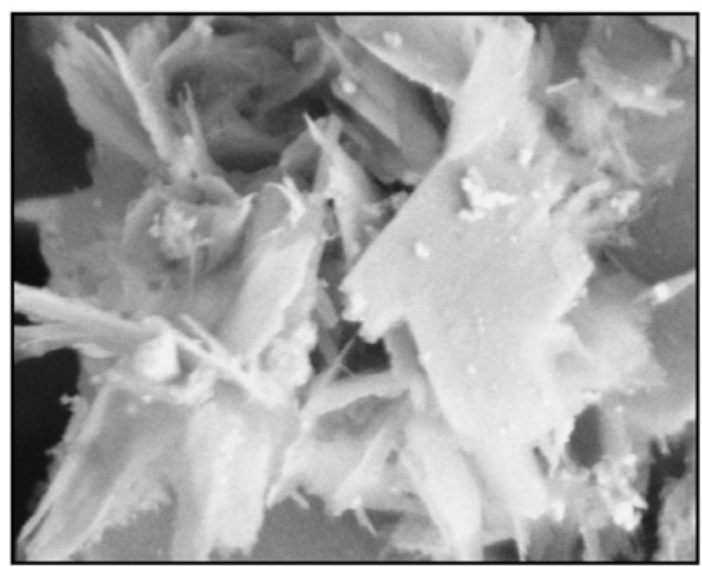

d) $\begin{aligned} & \text { Birnessite } \\ & 3.0 \mathrm{kV}, 20 \mathrm{~K} \times \quad 1.5 \text { microns }\end{aligned}$

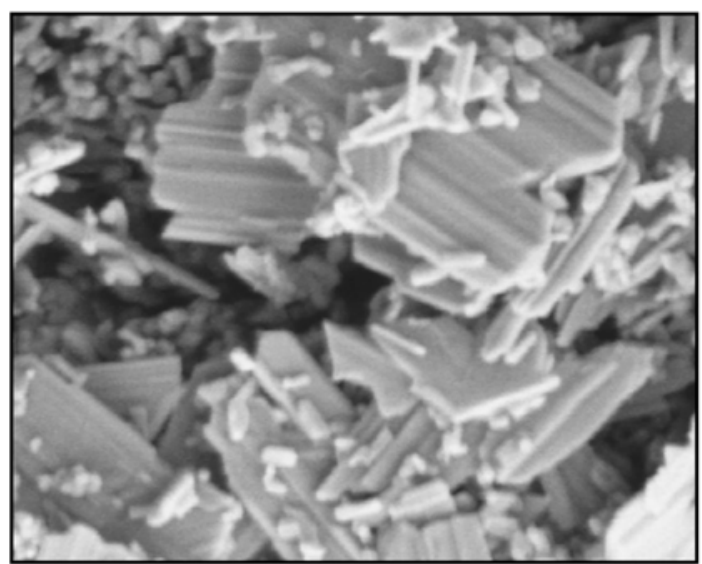

f) Cryptomelane

Figure 8. SEM images of the three manganese oxide minerals. Images on the left are magnified by 1500x; images on the right are magnified by 20,000x. 
Table 2 summarizes the surface areas measured for each mineral. Note that the surface area estimates of the birnessite and the cryptomelane for the $\mathrm{Np}(\mathrm{V})$ and $\mathrm{Pu}(\mathrm{IV})$ experiments are different. The two cryptomelane values are within the analytical error; however, the birnessite values are significantly different. The lower surface area of the birnessite used in the $\mathrm{Np}$ experiments resulted from the additional mineral rinsing described in Section 3.1.

Table 2. Mineral surface areas

\begin{tabular}{lcc}
\hline & $\mathrm{Np}$ & $\mathrm{Pu}$ \\
\hline Pyrolusite, $\mathrm{m}^{2} / \mathrm{g}$ & $2.30+/-0.04$ & $2.30+/-0.04$ \\
Birnessite, $\mathrm{m}^{2} / \mathrm{g}$ & $41.36+/-0.08$ & $54.70+/-0.13$ \\
Cryptomelane, $\mathrm{m}^{2} / \mathrm{g}$ & $11.79+/-0.15$ & $10.54+/-0.78$ \\
\hline
\end{tabular}

Although the additional rinsing of the birnessite reduced the measured surface area of birnessite, it is unlikely that it affected the stability of the mineral since rinsing was accomplished at near neutral $\mathrm{pH}$. However, the stability of all three minerals at the low pHs used in sorption experiments is questionable. In all six experiments, major cation concentrations in the sorption solutions were measured after one month. The concentration of aqueous $\mathrm{Mn}^{2+}$ increased dramatically with decreasing $\mathrm{pH}$, regardless of which mineral was used (Figure 9). Modeling ${ }^{6}$ the solubility of pyrolusite (Figure 9a), birnessite (Figure 9b), and cryptomelane (Figure 9c) in contact with batch sorption solutions indicates that the increase in aqueous $\mathrm{Mn}^{2+}$ measured in the lower $\mathrm{pH}$ solutions could be, in part, the result of mineral dissolution. However, the stability of the Mn oxide minerals would be compromised significantly at low $\mathrm{pH}$ only if the redox state of solutions decreased from equilibrium with the atmosphere to a lower Eh (i.e an $\mathrm{O}_{2}(\mathrm{~g})$ fugacity of $\sim 10^{-5}$ bar.).

Although the mineral solubility models can qualitatively explain the aqueous $\mathrm{Mn}^{2+}$ concentration at $\mathrm{pH} 3$, they do not accurately follow the measured changes in $\mathrm{Mn}^{2+}$ concentrations as a function of $\mathrm{pH}$. For instance, there is a small amount of $\mathrm{Mn}^{2+}$ present at the highest $\mathrm{pH}$ that is not predicted by our model. Furthermore, aqueous $\mathrm{Mn}^{2+}$ increases steadily with decreasing solution $\mathrm{pH}$ starting at approximately $\mathrm{pH} 7.5$ for all three minerals. The mineral solubility model suggests that aqueous $\mathrm{Mn}^{2+}$ should increase exponentially with decreasing $\mathrm{pH}$ at a much lower $\mathrm{pH}(\mathrm{pH} 3.2-5.5$, depending on which mineral and which oxygen fugacity are assumed).

\footnotetext{
${ }^{6}$ Modeling of the pyrolusite and birnessite dissolution at various oxygen fugacities was accomplished using the REACT program in the Geochemist's Workbench software suite (Bethke, 2002) in conjunction with the GEMBOCHS Datacom.V8.R6 thermodynamic database (Johnson and Lundeen, 1997). Modeling the cryptomelane dissolution was accomplished using the mineral solubility equation provided by Parc et al. (1989).
} 


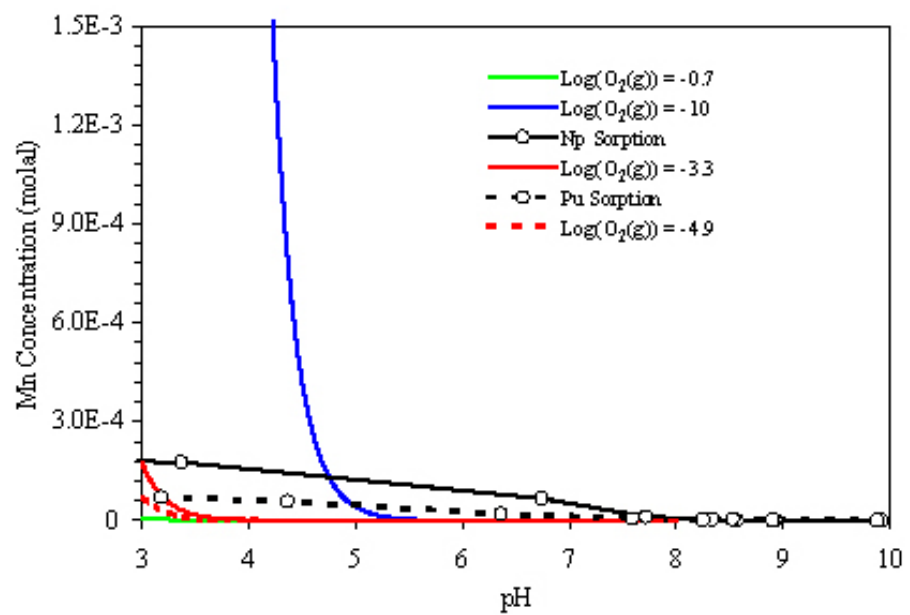

(a)

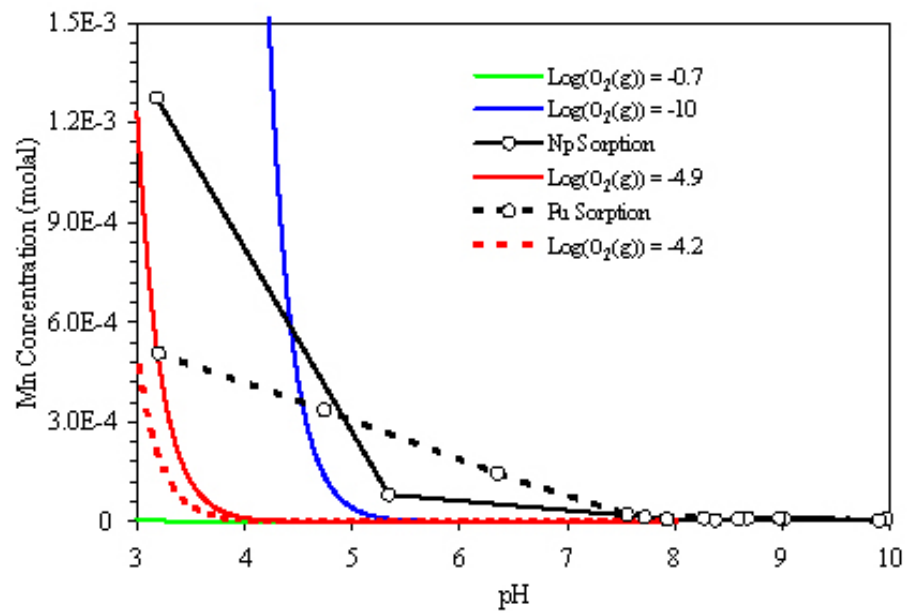

(b)

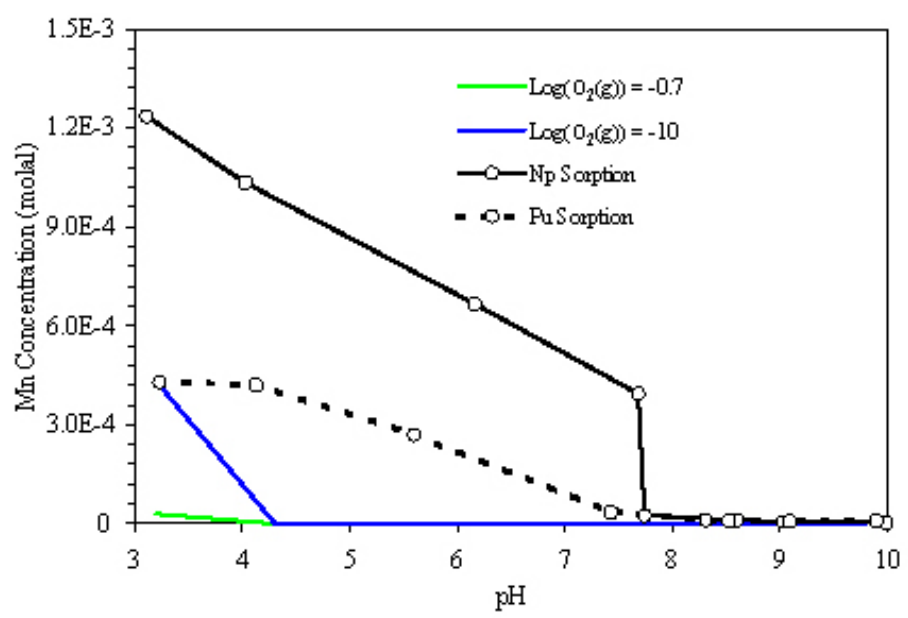

(c)

Figure 9. $\mathrm{Mn}^{2+}$ concentrations in $\mathrm{Np}(-\circ)$ and $\mathrm{Pu}\left(\cdot--_{-}\right)$sorption experiments with (a) pyrolusite, (b) birnessite, and (c) cryptomelane, predicted $\mathrm{Mn}^{2+}$ concentrations at $\log \left(\mathrm{O}_{2}(\mathrm{~g})\right)=-\mathbf{0 . 7}(-)$ and $\log \left(\mathrm{O}_{2}(\mathrm{~g})\right)=-10(-)$, and $\mathrm{O}_{2}(\mathrm{~g})$ fugacity consistent with measured $\mathrm{Mn}^{2+}$ concentrations at $\mathrm{pH} 3(\mathrm{~Np}(-)$ and $\mathrm{Pu}(---))$. 
A second source of $\mathrm{Mn}^{2+}$ in sorption solutions may be cation desorption from mineral surfaces: if $\mathrm{Mn}^{2+}$ remained sorbed to the surface after mineral synthesis, it could be released during sorption experiments. The effect is illustrated in Figure 10 which shows the predicted change in aqueous and sorbed $\mathrm{Mn}^{2+}$ as a function of $\mathrm{pH}$ based on the surface complexation model of Tonkin et al. (2004). The model suggests that a fraction of the $\mathrm{Mn}^{2+}$ observed at low $\mathrm{pH}$ may be the result of its desorption from surface sites.

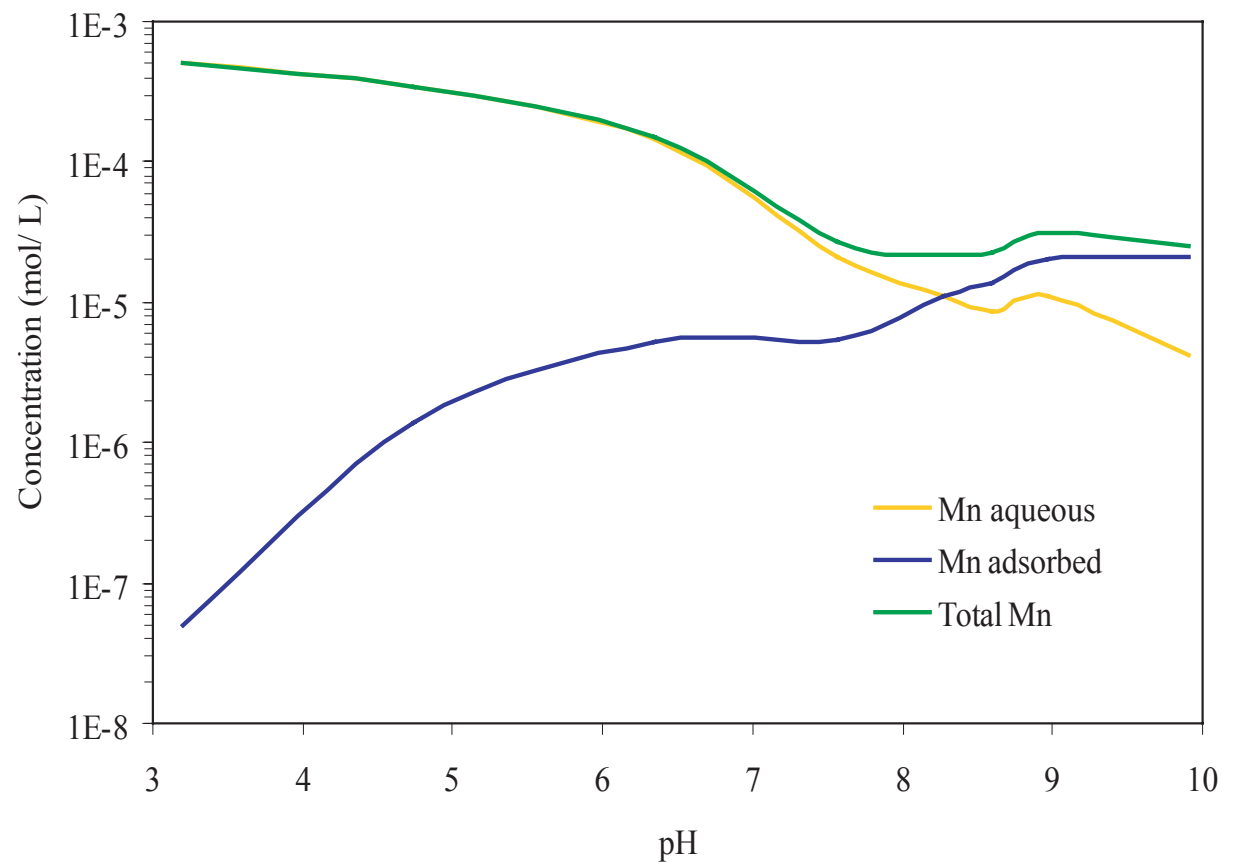

Figure 10. Predicted aqueous, total, and sorbed $\mathrm{Mn}^{2+}$ as a result of surface complexation using the Tonkin diffuse double layer model (Tonkin et al., 2004). 


\subsection{Np(V) Sorption and Desorption Experiments}

\subsubsection{Np Sorption Data}

The sorption of $\mathrm{Np}$ was examined using three different manganese oxide minerals for about four weeks. Data from these experiments are reported in Table A-1 of the Appendix. Figure 11 presents $\mathrm{Np}$ sorption onto three manganese oxides, as functions of $\mathrm{pH}$ and time. In general, the sorption of $\mathrm{Np}$ onto all three minerals increased from zero or a few percent at $\mathrm{pH} 3$ to $\sim 63 \%$ at around $\mathrm{pH} 8.2$, and then reached a plateau at higher $\mathrm{pH}$. The sorption behavior between $\mathrm{pH} \sim 3-8.2$ indicates that $\mathrm{pH}$ greatly affects $\mathrm{Np}$ sorption. Furthermore, the sorption of $\mathrm{Np}$ appears to correlated with the abundance of $\mathrm{NpO}_{2} \mathrm{OH}_{(\mathrm{aq})}$ in solution (Figure 5). The plateau in sorption at high $\mathrm{pH}$ may be the result of aqueous $\mathrm{Np}$-carbonate complexation which also results in a decrease in the abundance of $\mathrm{NpO}_{2} \mathrm{OH}_{(\mathrm{aq})}$. Our data show that the rates of $\mathrm{Np}$ sorption are initially fast ( $<1$ day). However a small amount of $\mathrm{Np}$ continues to sorb over the 30 day sorption time period. This two-step sorption behavior is commonly observed in batch sorption experiments.

$\mathrm{Np}(\mathrm{V})$ sorbed only moderately (up to $\sim 60 \%$ ) at $\mathrm{pH} 8$. Figure 12 compares sorption data obtained after one month for $\mathrm{Np}$ sorption onto the different minerals as a function of $\mathrm{pH}$. Interestingly, sorption of $\mathrm{Np}(\mathrm{V})$ to all three minerals is comparable when examined in terms of $\% \mathrm{~Np}$ sorbed. However, if sorption is evaluated on a surface area basis, sorption to the birnessite surface is much weaker than for cryptomelane and pyrolusite. The calculated $\mathrm{K}_{\mathrm{d}} \mathrm{s}$ from sorption experiments are plotted in Figure 13. The $\mathrm{K}_{\mathrm{d}}$ values range from $<100 \mathrm{~mL} \mathrm{~g}^{-1}$ at lower $\mathrm{pH}$ to $>1000 \mathrm{~mL} \mathrm{~g}^{-1}$ at higher $\mathrm{pH}$. The high-pH $\mathrm{K}_{\mathrm{d}} \mathrm{S}$ are in agreement with the values reported by Keeney-Kennicutt and Morse (1984) for synthetic $\mathrm{MnO}_{2}$ in deionized water and seawater $(16000$ and $4600 \mathrm{~mL} / \mathrm{g}$, respectively) when the order-of-magnitude difference in surface area is accounted for $\left(348 \mathrm{~m}^{2} / \mathrm{g}\right.$ versus 41.4 $\mathrm{m}^{2} / \mathrm{g}$ in our birnessite experiments). These values also agree with the $\mathrm{K}_{\mathrm{d}}$ reported in Kersting and Reimus (2003) (Figure 1). However, our data quantify the $\mathrm{pH}$-dependence and clearly show that $\mathrm{pH}$ will have a great effect on the sorption of $\mathrm{Np}$ to Mn oxides. 


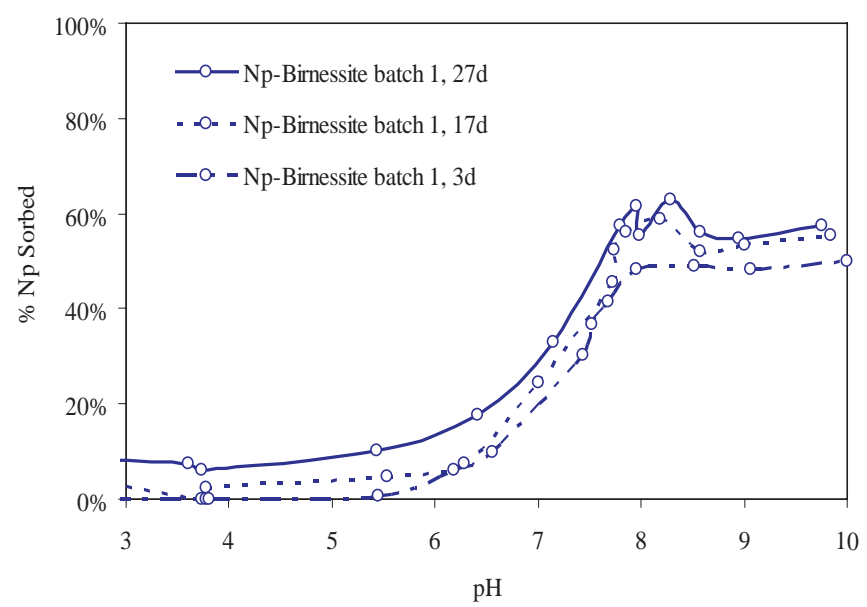

(a)

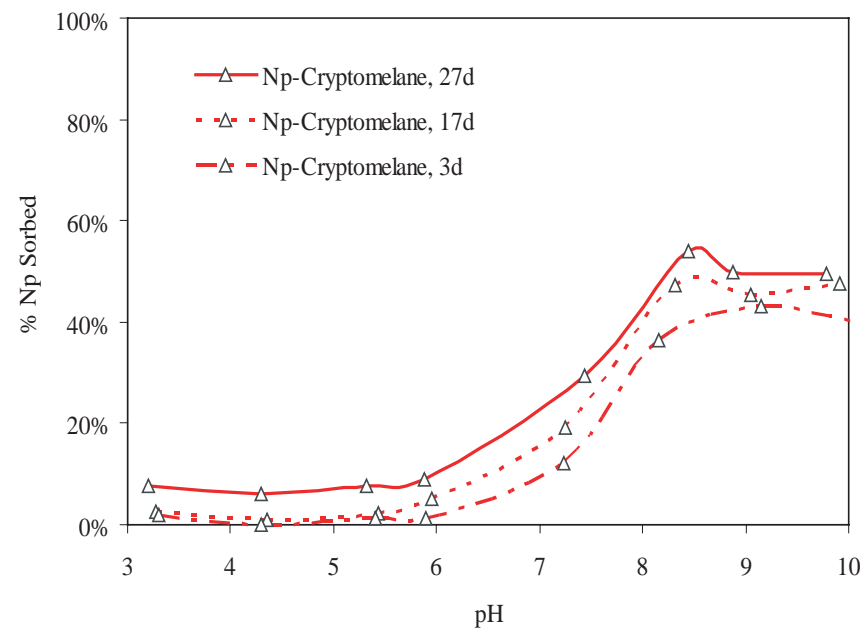

(b)

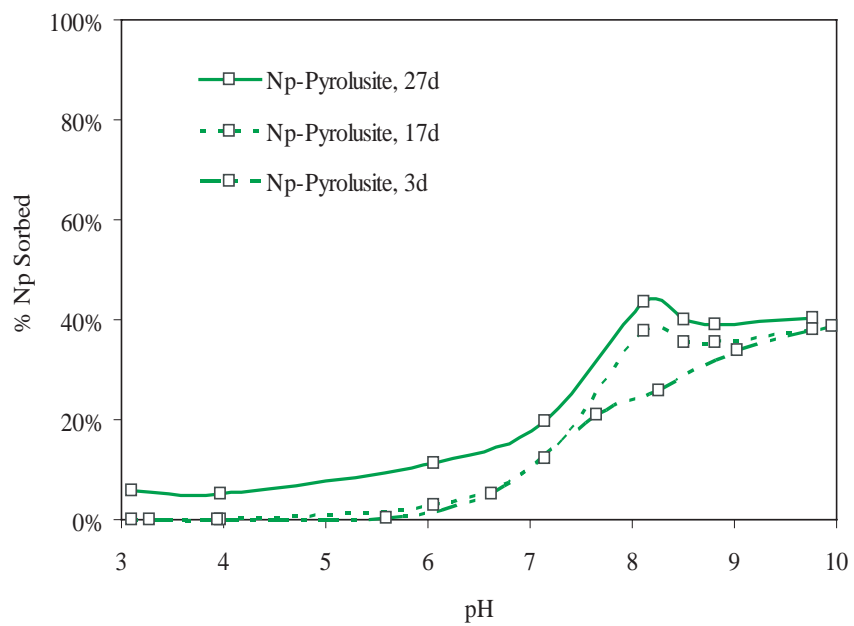

(c)

Figure 11. Np sorption to (a) birnessite, (b) cryptomelane, and (c) pyrolusite as functions of $\mathrm{pH}$ and time. 


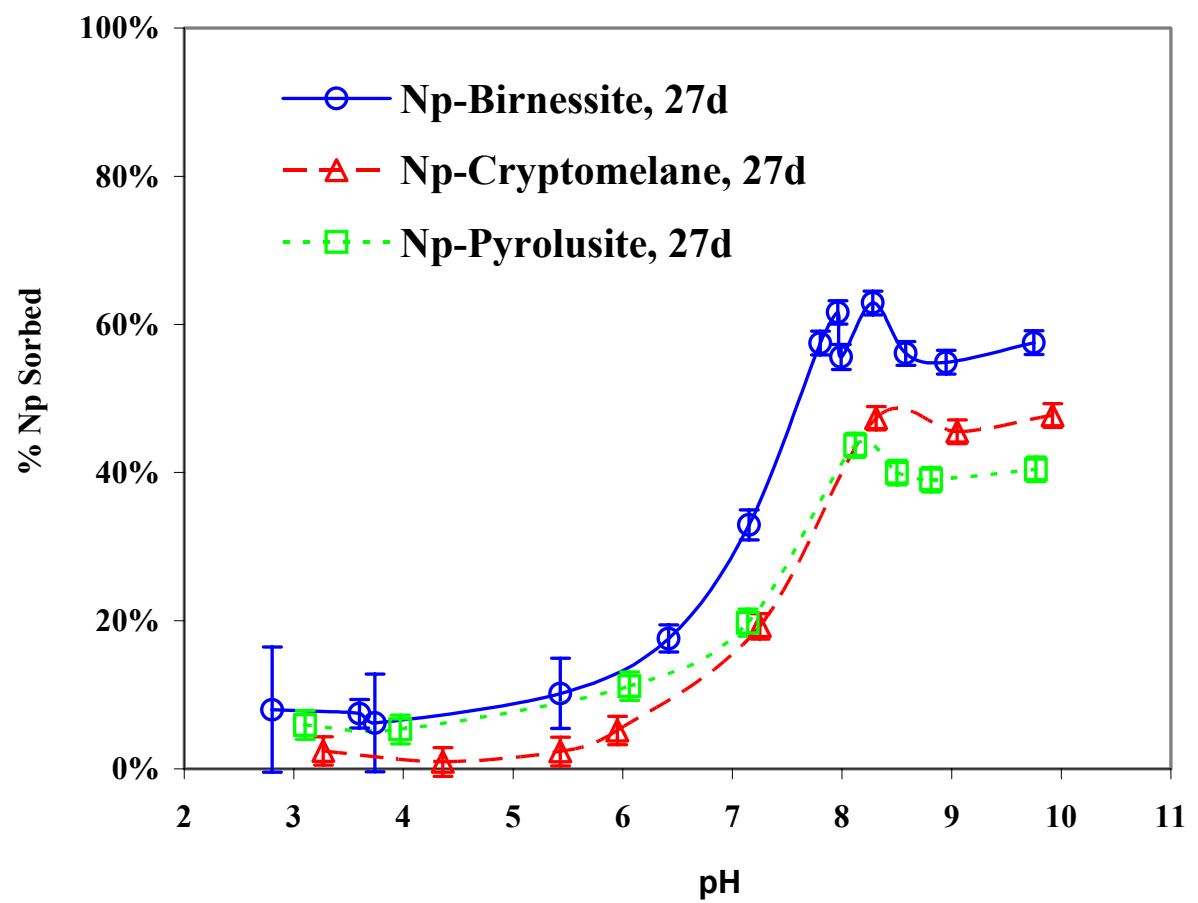

Figure 12. Comparison of Np sorption to three manganese oxides.

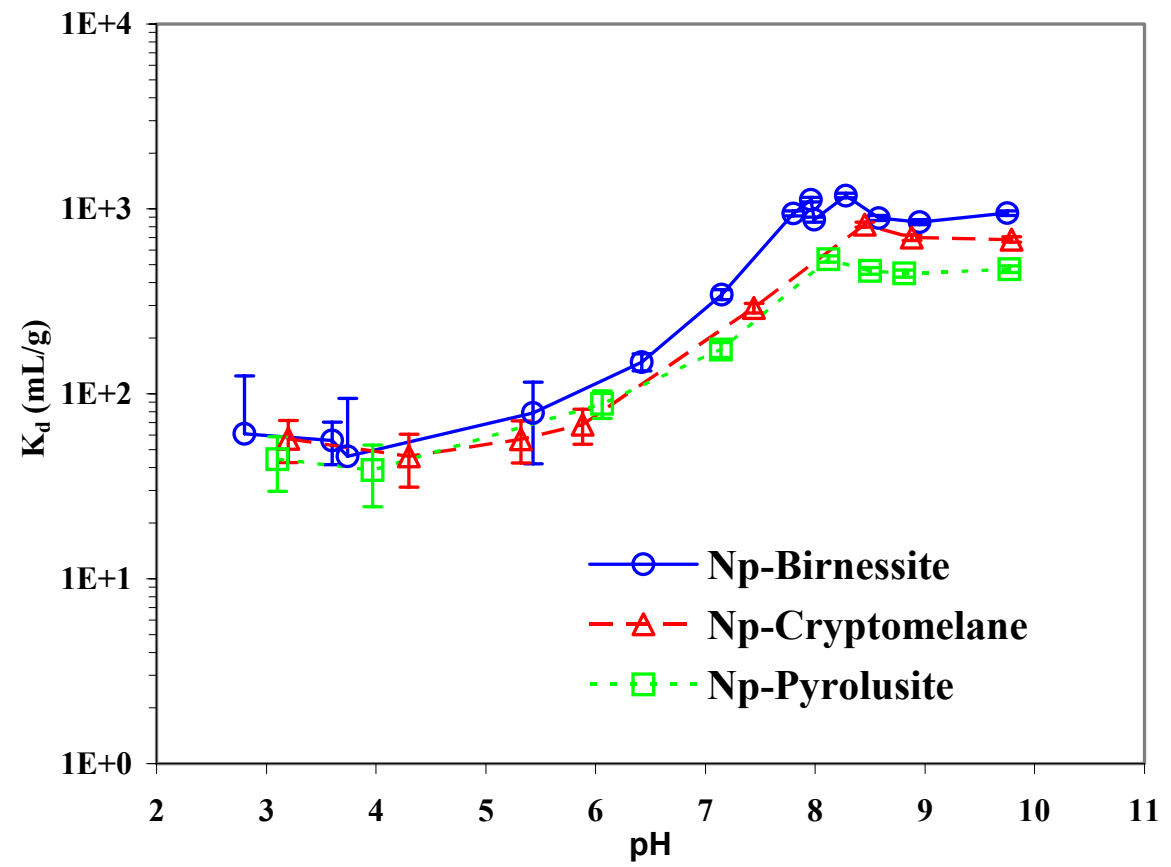

Figure 13. $\mathrm{Np} \mathrm{K}_{\mathrm{d}}$ versus $\mathrm{pH}$ at the end of the 30 day sorption experiment. 


\subsubsection{Np Desorption Data}

In order to investigate the reversibility of $\mathrm{Np}$ sorption onto manganese oxides, desorption experiments were initiated at the termination of the sorption experiments. See Table A-2 in the Appendix for a summary of the data. Sorption is considered reversible if the sorption curve obtained from the desorption experiment is the same or similar to the one obtained from the sorption experiment. Since $\mathrm{Np}(\mathrm{V})$ exhibited little to no sorption at $\mathrm{pH}$ $<6$, desorption over this $\mathrm{pH}$ range could not be measured. However, the desorption data above $\mathrm{pH} 7$ for all three minerals show similar trends as the sorption curves (Figure 14). This suggests that desorption of $\mathrm{Np}(\mathrm{V})$ from the three manganese oxides was fast and reversible.

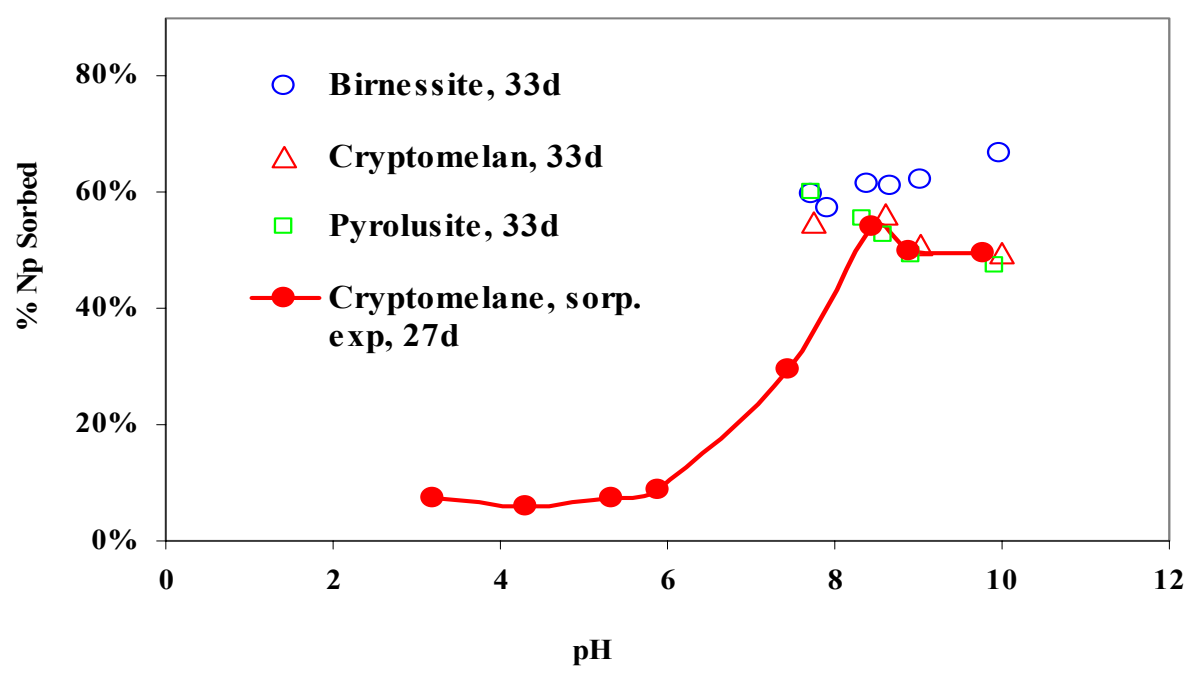

Figure 14. Comparison of Np sorption (cryptomelane, solid line) and desorption (birnessite $(\bigcirc)$, cryptomelane $(\triangle)$, and pyrolusite $(\square)$ ) data.

\subsubsection{Np Oxidation State Characterization}

The oxidation states of $\mathrm{Np}$ species in the desorption supernatant were examined by solvent extraction using chelating reagents PMBP and D2EHPA (Table 3). The results appear to indicate that in the presence of birnessite, $7 \%, 20 \%$ and $32 \%$ of $\mathrm{Np}$ at $\mathrm{pH} 4,7$ and 10 had been oxidized to $\mathrm{Np}(\mathrm{VI})$ in the desorption supernatant, respectively. This result is contrary to our general expectation that $\mathrm{Np}(\mathrm{V})$ will be the only stable aqueous species in solution under ambient conditions. The mechanism of oxidation remains unclear at this time, and further investigation would be necessary to confirm this result. There was no significant change in the oxidation state of $\mathrm{Np}$ in contact with cryptomelane and pyrolusite. 
Table 3. Np oxidation state in supernatant measured by solvent extraction.

\begin{tabular}{ccccc}
\hline & & \multicolumn{3}{c}{ Percentage of Np oxidation state } \\
& & $4+$ & $5+$ & $6+$ \\
\hline Birnessite & $\mathrm{pH} 4$ & $1 \%$ & $92 \%$ & $7 \%$ \\
& $\mathrm{pH} 7$ & & $80 \%$ & $20 \%$ \\
& $\mathrm{pH} 10$ & & $68 \%$ & $32 \%$ \\
Cryptomelane & $\mathrm{pH} 4$ & $3 \%$ & $96 \%$ & $1 \%$ \\
& $\mathrm{pH} 7$ & $1 \%$ & $97 \%$ & $2 \%$ \\
& $\mathrm{pH} 10$ & & $99 \%$ & $1 \%$ \\
Pyrolusite & $\mathrm{pH} 4$ & & $98 \%$ & $2 \%$ \\
& $\mathrm{pH} 10$ & & $99 \%$ & $1 \%$ \\
\hline
\end{tabular}

\subsubsection{Np Data Modeling}

The Np sorption data were modeled by applying the diffuse double layer model of Tonkin et al. (2004) to the 1-day sorption data for Np on birnessite. ${ }^{7}$ The sorption model accounted for changes in the major cation solution composition as a function of $\mathrm{pH}$ (data reported in Table A-3 of the Appendix) and sorption of these species to the birnessite surface along with $\mathrm{Np}$. The Tonkin model is based on a two-site model $(>\mathrm{XOH}$ and $>\mathrm{YOH}$ ) with $\alpha>\mathrm{XOH}$ sites and $1-\alpha>\mathrm{YOH}$ sites. Based on a number of acid-base titrations, Tonkin estimated $\alpha$ to be 0.64 . The reactive site density used in our model was based on the theoretical value of $2.8 \mu \mathrm{mol} / \mathrm{m}^{2}$. This is close to the total site density used by Dzombak and Morel (1990) for high surface area iron oxide $\left(3.8 \mu \mathrm{mol} / \mathrm{m}^{2}\right)$. Aqueous speciation reaction constants were taken from speciation data reported in Zavarin and Bruton (2004a; 2004b); surface complexation reaction constants for major cations were taken directly from Tonkin et al. (2004). These data are reported in Table 4.

Interestingly, $\mathrm{Ca}^{2+}, \mathrm{Mg}^{2+}$, and $\mathrm{Mn}^{2+}$ sorption occurs only on the $>\mathrm{XOH}$ site which has a very low $\mathrm{pKa}$ (very low acid dissociation constant). This is described by Tonkin et al. (2004) as the strong sorption site. It should also be noted that the Tonkin model does not include sorption of monovalent cations such as $\mathrm{Na}^{+}$and $\mathrm{K}^{+}$.

The one-site model of Appelo and Postma (1999) includes surface complexation of $\mathrm{Na}^{+}$ and $\mathrm{K}^{+}$as well as $\mathrm{Ca}^{2+}, \mathrm{Mg}^{2+}$ and $\mathrm{Mn}^{2+}$; under our experimental conditions, their model predicts, as does the Tonkin model, that $\mathrm{Mn}^{2+}$ will dominate on the surface. The Appelo and Postma model was used to fit our Np sorption data as well; like the Tonkin model, a two-species surface complexation model resulted in the best fit to the data, as will be described below. Major cation and acidity reaction constants for the Appelo and Postma model are reported in Table 4.

\footnotetext{
${ }^{7}$ Surface complexation to cryptomelane and pyrolusite was not attempted because a model was not available in the literature.
} 
Table 4. Reaction constants used in FITEQL surface complexation model.

\begin{tabular}{|c|c|}
\hline Reaction* & $\log K$ \\
\hline \multicolumn{2}{|l|}{ Dominant Aqueous Species } \\
\hline $\mathrm{H}^{+}+\mathrm{OH}^{-}=\mathrm{H}_{2} \mathrm{O}$ & 14.0 \\
\hline $\mathrm{NpO}_{2}^{+}+\mathrm{H} 2 \mathrm{O}=\mathrm{NpO}_{2} \mathrm{OH}+\mathrm{H}^{+}$ & -8.90 \\
\hline $\mathrm{NpO}_{2}^{+}+\mathrm{HCO}_{3}^{-}=\mathrm{NpO}_{2} \mathrm{CO}_{3}^{-}+\mathrm{H}^{+}$ & -5.73 \\
\hline $\mathrm{NpO}_{2}^{+}+2 \mathrm{HCO}_{3}^{-}=\mathrm{NpO}_{2}\left(\mathrm{CO}_{3}\right)^{3-}+2 \mathrm{H}^{+}$ & -13.66 \\
\hline $\mathrm{NpO}_{2}{ }^{+}+3 \mathrm{HCO}_{3}{ }^{-}=\mathrm{NpO}_{2}\left(\mathrm{CO}_{3}\right)_{3}{ }^{5-}+3 \mathrm{H}^{+}$ & -22.49 \\
\hline $\mathrm{HCO}_{3}^{-}+\mathrm{H}^{+}=\mathrm{H}_{2} \mathrm{CO}_{3}(\mathrm{aq})$ & 6.34 \\
\hline $\mathrm{HCO}_{3}^{-}=\mathrm{CO}_{3}^{2}-+\mathrm{H}^{+}$ & -10.33 \\
\hline \multicolumn{2}{|l|}{ Tonkin Model Surface Reactions } \\
\hline$>\mathrm{XOH}=>\mathrm{XO}^{-}+\mathrm{H}^{+}$ & -2.35 \\
\hline$>\mathrm{YOH}=>\mathrm{YO}^{-}+\mathrm{H}^{+}$ & -6.06 \\
\hline$>\mathrm{XOH}+\mathrm{Ca}^{2+}=>\mathrm{XOCa}^{+}+\mathrm{H}^{+}$ & -1.50 \\
\hline$>\mathrm{XOH}+\mathrm{Mg}^{2+}=>\mathrm{XOMg}^{+}+\mathrm{H}^{+}$ & -2.40 \\
\hline$>\mathrm{XOH}+\mathrm{Mg}^{2+}+\mathrm{H} 2 \mathrm{O}=>\mathrm{XOMgOH}+2 \mathrm{H}^{+}$ & -7.70 \\
\hline$>\mathrm{XOH}+\mathrm{Mn}^{2+}=>\mathrm{XOMn}^{+}+\mathrm{H}^{+}$ & 1.20 \\
\hline$>\mathrm{XOH}+\mathrm{Mn}^{2+}+\mathrm{H} 2 \mathrm{O}=>\mathrm{XOMnOH}+2 \mathrm{H}^{+}$ & -2.70 \\
\hline \multicolumn{2}{|l|}{ Appelo and Postma Model Surface Reactions } \\
\hline$>\mathrm{SO}_{3} \mathrm{H}_{2}+\mathrm{H}^{+}=>\mathrm{SO}_{3} \mathrm{H}_{3}^{+}$ & 1.84 \\
\hline$>\mathrm{SO}_{3} \mathrm{H}_{2}=>\mathrm{SO}_{3} \mathrm{H}^{-}+\mathrm{H}^{+}$ & -2.41 \\
\hline$>\mathrm{SO}_{3} \mathrm{H}_{2}=>\mathrm{SO}_{3}^{2-}+2 \mathrm{H}^{+}$ & -7.95 \\
\hline$>\mathrm{SO}_{3} \mathrm{H}_{2}+\mathrm{H}^{+}+\mathrm{Cl}^{-}=>\mathrm{SO}_{3} \mathrm{H}_{3} \mathrm{Cl}$ & 3.28 \\
\hline$>\mathrm{SO}_{3} \mathrm{H}_{2}+\mathrm{Na}^{+}=>\mathrm{SO}_{3} \mathrm{HNa}+\mathrm{H}^{+}$ & -1.41 \\
\hline$>\mathrm{SO}_{3} \mathrm{H}_{2}+\mathrm{Na}^{+}=>\mathrm{SO}_{3} \mathrm{Na}^{-}+2 \mathrm{H}^{+}$ & -5.92 \\
\hline$>\mathrm{SO}_{3} \mathrm{H}_{2}+\mathrm{K}^{+}=>\mathrm{SO}_{3} \mathrm{HK}+\mathrm{H}^{+}$ & -0.71 \\
\hline$>\mathrm{SO}_{3} \mathrm{H}_{2}+\mathrm{K}^{+}=>\mathrm{SO}_{3} \mathrm{~K}^{-}+2 \mathrm{H}^{+}$ & -5.22 \\
\hline$>\mathrm{SO}_{3} \mathrm{H}_{2}+\mathrm{Ca}^{2+}=>\mathrm{SO}_{3} \mathrm{HCa}^{+}+\mathrm{H}^{+}$ & -0.01 \\
\hline$>\mathrm{SO}_{3} \mathrm{H}_{2}+\mathrm{Ca}^{2+}=>\mathrm{SO}_{3} \mathrm{Ca}+2 \mathrm{H}^{+}$ & -5.09 \\
\hline$>\mathrm{SO}_{3} \mathrm{H}_{2}+\mathrm{Mg}^{2+}=>\mathrm{SO}_{3} \mathrm{HMg}^{+}+\mathrm{H}^{+}$ & -0.6 \\
\hline$>\mathrm{SO}_{3} \mathrm{H}_{2}+\mathrm{Mg}^{2+}=>\mathrm{SO}_{3} \mathrm{Mg}+2 \mathrm{H}^{+}$ & -5.51 \\
\hline$>\mathrm{SO}_{3} \mathrm{H}_{2}+\mathrm{Mn}^{2+}=>\mathrm{SO}_{3} \mathrm{HMn}^{+}+\mathrm{H}^{+}$ & 3.17 \\
\hline$>\mathrm{SO}_{3} \mathrm{H}_{2}+\mathrm{Mn}^{2+}=>\mathrm{SO}_{3} \mathrm{Mn}+2 \mathrm{H}^{+}$ & -1.97 \\
\hline
\end{tabular}

* Birnessite reactive site density is $2.8 \mathrm{E}-6 \mathrm{~mol} / \mathrm{m}^{2}$. Fraction of $>\mathrm{XOH}$ sites is 0.64 for the Tonkin model. 
The surface complexation modeling results based on the Tonkin model are shown in Figure 15 and summarized in Table 5. Figure 15a presents data fits using a single $\mathrm{Np}$ surface species. While no single species fits the sorption data well, the results suggest that $\mathrm{Np}$ sorption is best modeled as surface complexation to the $>\mathrm{YOH}$ surface site. The $\mathrm{Np}$ sorption edge ( $\mathrm{pH} 6$ to 8 ) correlates with the $\mathrm{pKa}$ of the $>\mathrm{YOH}$ site; Np sorption increases as the surface $>\mathrm{YOH}$ site deprotonates. The poor fits using a single-species suggest that at least two surface species are necessary to adequately fit our data.

Figure $15 \mathrm{~b}$ presents data fits using two Np surface species. Surface complexation models using two aqueous $\mathrm{Np}$ species provide a much better, particularly at the sorption plateau in the alkaline range. Note from Table 5 that the two species models have much lower WSOS/ DF values, indicating that the two species models statistically are a better fit to the data. The best fit using the Tonkin model was achieved with a Np oxide and hydroxide surface species.

The experience with modeling $\mathrm{Np}$ sorption using the Appelo and Postma model was similar (Figure 16). With this approach, a single surface species was unable to fit all the data while a two-species model fit the data quite well. As in the Tonkin model, the best fit was achieved with a $\mathrm{Np}$ oxide and hydroxide species. Best-fit reaction constants using two species are reported in Table 5.

All of the models described above more accurately fit the data below $\mathrm{pH} 8$ than above $\mathrm{pH}$ 8. Several factors could account for the lack of model fit. The disparity could be related to uncertainty in the aqueous Np-carbonate complexation that occurs at these higher $\mathrm{pHs}$. Uncertainty in other model parameters and the sorption data itself could be affecting the model fits as well. We chose to minimize the number of fitting parameters by only varying Np surface complexation constants. The surface complexation model includes both protonation and deprotonation reaction constants and surface complexation constants for the major cations in solution. If all protonation, deprotonation, and surface complexation reaction constants were allowed to vary, our model could certainly fit the data more precisely. However, it would result in a fitting exercise that could no longer be related directly to the surface complexation models of Appelo and Postma (1999) and Tonkin et al. (2004). 

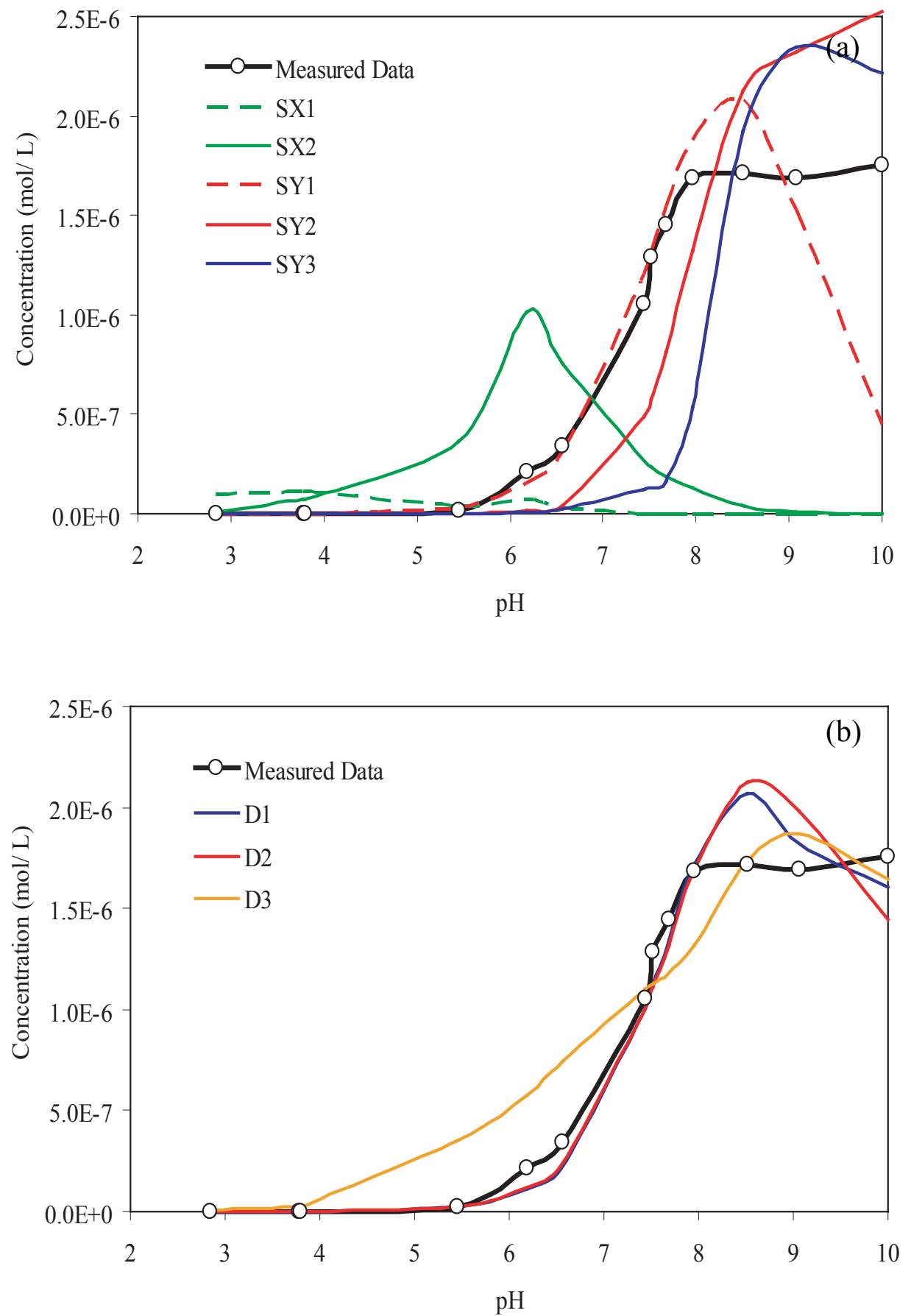

Figure 15. Model fits to Np sorption data based on the diffuse double layer model of Tonkin et al. (2004). (a) single surface species, (b) two surface species. Data and model fits reported as mol $\mathrm{L}^{-1}$ sorbed. Model names are explained in Table 5 . 


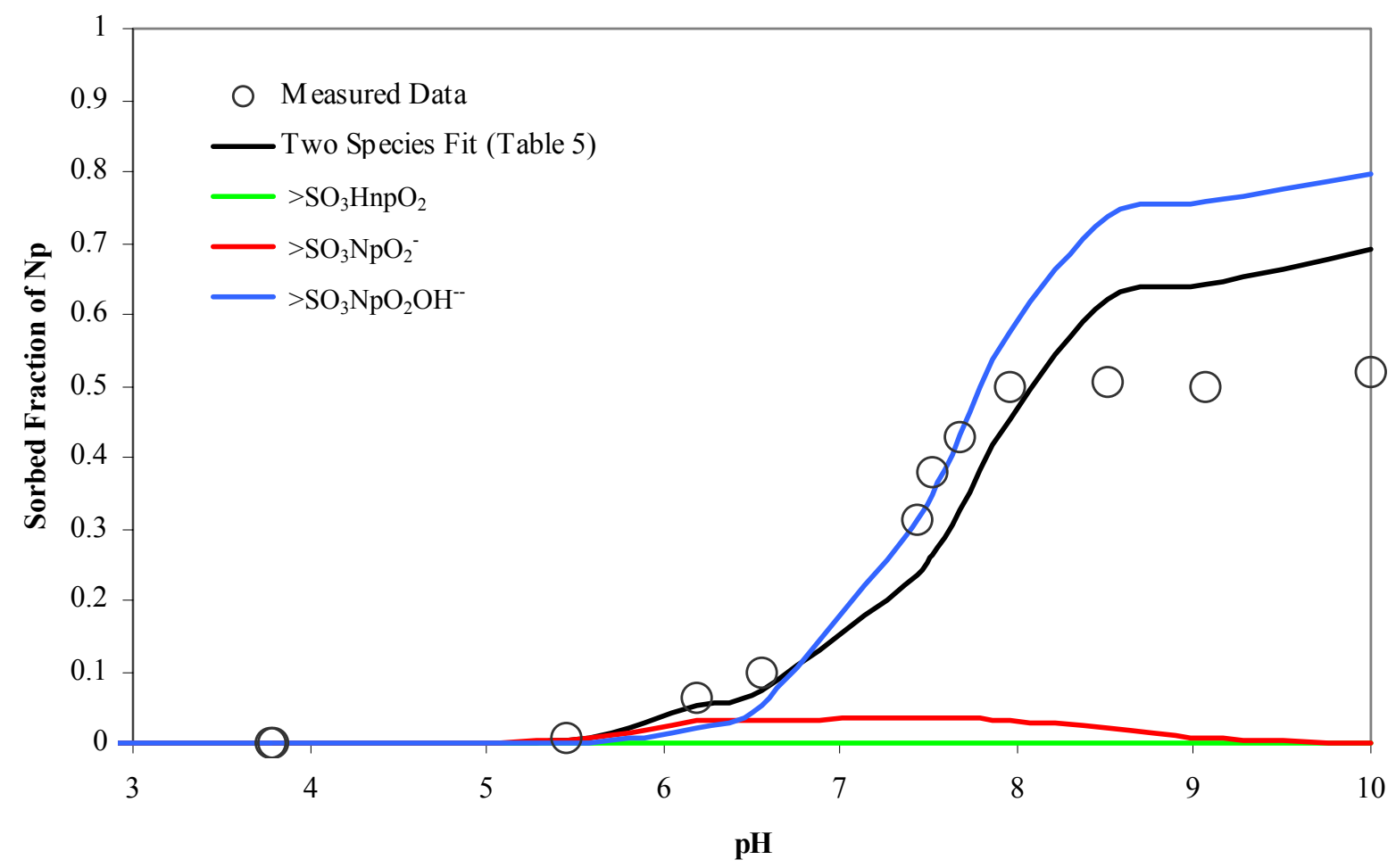

Figure 16. Model fits to Np sorption data based on the diffuse double layer model of Appelo and Postma (1999) using single surface species (green, red, blue) and two surface species (black). 
Table 5. Np surface complexation reaction constants.

\begin{tabular}{|c|c|c|c|c|}
\hline & Model Name & Reaction & $\log \mathrm{K}$ & WSOS/ DF ${ }^{1}$ \\
\hline & & Tonkin Model Results & & \\
\hline \multirow{5}{*}{$\begin{array}{l}\mathscr{0} \\
\frac{0}{0} \\
\text { के } \\
\frac{0}{00} \\
\stackrel{0}{0}\end{array}$} & SX1 & $>\mathrm{XOH}+\mathrm{NpO}_{2}^{+}=>\mathrm{XONpO}_{2}+\mathrm{H}^{+}$ & 0.71 & 1.35 \\
\hline & SX2 & $>\mathrm{XOH}+\mathrm{NpO}_{2}^{+}+\mathrm{H}_{2} \mathrm{O}=>\mathrm{XONpO}_{2} \mathrm{OH}^{-}+2 \mathrm{H}^{+}$ & -3.36 & 1.25 \\
\hline & SY1 & $>\mathrm{YOH}+\mathrm{NpO}_{2}^{+}=>\mathrm{YONpO}_{2}+\mathrm{H}^{+}$ & -3.21 & 0.16 \\
\hline & SY2 & $>\mathrm{YOH}+\mathrm{NpO}_{2}^{+}+\mathrm{H}_{2} \mathrm{O}=>\mathrm{YONpO}_{2} \mathrm{OH}^{-}+2 \mathrm{H}^{+}$ & -9.66 & 0.22 \\
\hline & SY3 & $\mathrm{YOH}+\mathrm{NpO}_{2}{ }^{+}+\mathrm{HCO}_{3}{ }^{-}=>\mathrm{YONpO}_{2} \mathrm{CO}_{3}{ }^{2-}+2 \mathrm{H}^{+}$ & -4.57 & 0.49 \\
\hline \multirow{6}{*}{ 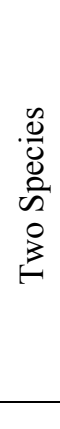 } & \multirow{2}{*}{ D1 } & $P \mathrm{YOH}+\mathrm{NpO}_{2}^{+}=>\mathrm{YONpO}_{2}+\mathrm{H}^{+}$ & -3.38 & \multirow{2}{*}{0.02} \\
\hline & & $>\mathrm{YOH}+\mathrm{NpO}_{2}^{+}+\mathrm{H}_{2} \mathrm{O}=>\mathrm{YONpO}_{2} \mathrm{OH}^{-}+2 \mathrm{H}^{+}$ & -10.23 & \\
\hline & \multirow{2}{*}{ D2 } & $>\mathrm{YOH}+\mathrm{NpO}_{2}^{+}=>\mathrm{YONpO}_{2}+\mathrm{H}^{+}$ & -3.34 & \multirow{2}{*}{0.04} \\
\hline & & $P \mathrm{YOH}+\mathrm{NpO}_{2}^{+}+\mathrm{HCO}_{3}^{-}=>\mathrm{YONpO}_{2} \mathrm{CO}_{3}^{2-}+2 \mathrm{H}^{+}$ & -5.07 & \\
\hline & \multirow{2}{*}{ D3 } & $>\mathrm{YOH}+\mathrm{NpO}_{2}^{+}+\mathrm{H}_{2} \mathrm{O}=>\mathrm{YONpO}_{2} \mathrm{OH}^{-}+2 \mathrm{H}^{+}$ & -1.77 & \multirow{2}{*}{0.06} \\
\hline & & $P \mathrm{YOH}+\mathrm{NpO}_{2}{ }^{+}+\mathrm{HCO}_{3}{ }^{-}=>\mathrm{YONpO}_{2} \mathrm{CO}_{3}{ }^{2-}+2 \mathrm{H}^{+}$ & -4.90 & \\
\hline & & Appelo and Postma Model Results & & \\
\hline & & $>\mathrm{SO}_{3} \mathrm{H}_{2}+\mathrm{NpO}_{2}^{+}=>\mathrm{SO}_{3} \mathrm{NpO}_{2}^{-}+2 \mathrm{H}^{+}$ & -4.55 & \multirow{2}{*}{$62^{2}$} \\
\hline & & $>\mathrm{SO}_{3} \mathrm{H}_{2}+\mathrm{NpO}_{2}^{+}+\mathrm{H}_{2} \mathrm{O}=>\mathrm{SO}_{3} \mathrm{NpO}_{2} \mathrm{OH}^{2-}+3 \mathrm{H}^{+}$ & -11.34 & \\
\hline
\end{tabular}

${ }^{1} \mathrm{WSOS} / \mathrm{DF}$ is the ratio of the Weighted Sum of the Squares and the loss of Degrees of Freedom. It is a measure of the goodness of fit between the model and the measured data, and can be used to compare the fits of two different models.

${ }^{2}$ Data fit achieved using a slightly different version of the FITEQL code which calculates WSOS/DF differently.

\subsection{Pu Sorption and Desorption Experiments}

\subsubsection{Pu Sorption Data}

Batch $\mathrm{Pu}(\mathrm{IV})$ sorption onto three different manganese oxides was measured over approximately one month. The data from these experiments are reported in Table A-4 of the Appendix. Figure 17 presents $\mathrm{Pu}(\mathrm{IV})$ sorption onto the manganese oxides as functions of $\mathrm{pH}$ and time. In general, $\mathrm{Pu}(\mathrm{IV})$ sorbed very little at $\mathrm{pH} 3$ but increased to $\sim 100 \%$ as the $\mathrm{pH}$ increased to 4.5 (pyrolusite) or 6 (birnessite and cryptomelane). Sorption remained high up to $\mathrm{pH} 8$, but beyond $\mathrm{pH} 8$ it decreased slightly for birnessite, significantly for pyrolusite, and negligibly for cryptomelane. As expected, $\mathrm{pH}$ played an important role in $\mathrm{Pu}(\mathrm{IV})$ sorption. Given the elevated carbonate concentrations at high $\mathrm{pH}$ (see Table A-6 in the Appendix), $\mathrm{Pu}$ (IV) was expected to form soluble carbonate complex species resulting in a decrease in Pu sorption. This was observed for both birnessite and pyrolusite (Figure 18). In the case of cryptomelane, Pu sorption may have 


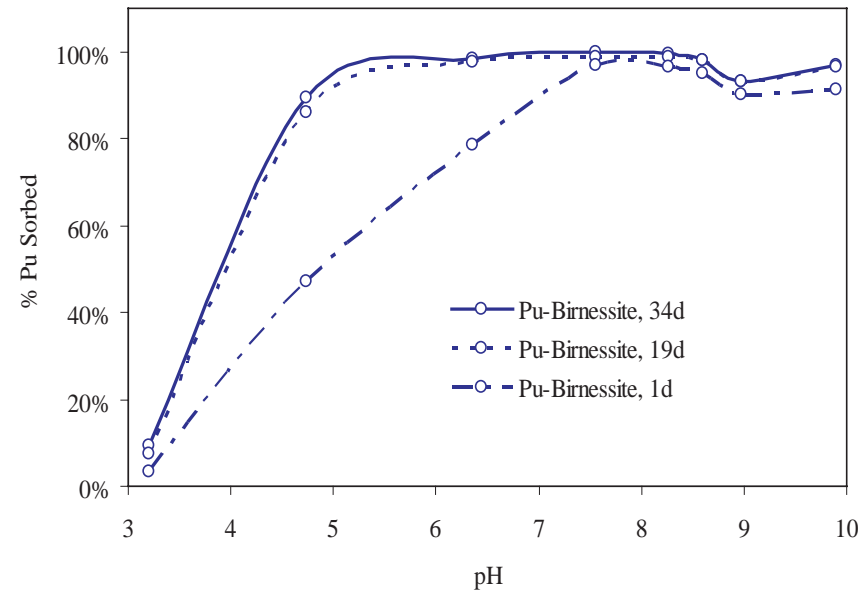

(a)

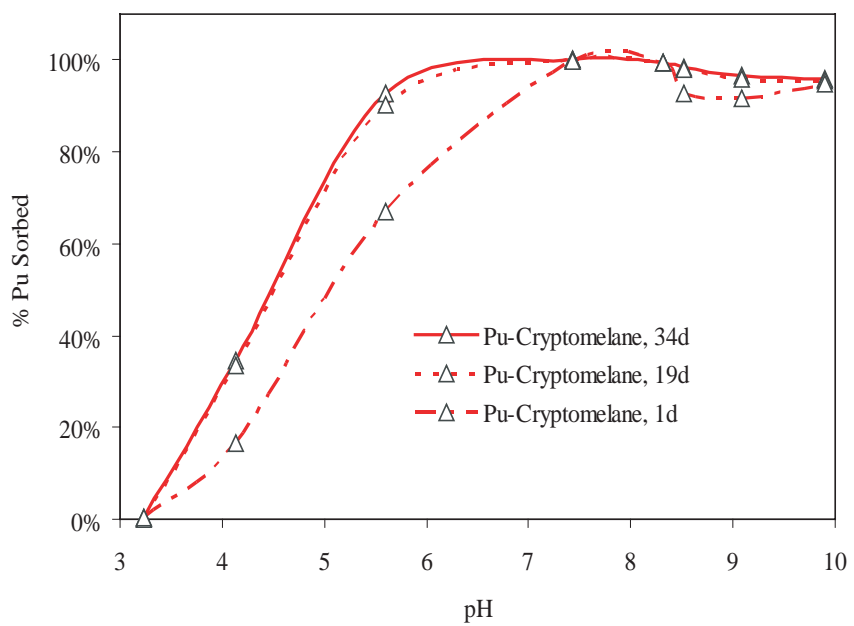

(b)

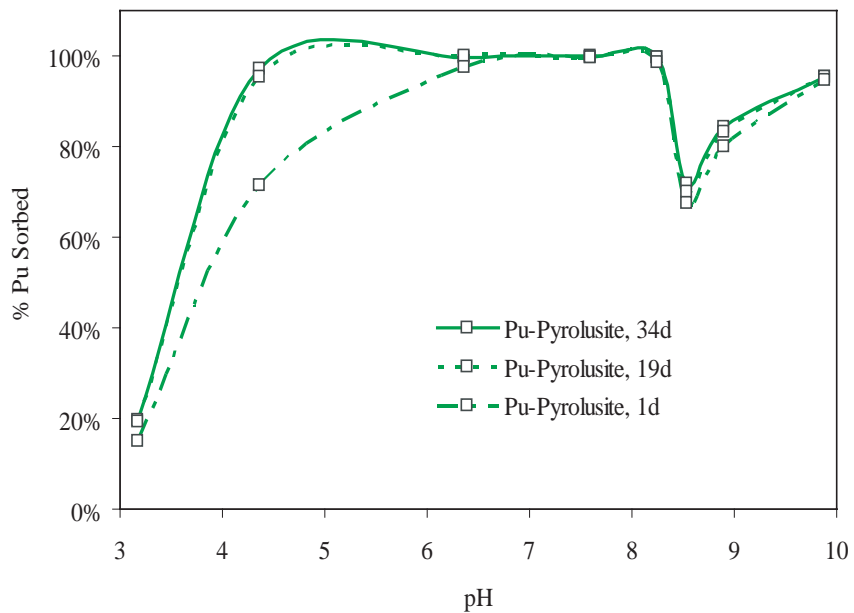

(c)

Figure 17. Pu sorption to (a) birnessite, (b) cryptomelane, and (c) pyrolusite as functions of $\mathrm{pH}$ and time. 
been strong enough to overcome any carbonate complexation effects. Data in Figure 17 also suggest that the rate of Pu sorption is significantly slower at low $\mathrm{pH}$. As will be described in the following section, these differences in sorption rates may result from significant oxidation state changes that occurred for $\mathrm{Pu}(\mathrm{IV})$ in the presence of $\mathrm{Mn}$ oxides.

When comparing the sorption behavior on the three minerals (Figure 19) as a function of $\mathrm{pH}$, we find that all three minerals behave similarly. However, Pu sorbs to pyrolusite more strongly at low $\mathrm{pH}$ and more weakly at high $\mathrm{pH}$ than to the other two minerals. The behavior does not correlate with mineral surface area, as pyrolusite has a much lower surface area than the other two minerals. Nevertheless, regardless of the mineral type, $\mathrm{Pu}(\mathrm{IV})$ sorbs very strongly.

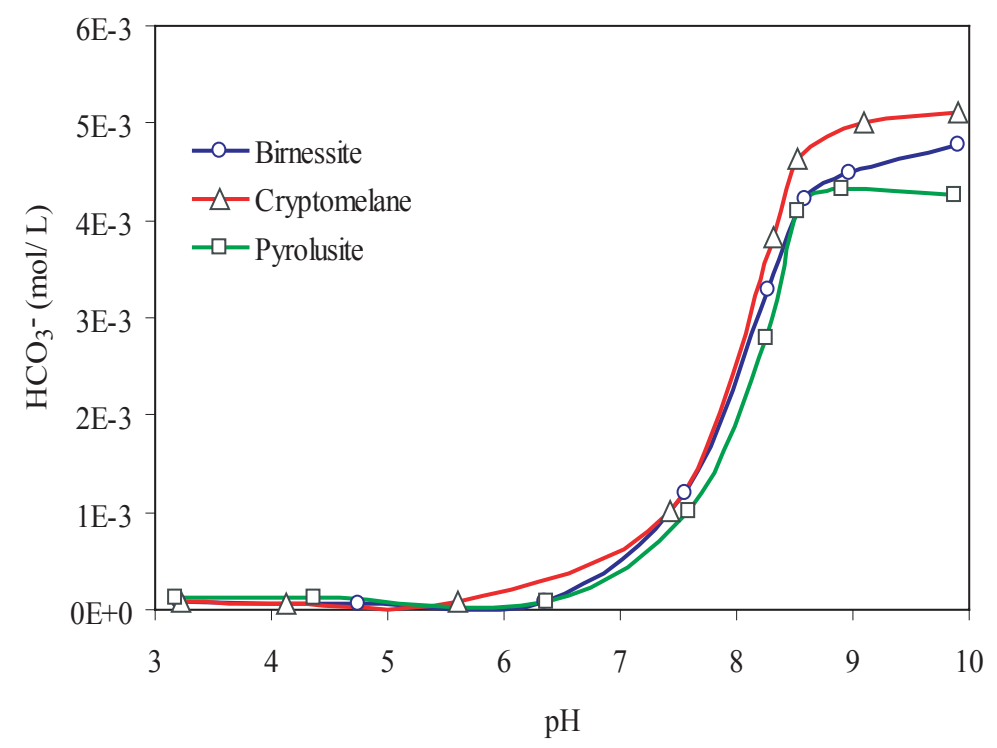

Figure 18. Bicarbonate concentrations as a function of $\mathrm{pH}$ for Pu sorption solutions.

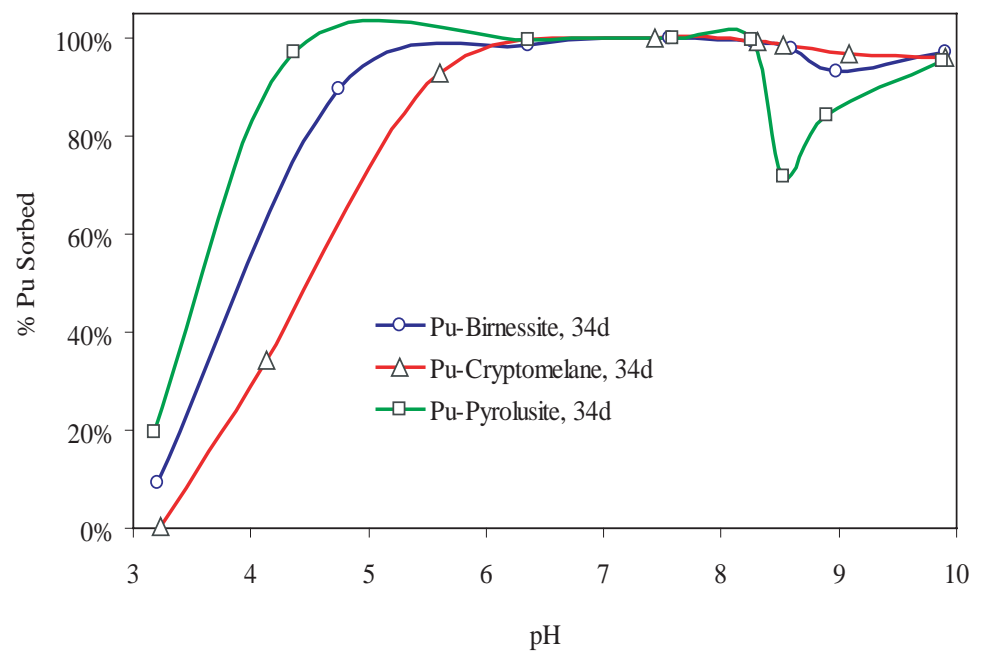

Figure 19. Comparison of Pu sorption to three manganese oxides at 34 days. 


\subsubsection{Pu Desorption Data}

For the desorption experiment, supernatant samples were taken after 1 day, 16 days, and 22 days. The data are reported in Table A-5 of the Appendix. The amount of sorbed $\mathrm{Pu}(\mathrm{IV})$ as a function of $\mathrm{pH}$ and time during the desorption experiments is plotted in Figure 20. For each of the minerals examined, only minor differences in supernatant $\mathrm{Pu}$ concentration were measured as a function of time, indicating that desorption is very fast for all three minerals, typically reaching equilibrium in less than a day. Furthermore, the good agreement between the sorption and desorption curves (Figure 21), within experimental error, suggests that the sorption process is reversible.

The $K_{d}$ values for the minerals investigated were calculated using data from the last sorption (a) and desorption (b) samples (see Figure $21 \mathrm{a}$ and $21 \mathrm{~b}$, respectively). The $\mathrm{K}_{\mathrm{d}} \mathrm{S}$ cover a wide range from $10^{3} \mathrm{~mL} / \mathrm{g}$ at $\mathrm{pH} 3$ up to $10^{7} \mathrm{~mL} / \mathrm{g}$ at $\mathrm{pH} 7$. Interestingly, the decrease in $\mathrm{Pu}$ sorption above $\mathrm{pH} \mathrm{8}$, presumably resulting from carbonate complexation, is more evident in the $\mathrm{Kd}$ plots than in the \%sorbed plots (Figure 16). At neutral $\mathrm{pH}$, the $\mathrm{Pu} \mathrm{K} \mathrm{d}_{\mathrm{d}}$ is four orders of magnitude greater than the $\mathrm{Np} \mathrm{K}_{\mathrm{d}}$. The $\mathrm{K}_{\mathrm{d}} \mathrm{s}$ measured here are much higher than those reported by Keeney-Kennicutt and Morse (1985). Their sorption experiments were performed with $\mathrm{Pu}(\mathrm{V})$ and resulted in behavior similar to that observed for $\mathrm{Np}(\mathrm{V})$ (Keeney-Kennicutt and Morse, 1986). Our $\mathrm{K}_{\mathrm{d}} \mathrm{S}$ are much higher, reflecting the different $\mathrm{Pu}$ oxidation state used in our experiments and the fact that $\mathrm{Pu}(\mathrm{IV})$ will sorb much more effectively than $\mathrm{Pu}(\mathrm{V})$. Dyer et al. (2000a) observed a qualitatively similar $\mathrm{pH}$ dependence as seen here, though a direct comparison is difficult due to differences in experimental conditions. Our results clearly show that $\mathrm{Pu}$ sorption to manganese oxides will be an important process controlling its migration and that sorption will be dependent on the $\mathrm{pH}$ and carbonate alkalinity of solutions. 


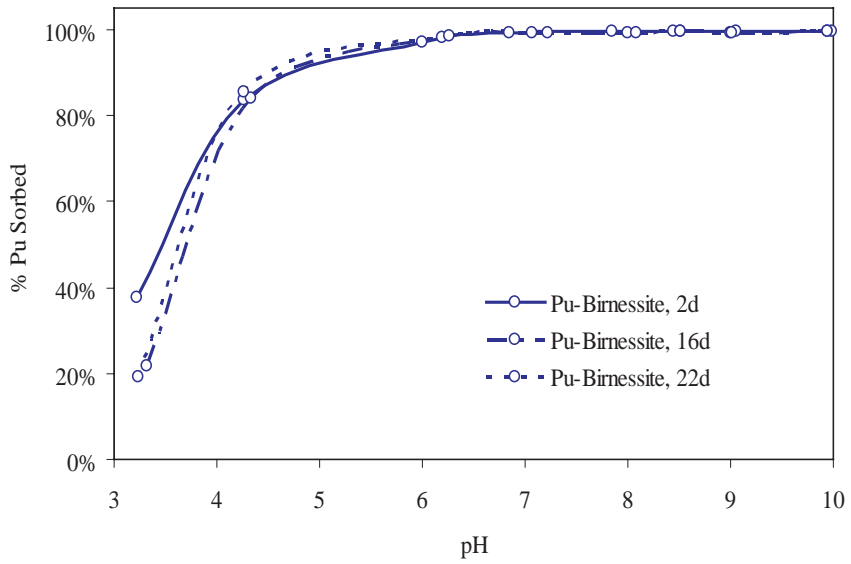

(a)

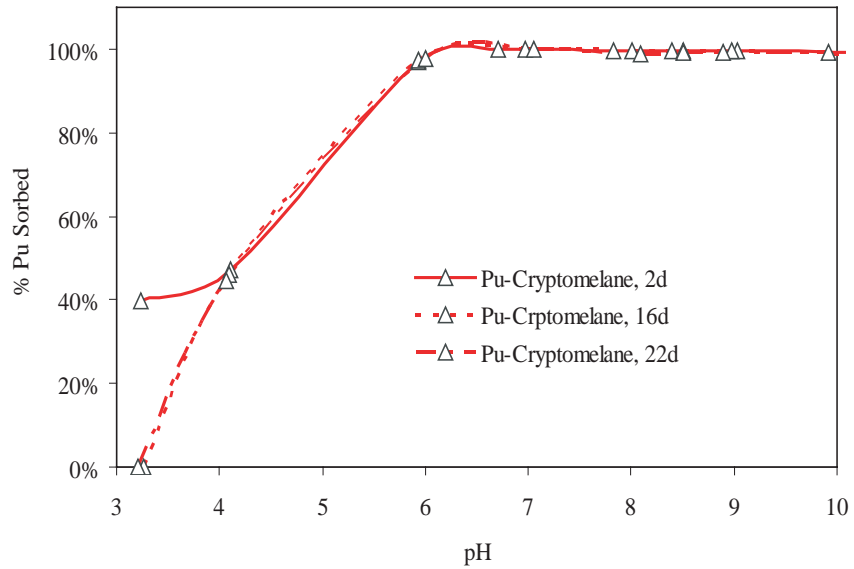

(b)

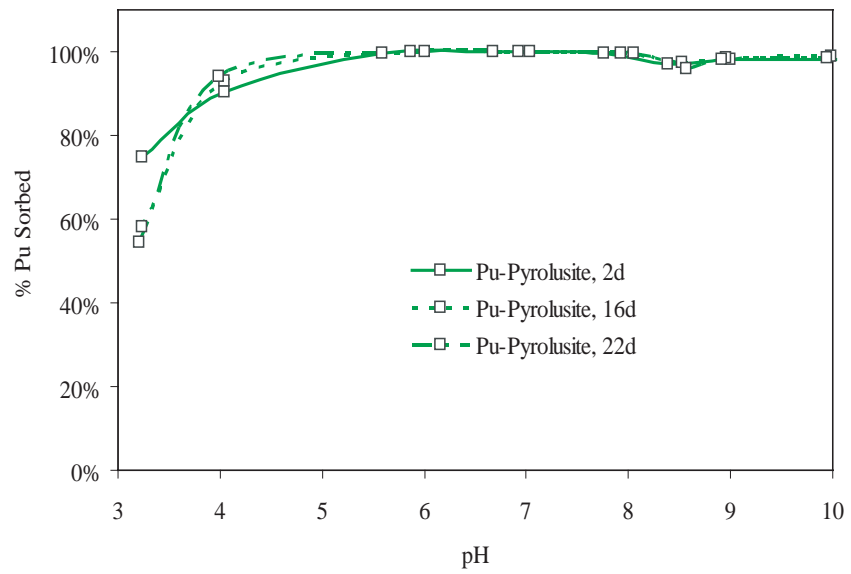

(c)

Figure 20. Pu sorption to (a) birnessite, (b) cryptomelane, and (c) pyrolusite as functions of solution $\mathrm{pH}$ and time in desorption experiments. 

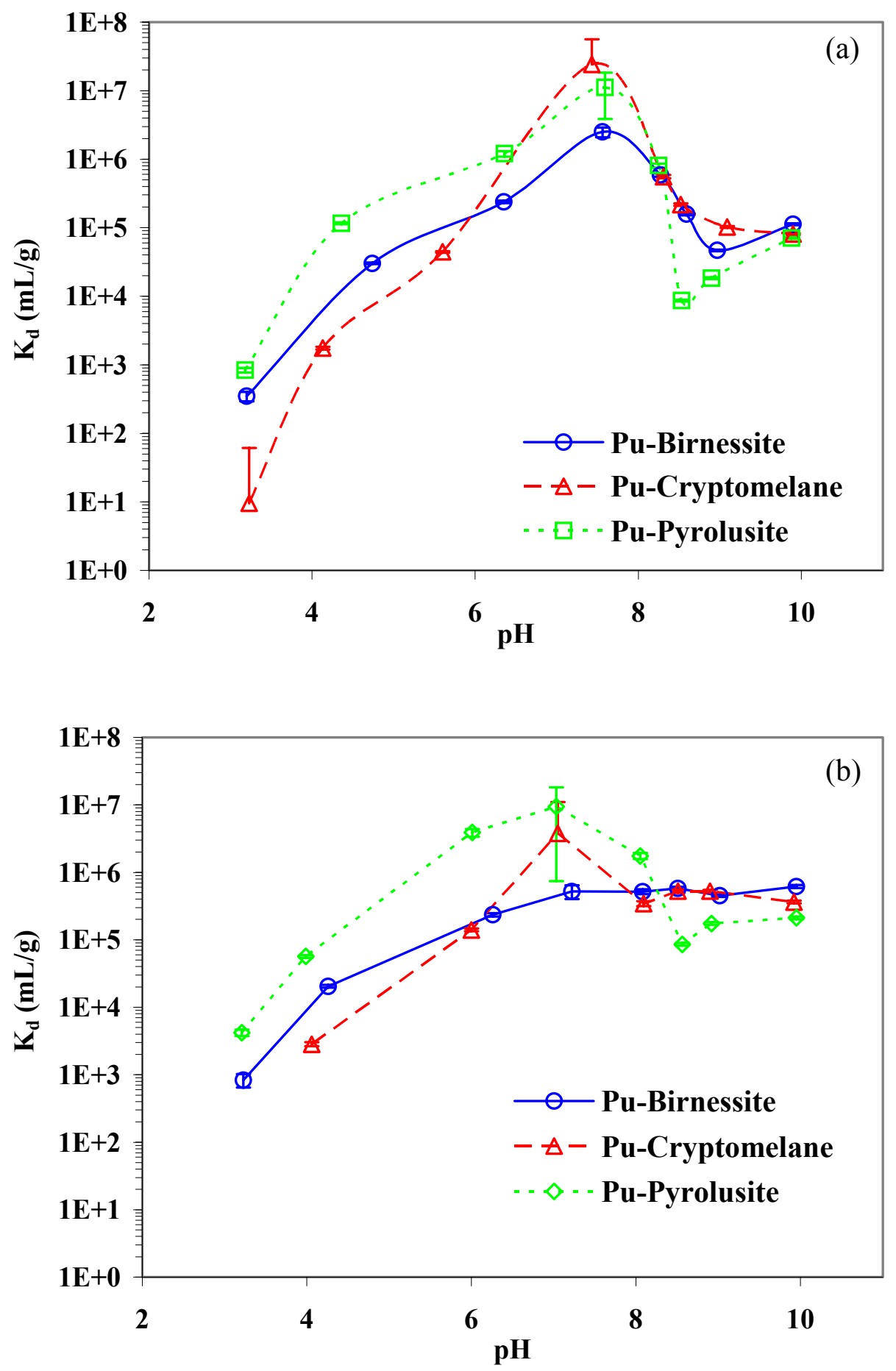

Figure 21. $K_{d}$ versus $\mathrm{pH}$ in 30 day $\mathrm{Pu}$ sorption (a) and 30 day Pu desorption (b) experiments. 


\subsubsection{Pu Oxidation State Characterization}

Plutonium ions in solution have four common oxidation states, $+3,+4,+5$, and +6 , as species $\mathrm{Pu}^{3+}, \mathrm{Pu}^{4+}, \mathrm{PuO}_{2}{ }^{+}$and $\mathrm{PuO}_{2}{ }^{2+}$, respectively. Because of the spontaneous disproportionation of $\mathrm{Pu}^{4+}$ and $\mathrm{PuO}_{2}^{+}$(especially $\mathrm{PuO}_{2}{ }^{+}$), and slow redox kinetics between $\mathrm{PuO}_{2}^{+} / \mathrm{PuO}_{2}{ }^{2+}$ and $\mathrm{Pu}^{3+} / \mathrm{Pu}^{4+}$ as a result of necessary configurational changes, plutonium is the only element in the periodic table that can have all its common oxidation states coexist in the same solution at appreciable concentrations. The most common methods for characterization of plutonium oxidation states in solutions are UV/VIS spectrometry for relatively high $\mathrm{Pu}$ concentrations $\left(>10^{-4} \mathrm{M}\right)$ and solvent extraction for lower $\mathrm{Pu}$ concentrations. Given the experimental conditions of these sorption experiments, any $\mathrm{Mn}(\mathrm{III})$ or $\mathrm{Mn}$ (IV) contained in or on the manganese oxides could oxidize $\mathrm{Pu}(\mathrm{IV})$ to higher oxidation states. Solvent extraction techniques were used to characterize the plutonium oxidation states in both liquid and solid samples at the end of the desorption experiments. The end of the desorption experiments was after approximately 60 days of $\mathrm{Pu}$ exposure to the manganese oxide minerals. Due to the complexity of the solvent extraction process, only $\mathrm{pH} \mathrm{4,} \mathrm{7,} \mathrm{and} 10$ samples were selected and represent weakly acidic, neutral and weakly basic solution conditions.

Solvent extractions typically result in a $\sim 2 \%$ experimental error, mostly from the liquid scintillation counting and volumetric measurements. However, some data reported here contain larger errors $(\sim 10-15 \%)$ due to extremely low Pu activity in sample solutions. Table 6 lists the solvent extraction results obtained from desorption experiment supernatants. The supernatant solutions were acidified but did not require any other pretreatment. The results show that at higher $\mathrm{pH}(\sim 10) \mathrm{Pu}(\mathrm{IV})$ remained the dominant species, although a significant amount of $\mathrm{Pu}(\mathrm{VI})$ was measured in the birnessite supernatant. Interestingly, at $\mathrm{pH} 4 \sim 99 \%$ of plutonium in the solutions was oxidized to $\mathrm{Pu}(\mathrm{V}), \mathrm{Pu}(\mathrm{VI})$, or both. We also found high concentration of $\mathrm{Mn}^{2+}(2 \sim 14 \mathrm{ppm})$ in the supernatant from the low $\mathrm{pH}$ batch solutions. It is possible that the dissolution of the $\mathrm{Mn}(\mathrm{IV})$-oxides and reduction of $\mathrm{Mn}(\mathrm{IV})$ to $\mathrm{Mn}$ (II) would provide a mechanism for the oxidation of $\mathrm{Pu}(\mathrm{IV})$ to $\mathrm{Pu}(\mathrm{V})$ or $\mathrm{Pu}(\mathrm{VI})$. While this mechanism cannot be confirmed, the results indicate very clearly that $\mathrm{Pu}(\mathrm{IV})$ is likely to oxidize, predominantly to $\mathrm{Pu}(\mathrm{V})$, under slightly acidic conditions.

\begin{tabular}{|c|c|c|c|c|c|c|}
\hline & & \multicolumn{4}{|c|}{ Pu Oxidation States } & \multirow{2}{*}{ colloids } \\
\hline & & $3+$ & $4+$ & $5+$ & $6+$ & \\
\hline \multirow{3}{*}{ Birnessite } & $\mathrm{pH} 4$ & & $1 \%$ & $66 \%$ & $28 \%$ & $5 \%$ \\
\hline & $\mathrm{pH} 7^{* *}$ & $10 \%$ & $40 \%$ & $10 \%$ & $40 \%$ & \\
\hline & $\mathrm{pH} 10$ & $1 \%$ & $55 \%$ & $7 \%$ & $37 \%$ & \\
\hline Cryptomelane & $\mathrm{pH} 4$ & & & $80 \%$ & $19 \%$ & \\
\hline \multirow{2}{*}{ Pyrolusite } & $\mathrm{pH} 4$ & & $1 \%$ & $94 \%$ & $3 \%$ & $2 \%$ \\
\hline & $\mathrm{pH} 10$ & & $89 \%$ & $2 \%$ & $7 \%$ & $1 \%$ \\
\hline
\end{tabular}

** Sample contained very low activity of $\mathrm{Pu}(<5 \mathrm{cmp} / \mathrm{mL})$, so that the results were associated with errors as much as $\pm 10 \%$. 
At $\mathrm{pH} 7$ and 10, the desorption supernatant contained very low $\mathrm{Pu}$ since much of the $\mathrm{Pu}$ had sorbed to the mineral surfaces. As a result, we attempted to measure the redox state of $\mathrm{Pu}$ on the mineral surface but not in the supernatant. The sorbed $\mathrm{Pu}$ was desorbed from the manganese oxides in $15 \mathrm{~mL}$ of $1 \mathrm{~N} \mathrm{HCl}$ and examined using solvent extraction. Table 7 shows the extraction results. It appears that $\mathrm{Pu}(\mathrm{VI})$ is dominant $(>90 \%)$ in birnessite and cryptomelane samples. In pyrolusite samples, there was some $\mathrm{Pu}(\mathrm{III}) /$ $\mathrm{Pu}(\mathrm{IV})$ but a larger percentage of $\mathrm{Pu}(\mathrm{VI})$. This appears to contradict the observations of Shaughnessy et al. (2003). However, our oxidation state results may be an artifact of the desorption pretreatment process. Based on our supernatant oxidation state measurements, we find that aqueous $\mathrm{Pu}(\mathrm{IV})$ will oxidize to $\mathrm{Pu}(\mathrm{VI})$ at low $\mathrm{pH}$. Since the sorbed $\mathrm{Pu}$ was treated with acid prior to solvent extraction, it is possible that the observed predominance of $\mathrm{Pu}(\mathrm{VI})$ results from the extraction procedure and does not represent the oxidation state of $\mathrm{Pu}$ on the manganese oxide mineral surface.

\begin{tabular}{|c|c|c|c|c|c|c|}
\hline & & \multicolumn{4}{|c|}{ Pu Oxidation States } & \multirow{2}{*}{ colloids } \\
\hline & & $3+$ & $4+$ & $5+$ & $6+$ & \\
\hline \multirow{2}{*}{ Birnessite } & $\mathrm{pH} 7$ & & & $5 \%$ & $94 \%$ & $1 \%$ \\
\hline & $\mathrm{pH} 10$ & & & $7 \%$ & $92 \%$ & $1 \%$ \\
\hline \multirow{2}{*}{ Cryptomelane } & $\mathrm{pH} 7$ & & & $9 \%$ & $90 \%$ & $1 \%$ \\
\hline & $\mathrm{pH} 10$ & & & $2 \%$ & $97 \%$ & $1 \%$ \\
\hline \multirow{2}{*}{ Pyrolusite } & $\mathrm{pH} 7$ & $14 \%$ & $14 \%$ & & $71 \%$ & $1 \%$ \\
\hline & $\mathrm{pH} 10$ & $9 \%$ & $20 \%$ & $3 \%$ & $67 \%$ & $1 \%$ \\
\hline
\end{tabular}

Given the possibility that the oxidation states of plutonium on the manganese oxides were altered during the pretreatment process, we also performed solvent extractions using $\mathrm{Pu}-$ sorbed minerals without the acidification pretreatment. For birnessite and pyrolusite these results (Table 8) still indicate that $>88 \%$ of the plutonium was $\mathrm{Pu}(\mathrm{VI})$. However, in contradiction to the pretreated samples (Table 7), the direct solvent extraction of plutonium showed $100 \% \mathrm{Pu}(\mathrm{IV})$ on cryptomelane.

Table 8. Oxidation state characterization of sorbed $P u$ (Pu-manganese oxide wet pastes).

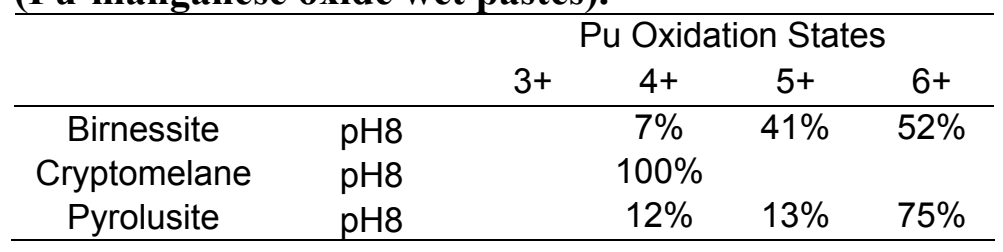

Because the $\mathrm{Pu}$ oxidation state may have changed during acidification pretreatment of samples and because the efficiency of solvent extraction without acidification is not 
known, these results should be interpreted with caution. Additional examination of the oxidation state of $\mathrm{Pu}$ in the presence of manganese oxides would be needed to better understand the redox processes at the manganese oxide surface. Given the weak sorption of $\mathrm{Np}(\mathrm{V})$ and the thermodynamic similarity of $\mathrm{Pu}(\mathrm{V})$ and $\mathrm{Np}(\mathrm{V})$ speciation, it appears unlikely that $\mathrm{Pu}(\mathrm{V})$ plays a significant role in the strong sorption of $\mathrm{Pu}$ on the $\mathrm{Mn}$ oxide surface. The oxidation state of $\mathrm{Pu}$ on the mineral surfaces is likely to be either $\mathrm{Pu}(\mathrm{IV})$ or $\mathrm{Pu}(\mathrm{VI})$. 


\section{CONCLUSIONS AND RECOMMENDATIONS}

Based on the experimental results described in this report:

- Sorption of both $\mathrm{Np}(\mathrm{V})$ and $\mathrm{Pu}(\mathrm{IV})$ is strongly $\mathrm{pH}$ dependent

- Sorption of $\mathrm{Np}(\mathrm{V})$ and $\mathrm{Pu}(\mathrm{IV})$ to all three Mn oxide minerals examined here was fast and reversible

- The oxidation state of $\mathrm{Pu}$ appeared to change during sorption experiments; additional experiments would be necessary to further elucidate its behavior

- On a mass basis, $\mathrm{Pu}$ (as well as $\mathrm{Np}$ ) sorbed to the three different Mn oxide minerals similarly. On a surface area basis, sorption affinity followed the order pyrolusite $>$ cryptomelane $>$ birnessite for both $\mathrm{Np}$ and $\mathrm{Pu}$

- $\mathrm{Pu}$ sorption $\mathrm{K}_{d} \mathrm{~S}$ were up to four orders of magnitude greater than $\mathrm{Np}$

- Surface complexation modeling of $\mathrm{Np}(\mathrm{V})$ sorption to birnessite was achieved using two surface species: a Np oxide and Np oxyhydroxide species

- $\mathrm{Pu}$ sorption to manganese oxide minerals will have a significant impact on its transport at NTS locations where Mn oxides are present (fractured tuff environments). Np and other radionuclide transport may be significantly affected as well.

The combination of experimental data reported here and literature data reviewed in this report provides sufficient data to begin to incorporate Mn oxide sorption reactions into HST (and upscaled) models and provide less conservative estimates of radionuclide transport. Future modeling efforts need to address the role of Mn oxides in radionuclide transport, particularly for $\mathrm{Pu}$ and $\mathrm{Np}$. 


\section{ACKNOWLEDGEMENTS}

Funding for this investigation was provided by the Environment Restoration Division's Underground Test Area Project at the U.S. Department of Energy, National Nuclear Security Administration, Nevada Site Office. This work was performed under the auspices of the U.S. Department of Energy by Univeristy of California, Lawrence Livermore National Laboratory under contract number W-7405-Eng-48. 


\section{REFERENCES}

Al-Attar, L. and Dyer A. (2002) Sorption behaviour of uranium on birnessite, a layered manganese oxide. Journal of Materials Chemistry 12, 1381-1386.

Appelo, C.A.J. and Postma D. (1999) A consistent model for surface complexation on birnessite (delta-MnO2) and its application to a column experiment. Geochimica et Cosmochimica Acta 63, 3039-3048.

Axe, L., Tyson T., Trivedi P., and Morrison T. (2000) Local structure analysis of strontium sorption to hydrous manganese oxide. Journal of Colloid and Interface Science 224, 408-416.

Balistrieri, L.S. and Murray J.W. (1982) The surface chemistry of delta-MnO2 in major ion seawater. Geochimica et Cosmochimica Acta 46, 1041-1052.

Bethke C.M. (2002) The Geochemist's Workbench: Release 4.0. Software Package. University of Illinois, Urbana.

Carlos, B.A., Chipera S.J., Bish D.L., and Craven S.J. (1993) Fracture lining manganese oxide minerals in silicic tuff, Yucca Mountain, Nevada, USA. Chemical Geology, 107, 47-69.

Catts, J.G. and Langmuir D. (1986) Adsorption of $\mathrm{Cu}, \mathrm{Pb}$ and $\mathrm{Zn}$ by delta-MnO2: applicability of the site binding-surface complexation model. Applied Geochemistry 1, 255-264.

Chen, C.C., Golden D.C., and Dixon J.B. (1986) Transformation of synthetic birnessite to cryptomelane: an electron microscopic study. Clays and Clay Minerals 34 (5), 565-571.

Drellack, S.L, Jr., Prothro L.B., Roberson K.E., Schier B.A., and Price E.H. (1997) Analysis of Fractures in Volcanic Cores from Pahute Mesa, Nevada Test Site. Bechtel Nevada, DOE/NV/11718-160.

Duff, M.C., Hunter D.B., Triay I.R., Bertsch P.M., Reed D.T., Sutton S.R., SheaMcCarthy G., Kitten J., Eng P., Chipera S. J., and Vaniman D. T. (1999) Mineral associations and average oxidation states of sorbed $\mathrm{Pu}$ on tuff. Environmental Science and Technology 33, 2163-2169.

Dyer, A., Pillinger M., Harjula R., and Amin S. (2000a) Sorption characteristics of radionuclides on synthetic birnessite-type layered manganese oxides. Journal of Materials Chemistry 10(8), 1867-1874.

Dyer A., Pillinger M., Newton J., Harjula R., Moller T., and Amin S. (2000b) Sorption behavior of radionuclides on crystalline synthetic tunnel manganese oxides. Chemistry of Materials 12(12), 3798-3804.

Dzombak D.A. and Morel F.M.M. (1990) Surface complexation modeling: hydrous ferric oxide. Wiley. 
Foster, A.L., Brown G.E. Jr., and Parks G.A. (2003) X-ray absorption fine structure study of As (V) and SE (IV) sorption complexes on hydrous Mn oxides. Geochimica et Cosmochimica Acta 67 (11), 1937-1953.

Golden, D.C., Dixon J.B., and Chen C.C. (1986) on exchange, thermal transformations, and oxidizing properties of birnessite. Clays and Clay Minerals 34 (5), 511-520.

Herbelin, A.L. and Westall J.C. (1999) FITEQL: A computer program for determination of chemical equilibrium constants from experimental data. Department of Chemistry, Oregon State University, Corvallis.

Johnson J.W. and Lundeen S.R. (1997) GEMBOCHS thermodynamic datafiles for use with the EQ3/6 modeling package. Lawrence Livermore National Laboratory, Livermore, California.

Kennedy, C., Smith D.S., and Warren L.A. (2004) Surface chemistry and relative Ni sorptive capacities of synthetic hydrous Mn oxyhydroxides under variable wetting and drying regimes. Geochimica et Cosmochimica Acta 68 (3), 443-454.

Keeney-Kennicutt, W.L. and Morse J.W. (1984) The interaction of Np(V) O2+ with common mineral surfaces in dilute aqueous solutions and seawater. Marine Chemistry 15, 133-150.

Keeney-Kennicutt, W.L. and Morse J.W. (1985) The redox chemistry of Pu(V)O2+ interaction with common mineral surfaces in dilute solutions and seawater. Geochimica et Cosmochimica Acta 49, 2577-2588.

Kersting A.B. and Reimus P.W.E., Editors (2003) Colloid-Facilitated Transport of Lowsolubility Radionuclides: A Field, Experimental, and Modeling Investigation. Lawrence Livermore National Laboratory, UCRL-ID-149688. Livermore, California.

Koeppenkastrop, D. and Carlo E.H.D. (1992) Sorption of rare-earth elements from seawater onto synthetic mineral particles: an experimental approach. Chemical Geology 95, 251-263.

Loganathan, P. and Burau R.G. (1973) Sorption of heavy metal ions by a hydrous manganese oxide. Geochimica et Cosmochimica Acta 37, 1277-1293.

Loganathan, P., Burau R.G., and Fuerstenau D.W. (1977) Influence of pH on the sorption of $\mathrm{Co}++, \mathrm{Zn}++$ and $\mathrm{Ca}++$ by a hydrous manganese oxide. Soil Science Society of America Journal 41, 57-62.

Manceau, A., Charlet L., Boisset M.C., Didier B., and Spadini L. (1992) Sorption and speciation of heavy metals on hydrous Fe and Mn oxides: from microscopic to macroscopic . Applied Clay Science 7, 201-223.

Matocha, C.J., Elzinga E.J., and Sparks D.L. (2001) Reactivity of Pb(II) at the Mn(III,IV) (oxyhydr)oxide-water interface. Environmental Science and Technology 35 (14), 2967-2972.

McKenzie, R.M. (1979) Proton release during adsorption of heavy metal ions by a hydrous manganese dioxide. Geochimica et Cosmochimica Acta 43, 1855-1857. 
Means, J.L., Crerar D.A., Borcsik M.P., and Duguid J.O. (1978) Adsorption of Co and selected actinides by Mn and Fe oxides in soils and sediments. Geochimica et Cosmochimica Acta 42, 1763-1773.

Misaelides, P., Katranas T., Godelitsas A., Lkewe-Nebenius H., and Anousis I. (2002) The chemical behavior of the natural microporous manganese-oxide todorokite in actinides (Th, U, Pa) aqueous solutions. Separation Science and Technology 37 (5), 1109-1121.

Murray, J.W. (1974) The surface chemistry of hydrous manganese dioxide. Journal of Colloid and Interface Science 46 (3), 357-371.

Murray, J.W. (1975) The interaction of metal ions at the manganese dioxide-solution interface. Geochimica et Cosmochimica Acta 39, 509-519.

Olin, M. and Lehikoinen J. (1997) Application of surface complexation modeling: Nickel sorption on quartz, manganese oxide, kaolinite and goethite, and thorium on silica. Posiva Oy, Posiva 97-10. Helsinki, Finland.

O'Reilly, S.E. and Hochella M.F. Jr. (2003) Lead sorption efficiencies of natural and synthetic Mn and Fe-oxides. Geochimica et Cosmochimica Acta 67 (23), 44714487.

Parc, S., Nahon D., Tardy Y., and Vieillard P. (1989) Estimated solubility products and fields of stability for cryptomelane, nsutite, birnessite, and lithiophorite based on natural lateritic weathering sequences. American Mineralogist 74, 466-475.

Posselt, H.S., Anderson F.J., and Weber W.J. Jr. (1968) Cation sorption on colloidal hydrous manganese dioxide. Environmental Science and Technology 2 (12), 1087-1093.

Post, J.E. (1999) Manganese oxide minerals: crystal structures and economic and environmental significance. Proceedings of the National Academy of Science 96, 3446-3454.

Prothro, L.B. (1998) Analysis of Fractures in Cores from the Tuff Confining Unit Beneath Yucca Flat, Nevada Test Site. Bechtel Nevada, August, 1998.

Rose, T.P., Keneally J.M., Smith D.K., Davidson M.L., Hudson G.B. and Rego J.A.H. (1997) Chemical and isotope data for groundwater in Southern Nevada. Lawrence Livermore National Laboratory, UCRL-ID-128000. Livermore, California

Shaughnessy, D.A., Nitsche H., Booth C.H., Shuh D.K., Waychunas G.A., Wilson R.E., Gill H., Cantrell K.J., and Serne R.J. (2003) Molecular interfacial reactions between $\mathrm{Pu}(\mathrm{VI})$ and manganese oxide minerals manganite and hausmannite. Environmental Science and Technology 37 (15), 3367-3374.

Smith, R.W. and Jenne A.E. (1991) Recalculation, evaluation, and prediction of surface complexation constants for metal adsorption on iron and manganese oxides. Environmental Science and Technology 25 (3), 525-531.

Stahl, R.S. and James B.R. (1991) Zinc sorption by manganese-oxide-coated sand as a function of pH. Soil Science Society of America Journal 55, 1291-1294. 
Tamura, H., Katayama N., and Furuichi R. (1997) The $\mathrm{Co}^{2+}$ adsorption properties of $\mathrm{Al} 2 \mathrm{O} 3, \mathrm{Fe} 2 \mathrm{O} 3, \mathrm{Fe} 3 \mathrm{O} 4, \mathrm{TiO} 2$, and $\mathrm{MnO} 2$ evaluated by modeling with the frumkin isotherm. Journal of Colloid and Interface Science 195, 192-202.

Tanaka, Y. and Tsuji M. (1997) Thermodynamic study of alkaki metal ion exchanges on a manganese dioxide with hexagonal structure. Materials Research Bulletin 32 (4), 461-475.

Tessier, A., Fortin D., Belzile N., DeVitre R.R., and Leppard G.G. (1996) Metal sorption to diagenetic iron and manganese oxyhydroxides and associated organic matter: Narrowing the gap between field and laboratory measurements. Geochimica et Cosmochimica Acta 60, 387-404.

Tonkin, J.W., Balistrieri L.S., and Murray J.W. (2004) Modeling sorption of divalent metal cations on hydrous manganese oxide using the diffuse double layer model. Applied Geochemistry 19, 29-53.

Triay, I.R., Meijer A., Conca J.L., Kung K.S., Rundberg R.S., Strietelmeier B.A., Tait C.D., Clark D.L., Neu M.P., and Hobart D.E. (1997) Summary and synthesis report on radionuclide retardation of the Yucca Mountain Site Characterization Project. Yucca Mountain Site Characterization Program Milestone 3784M, pp. 274. Los Alamos National Laboratory.

Triay, I.R., Mitchell A.J., and Ott M.A. (1991) Radionuclide migration as a function of mineralogy. Los Alamos National Laboratory, LA-UR-91-113. Los Alamos, New Mexico.

Trivedi, P. and Axe L. (1999) A comparison of strontium sorption to hydrous aluminum, iron, and manganese oxides. Journal of Colloid and Interface Science 218, 554563.

Trivedi, P. and Axe L. (2001) Predicting divalent metal sorption to hydrous Al, Fe, and Mn oxides. Environmental Science and Technology 35 (9), 1779-1784.

Trivedi, P., Axe L., and Tyson T.A. (2001) XAS studies of Ni and Zn sorbed to hydrous manganese oxide. Environmental Science and Technology 35 (22), 4515-4521.

Turin, H.J., Groffman A.R., Wolfsberg L.E., Roach J.L., and Strietelmeier B.A. (2002) Tracer and radionuclide sorption to vitric tuffs of Busted Butte, Nevada. Applied Geochemistry 17, 825-836.

Waychunas, G.A. (1991) Crystal chemistry of oxides and oxyhydroxides. Reviews in Mineralogy 25, 11-68.

Zachara, J.M., Smith S.C., and Kuzel L.S. (1995) Adsorption and dissociation of CoEDTA complexes in iron oxide-containing subsurface sands. Geochimica et Cosmochimica Acta 59 (23), 4825-4844.

Zavarin, M. (1999) Sorptive Properties of Synthetic and Soil Carbonates for Selenium, Nickel, and Manganese, Ph.D. Thesis, University of California at Berkeley.

Zavarin, M. and Bruton C.J. (2004a) A Non-Electrostatic Surface Complexation Approach to Modeling Radionuclide Migration at the Nevada Test Site: 
Aluminosilicates. Lawrence Livermore National Laboratory, UCRL-TRDRAFT. Livermore, California.

Zavarin, M. and Bruton C.J. (2004b) A Non-Electrostatic Surface Complexation Approach to Modeling Radionuclide Migration at the Nevada Test Site: Iron Oxides and Calcite. Lawrence Livermore National Laboratory, UCRL-TRDRAFT. Livermore, California. 


\title{
8 APPENDIX. BATCH SORPTION RAW DATA
}

\section{Table A-1. Np-Sorption Data}

\author{
Np-Manganese Oxides Sorption data \\ Volume in reaction tube $\quad 35 \mathrm{~mL}$ \\ Mass of mineral used: $\quad .05 \mathrm{~g}$ \\ Initial Np conc., M 3.5E-06
}

\begin{tabular}{|c|c|c|c|c|c|c|}
\hline \multicolumn{2}{|c|}{ Sampling time: 3 day } & \multicolumn{3}{|c|}{ Sampling time: 17 days } & \multicolumn{3}{|c|}{ Sampling time: 27 days } \\
\hline $\mathrm{pH}$ & $\%$ Sorption & $\mathrm{pH}$ & $\%$ Sorption & $\mathrm{pH}$ & $\%$ Sorption & $\mathrm{Kd}, \mathrm{mL} / \mathrm{g}$ \\
\hline 2.84 & $0.00 \%$ & 2.83 & $3.33 \%$ & 2.8 & $8.01 \%$ & 60.7 \\
3.78 & $0.00 \%$ & 3.74 & $0.0 \%$ & 3.60 & $7.5 \%$ & 56.0 \\
3.8 & $0.01 \%$ & 3.78 & $2.45 \%$ & 3.74 & $6.21 \%$ & 46.0 \\
5.45 & $0.57 \%$ & 5.54 & $4.75 \%$ & 5.43 & $10.18 \%$ & 78.7 \\
6.19 & $6.11 \%$ & 6.28 & $7.6 \%$ & 6.42 & $17.6 \%$ & 148.7 \\
6.56 & $9.71 \%$ & 7.01 & $24.47 \%$ & 7.15 & $32.94 \%$ & 343.8 \\
7.44 & $30.21 \%$ & 7.72 & $45.53 \%$ & 7.80 & $57.5 \%$ & 943.6 \\
7.52 & $36.76 \%$ & 7.74 & $52.3 \%$ & 7.96 & $61.6 \%$ & 1123.6 \\
7.68 & $41.39 \%$ & 7.86 & $56.2 \%$ & 7.99 & $55.60 \%$ & 873.2 \\
7.96 & $48.26 \%$ & 8.18 & $58.8 \%$ & 8.28 & $62.9 \%$ & 1183.1 \\
8.51 & $49.04 \%$ & 8.58 & $52.0 \%$ & 8.58 & $56.1 \%$ & 891.7 \\
9.07 & $48.34 \%$ & 9.00 & $53.4 \%$ & 8.95 & $54.9 \%$ & 846.5 \\
10.00 & $50.15 \%$ & 9.84 & $55.4 \%$ & 9.75 & $57.5 \%$ & 947.7 \\
\hline
\end{tabular}

Np-Cryptomelane sorption

\begin{tabular}{|c|c|c|c|c|c|c|}
\hline \multicolumn{2}{|c|}{ Sampling time: 3 day } & \multicolumn{3}{|c|}{ Sampling time: 17 days } & \multicolumn{3}{|c|}{ Sampling time: 27 days } \\
\hline $\mathrm{pH}$ & $\%$ Sorption & $\mathrm{pH}$ & $\%$ Sorption & $\mathrm{pH}$ & $\%$ Sorption & $\mathrm{Kd}, \mathrm{mL} / \mathrm{g}$ \\
\hline 3.30 & $1.83 \%$ & 3.27 & $2.4 \%$ & 3.20 & $7.6 \%$ & 57.1 \\
4.29 & $0.00 \%$ & 4.36 & $0.9 \%$ & 4.30 & $6.1 \%$ & 45.9 \\
5.40 & $1.26 \%$ & 5.43 & $2.3 \%$ & 5.32 & $7.5 \%$ & 56.8 \\
5.90 & $1.20 \%$ & 5.95 & $5.2 \%$ & 5.88 & $8.9 \%$ & 68.0 \\
7.24 & $12.01 \%$ & 7.25 & $19.3 \%$ & 7.44 & $29.5 \%$ & 291.2 \\
8.16 & $36.53 \%$ & 8.31 & $47.3 \%$ & 8.45 & $54.0 \%$ & 821.4 \\
9.15 & $43.10 \%$ & 9.05 & $45.5 \%$ & 8.88 & $50.0 \%$ & 698.8 \\
10.03 & $40.32 \%$ & 9.92 & $47.7 \%$ & 9.79 & $49.5 \%$ & 682.1 \\
\hline
\end{tabular}

Np-Pyrolusite sorption
\begin{tabular}{|c|c|c|c|c|c|c|}
\hline Sampling time: 3 day & \multicolumn{2}{|c|}{ Sampling time: 17 days } & \multicolumn{3}{|c|}{ Sampling time: 27 days } \\
\hline $\mathrm{pH}$ & $\%$ Sorption & $\mathrm{pH}$ & $\%$ Sorption & $\mathrm{pH}$ & $\%$ Sorption & $\mathrm{Kd}, \mathrm{mL} / \mathrm{g}$ \\
\hline 3.28 & $0.00 \%$ & 3.25 & $0.0 \%$ & 3.10 & $5.9 \%$ & 44.2 \\
3.94 & $0.00 \%$ & 4.00 & $0.0 \%$ & 3.97 & $5.3 \%$ & 38.7 \\
5.60 & $0.45 \%$ & 5.97 & $2.8 \%$ & 6.06 & $11.2 \%$ & 88.5 \\
6.62 & $5.17 \%$ & 6.97 & $12.3 \%$ & 7.14 & $19.8 \%$ & 173.4 \\
7.65 & $20.93 \%$ & 8.02 & $37.7 \%$ & 8.12 & $43.7 \%$ & 534.5 \\
8.26 & $25.76 \%$ & 8.43 & $35.5 \%$ & 8.50 & $40.0 \%$ & 461.8 \\
9.03 & $33.73 \%$ & 8.90 & $35.3 \%$ & 8.81 & $39.0 \%$ & 446.6 \\
9.95 & $38.55 \%$ & 9.89 & $38.2 \%$ & 9.77 & $40.4 \%$ & 471.3 \\
\hline
\end{tabular}


Table A-2. Np-Desorption data.

Np-Manganese Oxides Desorption data

Volume in reaction tube $\quad 35 \mathrm{~mL}$

Mass of mineral uesd: $\quad .05 \mathrm{~g}$

Np-Birnessite Desorption

\begin{tabular}{|c|c|c|c|c|c|c|c|c|c|c|}
\hline \multicolumn{4}{|c|}{ Sampling time: 1 days } & \multicolumn{3}{|c|}{ Sampling time: 15 days } & \multicolumn{4}{|c|}{ Sampling time: 33 days } \\
\hline $\mathrm{pH}$ & initial $\mathrm{Np}$, mmoles & desorbed mmoles & $\%$ Sorption & $\mathrm{pH}$ & desorbed mmoles & \% Sorption & $\mathrm{pH}$ & desorbed mmoles & \% Sorption & $\mathrm{Kd}, \mathrm{mL} / \mathrm{g}$ \\
\hline 3.02 & $9.81 \mathrm{E}-06$ & $1.72 \mathrm{E}-06$ & $82.4 \%$ & 3.07 & $1.75 \mathrm{E}-06$ & $82.2 \%$ & 3.08 & $1.95 \mathrm{E}-06$ & $80.1 \%$ & 2813.298 \\
\hline 3.17 & $9.14 \mathrm{E}-06$ & $2.18 \mathrm{E}-06$ & $76.1 \%$ & 3.17 & $2.51 \mathrm{E}-06$ & $72.6 \%$ & 3.18 & $2.28 \mathrm{E}-06$ & $75.1 \%$ & 2105.861 \\
\hline 3.55 & $7.61 \mathrm{E}-06$ & $2.02 \mathrm{E}-06$ & $73.4 \%$ & 3.57 & $2.05 \mathrm{E}-06$ & $73.0 \%$ & 3.62 & $2.14 \mathrm{E}-06$ & $71.9 \%$ & 1791.918 \\
\hline 5.14 & $2.16 \mathrm{E}-05$ & $1.44 \mathrm{E}-05$ & $33.1 \%$ & 5.35 & $1.47 \mathrm{E}-05$ & $32.1 \%$ & 3.80 & 4.98E-06 & $60.1 \%$ & 1054.689 \\
\hline 5.62 & $1.25 \mathrm{E}-05$ & $5.15 \mathrm{E}-06$ & $58.7 \%$ & 5.74 & $4.87 \mathrm{E}-06$ & $60.9 \%$ & 5.34 & $1.53 \mathrm{E}-05$ & $29.1 \%$ & 287.6652 \\
\hline 6.38 & 7.04E-05 & $5.65 \mathrm{E}-05$ & $19.7 \%$ & 6.89 & $2.57 \mathrm{E}-05$ & $36.4 \%$ & 7.00 & $2.57 \mathrm{E}-05$ & $36.4 \%$ & 400.5586 \\
\hline 6.65 & $4.04 \mathrm{E}-05$ & $2.80 \mathrm{E}-05$ & $30.7 \%$ & 7.35 & $4.01 \mathrm{E}-05$ & $43.0 \%$ & 7.72 & $3.05 \mathrm{E}-05$ & $56.7 \%$ & 917.0676 \\
\hline 6.75 & $7.55 \mathrm{E}-05$ & $5.54 \mathrm{E}-05$ & $26.6 \%$ & 7.65 & $3.64 \mathrm{E}-05$ & $51.8 \%$ & 7.93 & $2.91 \mathrm{E}-05$ & $61.4 \%$ & 1115.304 \\
\hline 7.32 & $7.70 \mathrm{E}-05$ & 4.33E-05 & $43.8 \%$ & 7.77 & $3.14 \mathrm{E}-05$ & $53.9 \%$ & 7.95 & $3.02 \mathrm{E}-05$ & $55.6 \%$ & 877.9574 \\
\hline 7.48 & $6.81 \mathrm{E}-05$ & $3.70 \mathrm{E}-05$ & $45.6 \%$ & 8.11 & $3.29 \mathrm{E}-05$ & $57.3 \%$ & 8.38 & 2.97E-05 & $61.4 \%$ & 1114.065 \\
\hline 8.20 & $6.87 \mathrm{E}-05$ & $2.65 \mathrm{E}-05$ & $61.4 \%$ & 8.56 & 2.77E-05 & $59.7 \%$ & 8.68 & 2.67E-05 & $61.1 \%$ & 1099.547 \\
\hline 9.02 & $6.72 \mathrm{E}-05$ & $2.37 \mathrm{E}-05$ & $64.7 \%$ & 9.07 & $2.59 \mathrm{E}-05$ & $61.5 \%$ & 9.02 & $2.53 \mathrm{E}-05$ & $62.4 \%$ & 1160.067 \\
\hline 9.98 & $7.05 \mathrm{E}-05$ & $2.19 \mathrm{E}-05$ & $68.9 \%$ & 9.96 & $2.31 \mathrm{E}-05$ & $67.2 \%$ & 9.96 & $2.35 \mathrm{E}-05$ & $66.6 \%$ & 1397.223 \\
\hline
\end{tabular}

Np-Cryptomelane Desorption

\begin{tabular}{|c|c|c|c|c|c|c|c|c|c|c|}
\hline \multicolumn{4}{|c|}{ Sampling time: 1 days } & \multicolumn{3}{|c|}{ Sampling time: 15 days } & \multicolumn{4}{|c|}{ Sampling time: 33 days } \\
\hline $\mathrm{pH}$ & initial $\mathrm{Np}$, mmoles & desorbed mmoles & $\%$ Sorption & $\mathrm{pH}$ & desorbed mmoles & \% Sorption & $\mathrm{pH}$ & desorbed mmoles & $\%$ Sorption & $\mathrm{Kd}, \mathrm{mL} / \mathrm{g}$ \\
\hline 3.05 & $9.25 \mathrm{E}-06$ & $2.00 \mathrm{E}-06$ & $78.4 \%$ & 3.08 & $2.10 \mathrm{E}-06$ & $77.3 \%$ & 3.11 & $1.90 \mathrm{E}-06$ & $79.5 \%$ & 2713.097 \\
\hline 3.87 & $7.53 \mathrm{E}-06$ & $2.71 \mathrm{E}-06$ & $64.0 \%$ & 3.95 & $2.94 \mathrm{E}-06$ & $61.0 \%$ & 4.03 & $2.71 \mathrm{E}-06$ & $64.1 \%$ & 1247.318 \\
\hline 5.59 & $9.25 \mathrm{E}-06$ & $3.84 \mathrm{E}-06$ & $58.5 \%$ & 6.00 & $4.04 \mathrm{E}-06$ & $56.3 \%$ & 6.16 & $3.70 \mathrm{E}-06$ & $60.0 \%$ & 1051.095 \\
\hline 6.39 & $1.09 \mathrm{E}-05$ & 4.99E-06 & $54.4 \%$ & 7.20 & $3.69 \mathrm{E}-06$ & $66.3 \%$ & 7.68 & $2.01 \mathrm{E}-06$ & $81.6 \%$ & 3112.746 \\
\hline 7.21 & $3.62 \mathrm{E}-05$ & $2.62 \mathrm{E}-05$ & $27.5 \%$ & 7.52 & $2.01 \mathrm{E}-05$ & $44.4 \%$ & 7.74 & $1.63 \mathrm{E}-05$ & $54.9 \%$ & 852.0243 \\
\hline 8.17 & $6.62 \mathrm{E}-05$ & $3.64 \mathrm{E}-05$ & $45.1 \%$ & 8.51 & $3.10 \mathrm{E}-05$ & $53.2 \%$ & 8.60 & $2.91 \mathrm{E}-05$ & $56.1 \%$ & 894.2491 \\
\hline 9.14 & $6.12 \mathrm{E}-05$ & $3.13 \mathrm{E}-05$ & $48.8 \%$ & 9.05 & $3.01 \mathrm{E}-05$ & $50.9 \%$ & 9.03 & $2.99 \mathrm{E}-05$ & $51.1 \%$ & 730.9958 \\
\hline 10.07 & $6.06 \mathrm{E}-05$ & $2.92 \mathrm{E}-05$ & $51.9 \%$ & 10.00 & 3.04E-05 & $49.7 \%$ & 9.99 & $3.05 \mathrm{E}-05$ & $49.6 \%$ & 689.3101 \\
\hline
\end{tabular}

Np-Pyrolusite Desorption

\begin{tabular}{|l|l|l|l|}
\hline Sampling time: 1 days & Sampling time: 15 days & Sampling time: 33 days \\
\hline
\end{tabular}

\begin{tabular}{|c|c|c|c|c|c|c|c|c|c|c|}
\hline $\mathrm{pH}$ & initial $\mathrm{Np}$, mmoles & desorbed mmoles & $\%$ Sorption & $\mathrm{pH}$ & desorbed mmoles & $\%$ Sorption & $\mathrm{pH}$ & desorbed mmoles & $\%$ Sorption & $\mathrm{Kd}, \mathrm{mL} / \mathrm{g}$ \\
\hline 3.00 & $7.25 \mathrm{E}-06$ & $7.33 \mathrm{E}-07$ & $89.9 \%$ & 3.04 & $6.36 \mathrm{E}-07$ & $91.2 \%$ & 2.97 & $6.77 \mathrm{E}-07$ & $90.7 \%$ & 6797.248 \\
\hline 3.40 & $6.51 \mathrm{E}-06$ & $1.64 \mathrm{E}-06$ & $74.9 \%$ & 3.43 & $1.70 \mathrm{E}-06$ & $73.9 \%$ & 3.37 & $1.49 \mathrm{E}-06$ & $77.2 \%$ & 2364.539 \\
\hline 5.06 & $1.37 \mathrm{E}-05$ & $6.48 \mathrm{E}-06$ & $52.7 \%$ & 6.11 & $6.30 \mathrm{E}-06$ & $54.0 \%$ & 6.74 & $5.96 \mathrm{E}-06$ & $56.5 \%$ & 907.805 \\
\hline 6.29 & $2.42 \mathrm{E}-05$ & $1.50 \mathrm{E}-05$ & $37.9 \%$ & 7.26 & $1.32 \mathrm{E}-05$ & $45.6 \%$ & 7.72 & $9.65 \mathrm{E}-06$ & $60.1 \%$ & 1055.298 \\
\hline 7.19 & $5.35 \mathrm{E}-05$ & $3.14 \mathrm{E}-05$ & $41.4 \%$ & 8.00 & $2.69 \mathrm{E}-05$ & $49.7 \%$ & 8.34 & $2.38 \mathrm{E}-05$ & $55.5 \%$ & 872.0654 \\
\hline 8.01 & $4.90 \mathrm{E}-05$ & $2.24 \mathrm{E}-05$ & $54.4 \%$ & 8.43 & $2.43 \mathrm{E}-05$ & $50.3 \%$ & 8.57 & $2.32 \mathrm{E}-05$ & $52.7 \%$ & 778.935 \\
\hline 9.04 & $4.78 \mathrm{E}-05$ & $2.15 \mathrm{E}-05$ & $55.1 \%$ & 9.00 & $2.37 \mathrm{E}-05$ & $50.4 \%$ & 8.93 & $2.42 \mathrm{E}-05$ & $49.3 \%$ & 681.5088 \\
\hline 10.01 & $4.95 \mathrm{E}-05$ & $2.18 \mathrm{E}-05$ & $56.0 \%$ & 9.98 & $2.47 \mathrm{E}-05$ & $50.1 \%$ & 9.92 & $2.60 \mathrm{E}-05$ & $47.6 \%$ & 634.8965 \\
\hline
\end{tabular}


Table A-3. Np batch-sorption major cation analyses (mol/ L).

Birnessite

\begin{tabular}{|c|c|c|c|c|c|c|}
\hline $\mathrm{pH}$ & $\mathrm{HCO}_{3}^{-}$ & $\mathrm{Na}^{+}$ & $\mathrm{K}^{+}$ & $\mathrm{Mg}^{2+}$ & $\mathrm{Mn}^{2+}$ & $\mathrm{Ca}^{2+}$ \\
\hline 3.18 & $7.86 \mathrm{E}-05$ & $1.71 \mathrm{E}-02$ & $2.30 \mathrm{E}-04$ & $1.46 \mathrm{E}-05$ & $1.27 \mathrm{E}-03$ & $6.54 \mathrm{E}-05$ \\
\hline 5.34 & $8.26 \mathrm{E}-05$ & $1.69 \mathrm{E}-02$ & $1.60 \mathrm{E}-04$ & $1.23 \mathrm{E}-06$ & $8.20 \mathrm{E}-05$ & $4.22 \mathrm{E}-06$ \\
\hline 7.72 & $8.06 \mathrm{E}-05$ & $1.40 \mathrm{E}-02$ & $2.98 \mathrm{E}-04$ & $(\mathrm{nd})^{*}$ & $1.42 \mathrm{E}-05$ & (nd) \\
\hline 7.93 & $1.68 \mathrm{E}-04$ & $1.19 \mathrm{E}-02$ & $1.44 \mathrm{E}-04$ & (nd) & $7.67 \mathrm{E}-06$ & (nd) \\
\hline 8.38 & $9.37 \mathrm{E}-04$ & $1.04 \mathrm{E}-02$ & $1.36 \mathrm{E}-04$ & (nd) & $4.82 \mathrm{E}-06$ & (nd) \\
\hline 8.68 & $1.80 \mathrm{E}-03$ & $1.11 \mathrm{E}-02$ & $1.81 \mathrm{E}-04$ & (nd) & $1.08 \mathrm{E}-05$ & (nd) \\
\hline 9.02 & $2.02 \mathrm{E}-03$ & $1.08 \mathrm{E}-02$ & $1.92 \mathrm{E}-04$ & (nd) & $9.56 \mathrm{E}-06$ & (nd) \\
\hline 9.96 & $2.30 \mathrm{E}-03$ & $1.08 \mathrm{E}-02$ & $3.44 \mathrm{E}-04$ & (nd) & $8.81 \mathrm{E}-06$ & (nd) \\
\hline
\end{tabular}

\section{Cryptomelane}

\begin{tabular}{|c|c|c|c|c|c|c|}
\hline $\mathrm{pH}$ & $\mathrm{HCO}_{3}^{-}$ & $\mathrm{Na}^{+}$ & $\mathrm{K}^{+}$ & $\mathrm{Mg}^{2+}$ & $\mathrm{Mn}^{2+}$ & $\mathrm{Ca}^{2+}$ \\
\hline 3.11 & $7.77 \mathrm{E}-05$ & $8.72 \mathrm{E}-03$ & $1.95 \mathrm{E}-03$ & $1.22 \mathrm{E}-05$ & $1.24 \mathrm{E}-03$ & $6.28 \mathrm{E}-05$ \\
\hline 4.03 & $8.24 \mathrm{E}-05$ & $1.09 \mathrm{E}-02$ & $2.12 \mathrm{E}-03$ & $1.14 \mathrm{E}-06$ & $1.03 \mathrm{E}-03$ & $2.29 \mathrm{E}-05$ \\
\hline 6.16 & $9.19 \mathrm{E}-05$ & $8.88 \mathrm{E}-03$ & $1.44 \mathrm{E}-03$ & $6.67 \mathrm{E}-07$ & $6.66 \mathrm{E}-04$ & $1.31 \mathrm{E}-05$ \\
\hline 7.68 & $1.63 \mathrm{E}-04$ & $7.94 \mathrm{E}-03$ & $1.14 \mathrm{E}-03$ & $2.30 \mathrm{E}-07$ & $3.94 \mathrm{E}-04$ & $7.14 \mathrm{E}-06$ \\
\hline 7.74 & $1.56 \mathrm{E}-04$ & $7.46 \mathrm{E}-03$ & $9.51 \mathrm{E}-04$ & (nd) & $2.48 \mathrm{E}-05$ & (nd) \\
\hline 8.60 & $1.05 \mathrm{E}-03$ & $1.09 \mathrm{E}-02$ & $1.38 \mathrm{E}-03$ & (nd) & $1.10 \mathrm{E}-05$ & (nd) \\
\hline 9.03 & $1.38 \mathrm{E}-03$ & $9.67 \mathrm{E}-03$ & $1.03 \mathrm{E}-03$ & (nd) & $5.86 \mathrm{E}-06$ & (nd) \\
\hline 9.99 & $1.66 \mathrm{E}-03$ & $1.21 \mathrm{E}-02$ & $8.35 \mathrm{E}-04$ & (nd) & $2.51 \mathrm{E}-06$ & (nd) \\
\hline
\end{tabular}

\section{Pyrolusite}

\begin{tabular}{|c|c|c|c|c|c|c|}
\hline $\mathrm{pH}$ & $\mathrm{HCO}_{3}{ }^{-}$ & $\mathrm{Na}^{+}$ & $\mathrm{K}^{+}$ & $\mathrm{Mg}^{2+}$ & $\mathrm{Mn}^{2+}$ & $\mathrm{Ca}^{2+}$ \\
\hline 2.97 & $7.78 \mathrm{E}-05$ & $9.33 \mathrm{E}-03$ & $4.54 \mathrm{E}-04$ & $1.04 \mathrm{E}-05$ & $1.79 \mathrm{E}-04$ & $4.34 \mathrm{E}-05$ \\
\hline 3.37 & $7.72 \mathrm{E}-05$ & $1.01 \mathrm{E}-02$ & $5.27 \mathrm{E}-04$ & $2.14 \mathrm{E}-06$ & $1.77 \mathrm{E}-04$ & $4.47 \mathrm{E}-06$ \\
\hline 6.74 & $8.26 \mathrm{E}-05$ & $9.56 \mathrm{E}-03$ & $5.33 \mathrm{E}-04$ & $1.06 \mathrm{E}-06$ & $6.69 \mathrm{E}-05$ & $2.35 \mathrm{E}-06$ \\
\hline 7.72 & $7.31 \mathrm{E}-05$ & $9.11 \mathrm{E}-03$ & $7.80 \mathrm{E}-04$ & (nd) & $1.17 \mathrm{E}-05$ & (nd) \\
\hline 8.34 & $8.53 \mathrm{E}-04$ & $9.32 \mathrm{E}-03$ & $8.57 \mathrm{E}-04$ & (nd) & $3.55 \mathrm{E}-06$ & (nd) \\
\hline 8.57 & $1.11 \mathrm{E}-03$ & $6.21 \mathrm{E}-03$ & $3.91 \mathrm{E}-04$ & (nd) & $1.16 \mathrm{E}-06$ & (nd) \\
\hline 8.93 & $2.09 \mathrm{E}-03$ & $7.55 \mathrm{E}-03$ & $6.14 \mathrm{E}-04$ & (nd) & $1.16 \mathrm{E}-06$ & (nd) \\
\hline 9.92 & $1.92 \mathrm{E}-03$ & $1.18 \mathrm{E}-02$ & $8.37 \mathrm{E}-04$ & (nd) & $8.29 \mathrm{E}-07$ & (nd) \\
\hline
\end{tabular}

* (nd) indicates that the species of interest was not detected at that $\mathrm{pH}$. 
Table A-4. Pu-Sorption Data.

Pu-Manganese Oxides Sorption data

Volume in reaction tube: $\quad 35 \mathrm{~mL}$

Mass of mineral used: $\quad 0.01 \mathrm{~g}$

Initial Pu conc., M 4.94E-09

Pu-Birnessite sorption

\begin{tabular}{|c|c|c|c|c|c|c|}
\hline \multicolumn{2}{|c|}{ Sampling time: 1 day } & \multicolumn{3}{|c|}{ Sampling time: 19 days } & \multicolumn{3}{|c|}{ Sampling time: 34 days } \\
\hline $\mathrm{pH}$ & $\%$ Sorption & $\mathrm{pH}$ & $\%$ Sorption & $\mathrm{pH}$ & $\%$ Sorption & $\mathrm{Kd}, \mathrm{mL} / \mathrm{g}$ \\
\hline 3.22 & $3.4 \%$ & 3.26 & $7.4 \%$ & 3.20 & $9.3 \%$ & $3.48 \mathrm{E}+02$ \\
4.71 & $47.0 \%$ & 4.76 & $86.1 \%$ & 4.74 & $89.6 \%$ & $3.02 \mathrm{E}+04$ \\
5.77 & $78.5 \%$ & 6.06 & $97.8 \%$ & 6.35 & $98.6 \%$ & $2.38 \mathrm{E}+05$ \\
6.81 & $96.8 \%$ & 7.25 & $98.9 \%$ & 7.56 & $99.9 \%$ & $2.50 \mathrm{E}+06$ \\
7.75 & $96.7 \%$ & 8.06 & $98.9 \%$ & 8.27 & $99.4 \%$ & $5.86 \mathrm{E}+05$ \\
8.54 & $95.2 \%$ & 8.56 & $97.9 \%$ & 8.59 & $97.9 \%$ & $1.57 \mathrm{E}+05$ \\
9.11 & $90.1 \%$ & 9.10 & $93.2 \%$ & 8.97 & $93.2 \%$ & $4.66 \mathrm{E}+04$ \\
9.95 & $91.3 \%$ & 9.95 & $96.6 \%$ & 9.90 & $97.0 \%$ & $1.12 \mathrm{E}+05$ \\
\hline
\end{tabular}

Pu-Cryptomelane sorption

\begin{tabular}{|c|c|c|c|c|c|c|}
\hline \multicolumn{2}{|c|}{ Sampling time: 1 day } & \multicolumn{2}{|c|}{ Sampling time: 19 days } & \multicolumn{3}{|c|}{ Sampling time: 34 days } \\
\hline $\mathrm{pH}$ & $\%$ Sorption & $\mathrm{pH}$ & $\%$ Sorption & $\mathrm{pH}$ & $\%$ Sorption & $\mathrm{Kd}, \mathrm{mL} / \mathrm{g}$ \\
\hline 3.22 & $0.35 \%$ & 3.30 & $0.04 \%$ & 3.23 & $0.27 \%$ & $9.53 \mathrm{E}+00$ \\
4.08 & $16.54 \%$ & 4.22 & $33.48 \%$ & 4.13 & $34.46 \%$ & $1.75 \mathrm{E}+03$ \\
5.19 & $67.15 \%$ & 5.45 & $90.32 \%$ & 5.60 & $92.82 \%$ & $4.44 \mathrm{E}+04$ \\
6.71 & $99.61 \%$ & 7.11 & $100.00 \%$ & 7.43 & $99.99 \%$ & $2.41 \mathrm{E}+07$ \\
7.78 & $99.44 \%$ & 8.06 & $99.47 \%$ & 8.31 & $99.38 \%$ & $5.55 \mathrm{E}+05$ \\
8.32 & $92.75 \%$ & 8.53 & $98.16 \%$ & 8.52 & $98.43 \%$ & $2.17 \mathrm{E}+05$ \\
9.15 & $91.62 \%$ & 9.15 & $95.75 \%$ & 9.09 & $96.68 \%$ & $1.02 \mathrm{E}+05$ \\
9.97 & $94.91 \%$ & 10.00 & $95.66 \%$ & 9.90 & $96.02 \%$ & $8.11 \mathrm{E}+04$ \\
\hline
\end{tabular}

Pu-Pyrolusite sorption

\begin{tabular}{|c|c|c|c|c|c|c|}
\hline \multicolumn{2}{|c|}{ Sampling time: 1 day } & \multicolumn{3}{|l|}{ Sampling time: 19 days } & \multicolumn{3}{|l|}{ Sampling time: 34 days } \\
\hline $\mathrm{pH}$ & $\%$ Sorption & $\mathrm{pH}$ & $\%$ Sorption & $\mathrm{pH}$ & $\%$ Sorption & $\mathrm{Kd}, \mathrm{mL} / \mathrm{g}$ \\
\hline 3.27 & $14.97 \%$ & 3.28 & $19.44 \%$ & 3.18 & $19.48 \%$ & $8.38 \mathrm{E}+02$ \\
4.30 & $71.42 \%$ & 4.40 & $95.37 \%$ & 4.36 & $97.12 \%$ & $1.16 \mathrm{E}+05$ \\
5.56 & $97.35 \%$ & 5.98 & $99.90 \%$ & 6.36 & $99.72 \%$ & $1.21 \mathrm{E}+06$ \\
6.84 & $99.68 \%$ & 7.22 & $99.61 \%$ & 7.59 & $99.97 \%$ & $1.11 \mathrm{E}+07$ \\
7.73 & $98.45 \%$ & 8.02 & $99.63 \%$ & 8.25 & $99.58 \%$ & $8.07 \mathrm{E}+05$ \\
8.34 & $67.38 \%$ & 8.48 & $70.00 \%$ & 8.53 & $71.84 \%$ & $8.67 \mathrm{E}+03$ \\
9.04 & $79.84 \%$ & 9.02 & $83.35 \%$ & 8.90 & $84.36 \%$ & $1.83 \mathrm{E}+04$ \\
9.97 & $94.50 \%$ & 9.97 & $95.42 \%$ & 9.88 & $95.47 \%$ & $7.09 \mathrm{E}+04$ \\
\hline
\end{tabular}




\title{
Table A-5. Pu-Desorption Data.
}

\author{
Pu-Manganese Oxides Desorption data \\ Volume in reaction tube $\quad 35 \mathrm{~mL}$ \\ Mass of mineral uesd: $\quad 0.01 \mathrm{~g}$
}

Pu-Birnessite Desorption

\begin{tabular}{|c|c|c|c|c|c|c|c|c|c|c|}
\hline \multicolumn{4}{|c|}{ Sampling time: 2 days } & \multicolumn{3}{|c|}{ Sampling time: 16 days } & \multicolumn{4}{|c|}{ Sampling time: 22 days } \\
\hline $\mathrm{pH}$ & initial $\mathrm{Pu}$, mmoles & desorbed mmoles & $\%$ Sorption & $\mathrm{pH}$ & desorbed mmoles & $\%$ Sorption & $\mathrm{pH}$ & desorbed mmoles & $\%$ Sorption & $\mathrm{Kd}, \mathrm{mL} / \mathrm{g}$ \\
\hline 3.22 & $1.61 \mathrm{E}-08$ & $1.00 \mathrm{E}-08$ & $37.5 \%$ & 3.32 & $1.26 \mathrm{E}-08$ & $21.9 \%$ & 3.23 & $1.30 \mathrm{E}-08$ & $19.2 \%$ & $8.33 \mathrm{E}+02$ \\
\hline 4.26 & $1.55 \mathrm{E}-07$ & $2.53 \mathrm{E}-08$ & $83.7 \%$ & 4.34 & 2.4581E-08 & $84.1 \%$ & 4.26 & 2.27E-08 & $85.4 \%$ & $2.04 \mathrm{E}+04$ \\
\hline 6.00 & $1.70 \mathrm{E}-07$ & $4.96 \mathrm{E}-09$ & $97.1 \%$ & 6.20 & $3.25991 \mathrm{E}-09$ & $98.1 \%$ & 6.26 & $2.51 \mathrm{E}-09$ & $98.5 \%$ & $2.35 \mathrm{E}+05$ \\
\hline 6.85 & $1.73 \mathrm{E}-07$ & $1.40 \mathrm{E}-09$ & $99.2 \%$ & 7.07 & $1.4563 \mathrm{E}-09$ & $99.2 \%$ & 7.22 & $1.15 \mathrm{E}-09$ & $99.3 \%$ & $5.21 \mathrm{E}+05$ \\
\hline 7.85 & $1.72 \mathrm{E}-07$ & $6.44 \mathrm{E}-10$ & $99.6 \%$ & 8.00 & $1.18306 \mathrm{E}-09$ & $99.3 \%$ & 8.08 & $1.16 \mathrm{E}-09$ & $99.3 \%$ & $5.15 \mathrm{E}+05$ \\
\hline 8.44 & $1.69 \mathrm{E}-07$ & $4.68 \mathrm{E}-10$ & $99.7 \%$ & 8.52 & $9.5185 \mathrm{E}-10$ & $99.4 \%$ & 8.51 & $1.01 \mathrm{E}-09$ & $99.4 \%$ & $5.80 \mathrm{E}+05$ \\
\hline 9.05 & $1.61 \mathrm{E}-07$ & $4.18 \mathrm{E}-10$ & $99.7 \%$ & 9.00 & $1.05895 \mathrm{E}-09$ & $99.3 \%$ & 9.02 & $1.24 \mathrm{E}-09$ & $99.2 \%$ & $4.50 \mathrm{E}+05$ \\
\hline 9.98 & $1.68 \mathrm{E}-07$ & $5.42 \mathrm{E}-10$ & $99.7 \%$ & 9.95 & $9.33834 \mathrm{E}-10$ & $99.4 \%$ & 9.95 & $9.46 \mathrm{E}-10$ & $99.4 \%$ & $6.17 \mathrm{E}+05$ \\
\hline
\end{tabular}

Pu-Cryptomelane Desorption

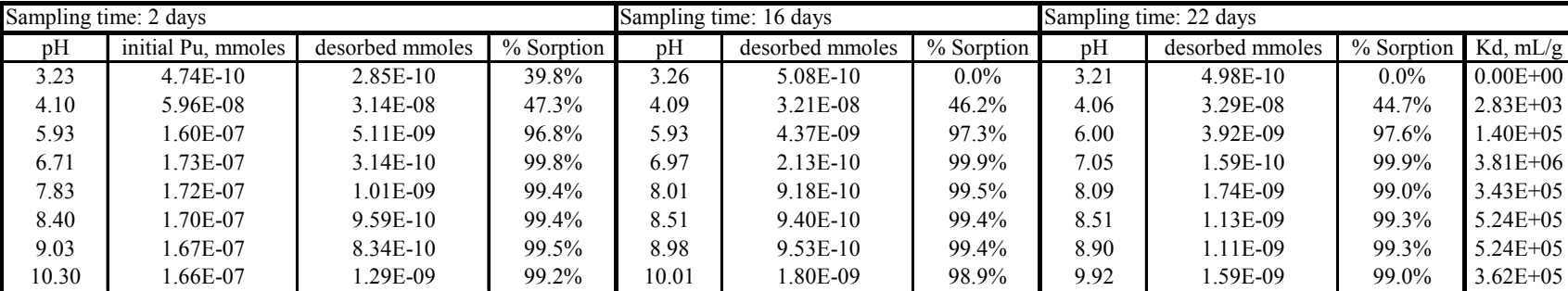

Pu-Pyrolusite Desorption

Sampling time: 2 days

\begin{tabular}{|l|l}
\hline Sampling time: 16 days & Sampling time: 22 days
\end{tabular}

\begin{tabular}{|c|c|c|c|c|c|c|c|c|c|c|}
\hline $\mathrm{pH}$ & initial Pu, mmoles & desorbed mmoles & $\%$ Sorption & $\mathrm{pH}$ & desorbed mmoles & $\%$ Sorption & $\mathrm{pH}$ & desorbed mmoles & $\%$ Sorption & $\mathrm{Kd}, \mathrm{mL} / \mathrm{g}$ \\
\hline 3.24 & $3.37 \mathrm{E}-08$ & $8.53 \mathrm{E}-09$ & $74.7 \%$ & 3.23 & $1.42 \mathrm{E}-08$ & $58.0 \%$ & 3.21 & $1.53 \mathrm{E}-08$ & $54.6 \%$ & $4.21 \mathrm{E}+03$ \\
4.05 & $1.68 \mathrm{E}-07$ & $1.62 \mathrm{E}-08$ & $90.4 \%$ & 4.05 & $1.20 \mathrm{E}-08$ & $92.8 \%$ & 3.99 & $9.80 \mathrm{E}-09$ & $94.2 \%$ & $5.65 \mathrm{E}+04$ \\
5.59 & $1.72 \mathrm{E}-07$ & $6.07 \mathrm{E}-10$ & $99.6 \%$ & 5.86 & $1.72 \mathrm{E}-10$ & $99.9 \%$ & 6.01 & $1.55 \mathrm{E}-10$ & $99.9 \%$ & $3.89 \mathrm{E}+06$ \\
6.67 & $1.73 \mathrm{E}-07$ & $2.12 \mathrm{E}-10$ & $99.9 \%$ & 6.92 & $4.80 \mathrm{E}-11$ & $100.0 \%$ & 7.03 & $6.39 \mathrm{E}-11$ & $100.0 \%$ & $9.46 \mathrm{E}+06$ \\
7.76 & $1.72 \mathrm{E}-07$ & $4.49 \mathrm{E}-10$ & $99.7 \%$ & 7.93 & $3.46 \mathrm{E}-10$ & $99.8 \%$ & 8.05 & $3.43 \mathrm{E}-10$ & $99.8 \%$ & $1.76 \mathrm{E}+06$ \\
8.39 & $1.24 \mathrm{E}-07$ & $3.69 \mathrm{E}-09$ & $97.0 \%$ & 8.53 & $3.15 \mathrm{E}-09$ & $97.5 \%$ & 8.56 & $4.88 \mathrm{E}-09$ & $96.1 \%$ & $8.57 \mathrm{E}+04$ \\
9.00 & $1.46 \mathrm{E}-07$ & $2.97 \mathrm{E}-09$ & $98.0 \%$ & 8.96 & $2.24 \mathrm{E}-09$ & $98.5 \%$ & 8.92 & $2.87 \mathrm{E}-09$ & $98.0 \%$ & $1.74 \mathrm{E}+05$ \\
10.03 & $1.65 \mathrm{E}-07$ & $3.05 \mathrm{E}-09$ & $98.2 \%$ & 9.99 & $2.12 \mathrm{E}-09$ & $98.7 \%$ & 9.95 & $2.69 \mathrm{E}-09$ & $98.4 \%$ & $2.11 \mathrm{E}+05$ \\
\hline
\end{tabular}


Table A-6. Pu batch-sorption major cation analyses ( $\mathrm{mol} / \mathrm{L}$ ). Birnessite

\begin{tabular}{|c|c|c|c|c|c|c|}
\hline $\mathrm{pH}$ & $\mathrm{HCO}_{3}^{-}$ & $\mathrm{Na}^{+}$ & $\mathrm{K}^{+}$ & $\mathrm{Mg}^{2+}$ & $\mathrm{Mn}^{2+}$ & $\mathrm{Ca}^{2+}$ \\
\hline 3.20 & $7.35 \mathrm{E}-05$ & $1.10 \mathrm{E}-02$ & $7.04 \mathrm{E}-04$ & $1.04 \mathrm{E}-05$ & $5.07 \mathrm{E}-04$ & $3.27 \mathrm{E}-05$ \\
\hline 4.74 & $7.14 \mathrm{E}-05$ & $1.07 \mathrm{E}-02$ & $4.88 \mathrm{E}-04$ & $2.67 \mathrm{E}-06$ & $3.37 \mathrm{E}-04$ & $5.18 \mathrm{E}-06$ \\
\hline 6.35 & $8.63 \mathrm{E}-05$ & $1.08 \mathrm{E}-02$ & $4.35 \mathrm{E}-04$ & $1.46 \mathrm{E}-06$ & $1.45 \mathrm{E}-04$ & $1.25 \mathrm{E}-06$ \\
\hline 7.56 & $1.21 \mathrm{E}-03$ & $1.10 \mathrm{E}-02$ & $3.54 \mathrm{E}-04$ & $8.72 \mathrm{E}-07$ & $2.13 \mathrm{E}-05$ & $4.99 \mathrm{E}-06$ \\
\hline 8.27 & $3.28 \mathrm{E}-03$ & $9.84 \mathrm{E}-03$ & $9.71 \mathrm{E}-04$ & $9.22 \mathrm{E}-07$ & $1.12 \mathrm{E}-05$ & $4.99 \mathrm{E}-06$ \\
\hline 8.59 & $4.21 \mathrm{E}-03$ & $9.70 \mathrm{E}-03$ & $4.69 \mathrm{E}-04$ & $8.80 \mathrm{E}-07$ & $8.60 \mathrm{E}-06$ & $4.99 \mathrm{E}-06$ \\
\hline 8.97 & $4.48 \mathrm{E}-03$ & $1.02 \mathrm{E}-02$ & $2.48 \mathrm{E}-04$ & $1.07 \mathrm{E}-06$ & $1.09 \mathrm{E}-05$ & $4.99 \mathrm{E}-06$ \\
\hline 9.90 & $4.78 \mathrm{E}-03$ & $1.23 \mathrm{E}-02$ & $2.46 \mathrm{E}-04$ & $1.03 \mathrm{E}-06$ & $4.16 \mathrm{E}-06$ & $4.99 \mathrm{E}-06$ \\
\hline
\end{tabular}

\section{Cryptomelane}

\begin{tabular}{|c|c|c|c|c|c|c|}
\hline $\mathrm{pH}$ & $\mathrm{HCO}_{3}^{-}$ & $\mathrm{Na}^{+}$ & $\mathrm{K}^{+}$ & $\mathrm{Mg}^{2+}$ & $\mathrm{Mn}^{2+}$ & $\mathrm{Ca}^{2+}$ \\
\hline 3.23 & $7.49 \mathrm{E}-05$ & $9.87 \mathrm{E}-03$ & $2.22 \mathrm{E}-03$ & $8.39 \mathrm{E}-06$ & $4.29 \mathrm{E}-04$ & $2.55 \mathrm{E}-05$ \\
\hline 4.13 & $7.18 \mathrm{E}-05$ & $9.71 \mathrm{E}-03$ & $1.26 \mathrm{E}-03$ & $4.11 \mathrm{E}-06$ & $4.21 \mathrm{E}-04$ & $9.81 \mathrm{E}-06$ \\
\hline 5.60 & $7.36 \mathrm{E}-05$ & $9.21 \mathrm{E}-03$ & $1.14 \mathrm{E}-03$ & $1.88 \mathrm{E}-06$ & $2.70 \mathrm{E}-04$ & $2.74 \mathrm{E}-06$ \\
\hline 7.43 & $1.02 \mathrm{E}-03$ & $9.86 \mathrm{E}-03$ & $9.41 \mathrm{E}-04$ & $1.04 \mathrm{E}-06$ & $3.47 \mathrm{E}-05$ & (nd) \\
\hline 8.31 & $3.82 \mathrm{E}-03$ & $9.50 \mathrm{E}-03$ & $9.49 \mathrm{E}-04$ & $9.30 \mathrm{E}-07$ & $1.21 \mathrm{E}-05$ & (nd) \\
\hline 8.52 & $4.63 \mathrm{E}-03$ & $9.46 \mathrm{E}-03$ & $8.38 \mathrm{E}-04$ & $1.04 \mathrm{E}-06$ & $9.02 \mathrm{E}-06$ & (nd) \\
\hline 9.09 & $5.00 \mathrm{E}-03$ & $9.39 \mathrm{E}-03$ & $9.42 \mathrm{E}-04$ & $1.05 \mathrm{E}-06$ & $7.37 \mathrm{E}-06$ & (nd) \\
\hline 9.90 & $5.11 \mathrm{E}-03$ & $1.19 \mathrm{E}-02$ & $9.08 \mathrm{E}-04$ & $1.07 \mathrm{E}-06$ & $8.71 \mathrm{E}-06$ & (nd) \\
\hline
\end{tabular}

\section{Pyrolusite}

\begin{tabular}{|c|c|c|c|c|c|c|}
\hline $\mathrm{pH}$ & $\mathrm{HCO}_{3}^{-}$ & $\mathrm{Na}^{+}$ & $\mathrm{K}^{+}$ & $\mathrm{Mg}^{2+}$ & $\mathrm{Mn}^{2+}$ & $\mathrm{Ca}^{2+}$ \\
\hline 3.18 & $1.24 \mathrm{E}-04$ & $9.52 \mathrm{E}-03$ & $4.26 \mathrm{E}-04$ & $1.11 \mathrm{E}-05$ & $7.14 \mathrm{E}-05$ & $3.33 \mathrm{E}-05$ \\
\hline 4.36 & $1.29 \mathrm{E}-04$ & $1.00 \mathrm{E}-02$ & $5.99 \mathrm{E}-04$ & $3.94 \mathrm{E}-06$ & $5.87 \mathrm{E}-05$ & $9.88 \mathrm{E}-06$ \\
\hline 6.36 & $7.86 \mathrm{E}-05$ & $9.26 \mathrm{E}-03$ & $6.22 \mathrm{E}-04$ & $1.96 \mathrm{E}-06$ & $2.00 \mathrm{E}-05$ & (nd) \\
\hline 7.59 & $1.02 \mathrm{E}-03$ & $9.68 \mathrm{E}-03$ & $1.35 \mathrm{E}-03$ & $1.71 \mathrm{E}-06$ & $6.17 \mathrm{E}-06$ & (nd) \\
\hline 8.25 & $2.80 \mathrm{E}-03$ & $9.98 \mathrm{E}-03$ & $1.30 \mathrm{E}-03$ & $1.41 \mathrm{E}-06$ & $2.35 \mathrm{E}-06$ & (nd) \\
\hline 8.53 & $4.10 \mathrm{E}-03$ & $9.80 \mathrm{E}-03$ & $8.88 \mathrm{E}-04$ & $1.30 \mathrm{E}-06$ & $3.70 \mathrm{E}-06$ & (nd) \\
\hline 8.90 & $4.31 \mathrm{E}-03$ & $9.83 \mathrm{E}-03$ & $5.12 \mathrm{E}-04$ & $1.22 \mathrm{E}-06$ & $2.01 \mathrm{E}-06$ & (nd) \\
\hline 9.88 & $4.26 \mathrm{E}-03$ & $1.20 \mathrm{E}-02$ & $7.20 \mathrm{E}-04$ & $1.15 \mathrm{E}-06$ & $6.94 \mathrm{E}-07$ & (nd) \\
\hline
\end{tabular}

